\title{
Improvement of methods for the detection of Gram-negative foodborne pathogens
}




\section{Thesis committee}

\section{Promotors}

Prof. Dr M. H. Zwietering

Professor of Food Microbiology

Wageningen University

Prof. Dr H. M. L. J. Joosten

European Chair in Food Safety Microbiology

Wageningen University

\section{Co-promotor}

Prof. Dr R. Stephan

Professor of Food Safety and Hygiene

University of Zurich, Switzerland

\section{Other members}

Prof. Dr V. Fogliano, Wageningen University

Prof. Dr M. Uyttendaele, Ghent University, Belgium

Dr P. H. in`t Veld, NVWA

Dr H. J. M. Aarts, RIVM, Bilthoven

This research was conducted under the auspices of the Graduate School VLAG (Advanced studies in Food Technology, Agrobiotechnology, Nutrition and Health Sciences) 


\title{
Improvement of methods for the detection of Gram-negative foodborne pathogens
}

\author{
Heike F.T. Margot
}

\section{Thesis}

submitted in fulfilment of the requirements for the degree of doctor at Wageningen University

by the authority of the Rector Magnificus

Prof. Dr. A. P. J. Mol,

in the presence of the

Thesis Committee appointed by the Academic Board

to be defended in public

on Friday 16 September 2016

at 11 a.m. in the Aula. 
Heike F.T. Margot

Improvement of methods for the detection of Gram-negative foodborne pathogens, 160 pages.

PhD thesis, Wageningen University, Wageningen, NL (2016)

With references, with summary in English

ISBN 978-94-6257-870-8

DOI http://dx.doi.org/10.18174/386550 


\section{Table of Contents}

$\begin{array}{ll}\text { Abstract } & 7\end{array}$

Chapter 1

Introduction and outline

\section{Chapter 2}

Inclusivity, exclusivity and limit of detection of commercially available

real-time PCR assays for the detection of Salmonella

\section{Chapter 3}

Comparison of rapid cultural methods for the detection of Salmonella species

\section{Chapter 4}

Evaluation of seven different commercially available real-time PCR assays for detection of Shiga toxin 1 and 2 gene subtypes

\section{Chapter 5}

Evaluation of different buffered peptone water (BPW) based enrichment broths for detection of Gram-negative foodborne pathogens from various food matrices

\section{Chapter 6}

Effects of different media on the enrichment of low numbers of Shiga toxin-producing Escherichia coli in mungo bean sprouts and on the development of the sprout microbiome

\section{Chapter 7}

Determination of single cell lag times of Cronobacter spp. strains exposed to different stress conditions: impact on detection

\section{Chapter 8}

Summarizing discussion, conclusions and future perspectives

Summary 153

Acknowledgements

About the author 156

List of publications

Overview of completed training activities 


\section{Abstract}

Foodborne diseases are a major source of morbidity and mortality worldwide. In most cases, these diseases are caused by contaminated food products, but transmission can also subsequently occur via person to person contact. The ability to detect the pathogens is an important aspect in the verification of food safety. A major proportion of foodborne disease is caused by Gram-negative bacteria. In this thesis, the detection of Gram-negative foodborne pathogens is addressed by looking at the successive steps from enrichment to detection with Salmonella, Shiga toxin-producing E. coli and Cronobacter spp. as example pathogens. The detection of foodborne pathogens using microbiological culture media aiming at the resuscitation and growth of bacteria is still regarded as the gold standard and included in many reference methods. However, cultural methods are time and labour-intensive. Since an immediate response is required in case of contamination and during outbreaks there is a strong interest in methods that deliver information on the microbiological status of the product as quickly and reliable as possible. Rapid cultural methods and commercially available real-time PCR systems for the detection of Salmonella and STEC were compared with regards to their sensitivity and specificity. It was shown that most of the marketed systems are as reliable as the standard methods. However, false-positive results were obtained with real-time PCR systems for the detection of Salmonella. Rapid cultural methods that were based on procedures without the pre-enrichment step, reduced the time to detection but did show some ambiguous results with difficult matrices such as tea. Of the seven rapid tests for the detection of STEC, one did not detect relevant Stx subtypes.

In order to be detected, pathogens need to multiply to reach a minimum threshold level. However, because they are often sublethally injured due to hostile processing and storage conditions, they first need to be resuscitated. For most pathogens, (Salmonella, STEC and Cronobacter spp.) the first step in the detection is an enrichment including resuscitation in a non-selective medium such as BPW. Modifications to BPW were compared with respect to their ability to promote growth of unstressed and stressed Gram-negative pathogens. The aim was to develop a medium that could be used for the enrichment of pathogens in horizontal methods using only one enrichment step. The resuscitation of stressed Cronobacter cells was improved in BPW supplemented with an additional iron source and sodium pyruvate along with low levels of compounds for the inhibition of Gram-positive bacteria. However, it was observed that BPW containing these supplements allowed for less resuscitation of STEC when compared to regular BPW. Based on these results it was concluded that the application of a one-broth enrichment in food products with a high number of competing bacteria is not recommended due to the overgrowth of the target bacteria. 
Limitations of the current method for the detection of STEC from sprouted seeds were noticed. Therefore, the growth of stressed STEC cells from different serotypes was assessed in media used for the enrichment of Enterobacteriaceae. In addition, the growth of STEC was examined in the enrichment of sprouts using different media and incubation temperatures. It was shown that the high level of competitors was inhibiting the detection of the target pathogen and that the similarity of target and competing bacteria prevents the design of a selective enrichment procedure. In order to get a better insight in the enrichment ecology, the microbiome of mungo bean sprouts was analysed using Illumina HiSeq sequencing prior to and during the enrichment in BPW and EE-broth at different temperatures. The majority of the sprout flora was composed of bacteria belonging to the phylum Proteobacteria. Enrichment in BPW increased the proportion of Firmicutes whereas the incubation in EE-broth enriched Proteobacteria. The results point out that with the application of a selective medium like EE-broth, growth of the competitive microflora that complicates the detection of STEC is promoted. It was shown that EE-broth also resulted in good growth of STEC however, the problematic situation of low maximum population densities of the target strain in the matrix is still present. The probability of detection is not only influenced by the natural flora of a food product, but also by the physiological state of the pathogen. The influence of stress on the lag time of single cells and the resulting probability of detection were determined for Cronobacter spp. in powdered infant formula. Lag time was calculated from optical density measurement data and different scenarios were modelled. Lag time was longest after acid stress and lag time increase coincided with increased lag time variability. The probability of detection, however, depended both on the sampling plan and on the duration of the lag phase.

This thesis provides a critical evaluation of rapid methods and valuable new insights on enrichment procedures, the role of competitors in bacterial enrichment procedures and the limitations of selective agents. This information will be of great help to further improve microbiological methods and thereby contribute to more effective management of food safety. 


\section{Chapter}

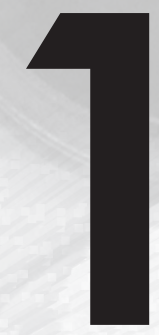

Introduction and outline 


\section{Foodborne disease}

Foodborne diseases are a major cause of morbidity and mortality worldwide.

The WHO defines foodborne disease as "a disease of an infectious or toxic nature caused by, or thought to be caused by, the consumption of food or water" (1). The most common clinical symptoms of foodborne disease are gastrointestinal such as diarrhoea, vomiting, and abdominal pain. However, such diseases can also have neurological, immunological and gynaecological manifestations and can result in long-term sequelae and even mortality. Foodborne disease can be caused by bacteria and their toxins, viruses, parasitic pathogens and chemical agents. Bacteria and viruses cause the highest number of foodborne illnesses, hospitalizations and deaths (2). In the United States, there are over 5 million cases of infection caused by foodborne pathogenic bacteria every year (3). Next to the negative effect on human health and wellbeing, the economic effect has been estimated to be 2.9 to 6.7 bilion $\$$. In the EU, a total of 5,196 foodborne outbreaks, including waterborne outbreaks were reported in 2013. These outbreaks resulted in 43,183 reported human cases with almost 6,000 hospitalizations and reported 11 deaths. (4). Per definition, an outbreak is an incident in which two or more persons experience similar foodborne disease after the ingestion of a common food (5). Because only a fraction of illnesses is diagnosed and reportet, there is an enormous difference between estimated and reported numbers of illness. In Switzerland, the annual number of reported foodborne outbreaks decreased steadily from ca. 30 outbreaks in 1993 to only 5 outbreaks in 2010. The decrease was mainly attributed to the strict control of the Salmonella epidemic in laying hens (6). Even though everyone is at risk for infection, the consequences are most severe in vulnerable populations like children, elderly and immunocompromised people. Many pathogens are sustained in animal reservoirs and are present in animal derived food products. Their ability to grow outside the animal host, in contrast to viruses, increases the possibility for the dissemination. Norovirus is not a zoonotic pathogen, however, it is a key enteric pathogen that can be associated with about $12 \%$ of all cases of acute gastroenteritis (7). Next to the number of cases caused, the severity of the infection can differ largely from pathogen to pathogen. The foods that are most frequently associated with foodborne disease in Europe and North America are those of animal origin such as meat, poultry, milk, eggs and related products. Contamination mostly occurs via faeces of these animals. This is particularly true for infections caused by Salmonella and pathogenic E. coli. Of the numerous pathogens that can contaminate foods, some can be shed by healthy human hosts. If personal hygiene is poor, those can subsequently contaminate the food supply. Some pathogens are of environmental origin and can therefore contaminate food products via numerous 
routes during production or preparation (8). Strikingly, while many pathogens have animal reservoirs, numerous outbreaks show that plants can be vehicles for human pathogens. Contamination can occur via untreated manure, water, wild animals or unhygienic processing (9). Another significant contribution to the number of foodborne infections is the acquisition at home. $31 \%$ of reported outbreaks in OECD countries occur in private homes. The main sources of bacterial pathogens are raw food ingredients and infected persons preparing food from which pathogens can be spread via cross contamination. Temperature abuse during preparation and storage increases the risk of infection (10).

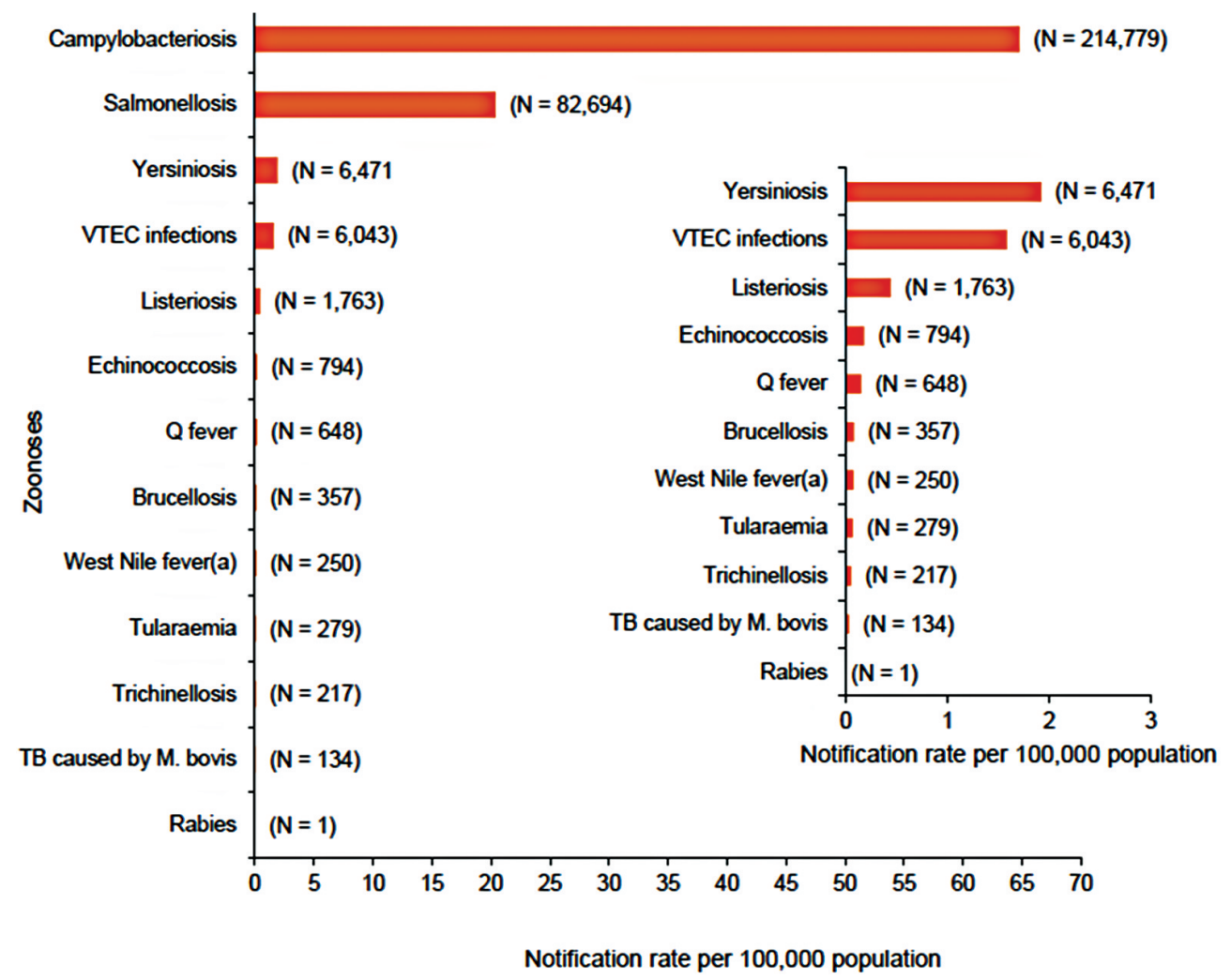

Figure 1. Reported notification rates of zoonoses in confirmed human cases in the EU, 2013. EFSA European summary report (42).

\section{Gram-negative foodborne pathogens}

Gram-negative enteric pathogens are major contributors to foodborne infection (4). They account for approximately $69 \%$ of all reported cases. In Europe, Campylobacter 
is the most commonly reported pathogen causing gastrointestinal disease in humans with 214,779 cases in 2013 (Figure 1) (4). 32 strong-evidence outbreaks were attributed to this pathogen. Second with 82,694 confirmed cases is Salmonellosis followed by infections with Yersinia spp. and Shiga toxin-producing Escherichia coli (6,043 cases) (4). Cronobacter spp. only accounts for a very small number of infections, however, due to the high rate of mortality in infants, it is regarded as a significant hazard in powdered infant formulae. Since Campylobacter requires microaerophilic enrichment conditions with $5-10 \%$ oxygen and $3-5 \%$ carbon dioxide and since the organism is sensitive to temperatures below $28^{\circ} \mathrm{C}$, drying and reduced $\mathrm{pH}$, its detection follows a completely different methodology then the one for Salmonella, STEC and Cronobacter spp. (11). Salmonella spp., Shiga toxinproducing E. coli and Cronobacter spp. on the other hand share certain physiological traits such as growth at aerobic conditions at mesophilic temperatures.

The focus of this PhD project is on methods for the detection of Salmonella spp., Shigatoxin-producing Escherichia coli and Cronobacter spp.. The following section provides an introduction to these pathogens.

\section{Salmonella}

Salmonella are Gram-negative, non-spore-forming rods, which are facultative anaerobic, catalase-positive, oxidase-negative and are generally motile member of the Enterobacteriaceae with peritrichous flagella. Salmonella can be divided into two species: $S$. bongori and $S$. enterica. The six subspecies (spp.) of $S$. enterica are: ssp. enterica, spp. salmonae, spp. arizonae, spp. diarizonae, spp. houtenae and spp. indica. The genus constitutes over 2500 different serovars of which $59 \%$ belong to S. enterica spp. enterica (12). Almost all infections in humans and warm-blooded animals are caused by serovars belonging to $S$. enterica spp. enterica.

In the EU, 82,694 confirmed cases of Salmonellosis were reported in 2013 and the most commonly reported serovars in human cases were $S$. Enteritidis and $S$. Typhimurium (4). In the same year, Salmonella was the most frequently detected agent in reported foodborne outbreaks (22.5\%) (4). In Switzerland, 1,271 cases were reported in 2013 (6). Salmonella are responsible for a number of different clinical syndromes, which can be grouped as enteritis and systemic disease. Salmonellosis is characterized by diarrhoea, abdominal pain, vomiting and fever. The illness is usually self-limiting but can be more severe in susceptible groups such as very young, the elderly, pregnant and immune compromised. In serious cases, patients can suffer from long-term reactive arthritis (13) or life threatening dehydration. Systemic infections such as typhoid fever are caused by $S$. Typhi and $S$. Paratyphi 
and can be life-threatening illnesses that are a major cause of morbidity in the developing world (14). The virulence of Salmonella varies with the strain, the food vehicle and the health status of the infected person. The virulence can be higher in food products that pass the organism through the stomach more rapidly or foods that protect the microorganism from the acidity in the stomach. Increased $\mathrm{pH}$ in the stomach or malnutrition are only two factors possibly influencing the susceptibility of the host (15).

\section{Reservoirs for Salmonella}

Salmonella (except Salmonella Typhi and Paratyphi A) are primarily inhabitants of the gastrointestinal tract and are carried by a wide range of food animals, wild animals, rodents, pets, birds, reptiles and insects. The bacteria can be disseminated via faeces to soil, water, foods and feed and to other animals and humans (16). Humans can be asymptomatic carriers that can shed the organism several weeks and up to one year (17). Foodstuffs most commonly contaminated with Salmonella are fresh turkey meat, fresh broiler meat followed by pig and bovine meat. Contamination of eggs and egg products is very low, however, eggs and egg products are the most commonly identified vehicles for human infection (4). Next to products of animal origin, outbreaks were caused by products of non-animal source such as vegetables, fruits and herbs. In Europe, 7 outbreaks linked to leafy greens contaminated with Salmonella were reported from 2007-2011 (18). Contamination has been reported in commodities such as tomatoes, cucumbers, sprouted seeds and melons $(19,20)$. Direct contact with animals, animal faeces, indirect contact with water or soil can lead to contamination at the pre-harvest level. After harvest, the produce can be contaminated by polluted water, process machines or workers asymptomatically carrying the pathogen. Low-moisture foods are not traditionally considered as high-risk foods because the low $\mathrm{a}_{\mathrm{w}}$ is a barrier for bacterial growth. Nevertheless, numerous outbreaks linked to low-moisture foods such as nuts, seeds, spices and chocolates $(21,22,23)$ have been recorded worldwide. Two documented outbreaks were associated with the consumption of herbal teas $(24,25)$. Even though Salmonella cannot grow on dry products, its known ability to persist lowmoisture environments allows survival for months or even years (27).

\section{Pathogenic Escherichia coli}

Escherichia coli is a species in the family of Enterobacteriaceae. It is a non-sporulating, rod-shaped and facultative anaerobe with an optimal growth temperature of $37^{\circ} \mathrm{C}$. In its natural environment, $E$. coli colonizes the intestines of mammalians. Even though in this ecological niche it is the most dominant facultative anaerobic, 
its proportion of the total microflora is very small (16). Its common presence in faeces, easy culturability and survival characteristics led to the adoption of $E$. coli as indicator organism for faecal contamination. Most $E$. coli strains that colonize the human bowel are harmless commensals. However, there are several highly adapted $E$. coli clones that have acquired specific virulence traits that allow the bacteria to cause a wide spectrum of disease and confer the ability to adapt to new niches (28). These virulence attributes are often encoded on mobile genetic elements like plasmids that can be transferred into different strains and lead to the evolution of new combinations of virulence factors. Strains that incorporate such virulence traits and can cause gastrointestinal infections are divided into the following six categories: enteropathogenic E. coli (EPEC), enterohaemorrhagic E. coli (EHEC), enterotoxogenic E. coli (ETEC), enteroaggregative $E$. coli (EAEC), enteroinvasive $E$. coli (EIEC) and diffusely adherent $E$. coli (DAEC). EHEC are a subgroup of Shiga toxin-producing E. coli (STEC) (28). Shiga toxin-producing E. coli (STEC or VTECVerocytotoxin-producing $E$. coli) are named after their capacity to form Shiga-like toxins, which is one of the main virulence factors in human STEC infection. In the absence of common disctinctive characteristics, detection of STEC mainly depends on the presence of one or both of the genes encoding these toxins ( $s t x_{1}$ and $\left.s t x_{2}\right)$. Shiga toxin-producing $E$. coli as a cause of gastrointestinal disease was first described in 1982 (29), when two outbreaks caused by the consumption of undercooked hamburgers occurred in the US. Patients showed gastrointestinal symptoms characterized by strong abdominal pain, watery and bloody diarrhoea and absence of fever. The responsible isolate was an E. coli strain expressing the $\mathrm{O}$ antigen 157 and the $\mathrm{H}$ antigen 7. Since then, the serotype O157:H7 has been considered as one of the most important STECs because it was associated with severe clinical signs (30) such as the haemolytic uraemic syndrome (HUS) that can lead to renal failure and lifelong sequelae, or even death. Next to STEC 0157, there are a number of non-O157 serotypes that were responsible for numerous cases of infections in humans: O26, O103, O111, O121, O45, O145 (31). Worldwide, the number of reported outbreaks of human illness due to STEC increased considerable in the past decade. In 2013, 6,043 confirmed cases of STEC infections were reported in the EU. The outcome was fatal in 13 cases. 73 outbreaks were reported in the same year (4). The most commonly reported serogroup was 0157 (49\%), followed by 026. In Switzerland, the number of confirmed cases fluctuates between 31 and 72 cases per year (32). A large outbreak with a Shiga toxin-producing enteroaggregative $E$. coli O104:H4 affected 3,800 people in Germany in 2011 and caused a large peak in the number of European cases. The number of STEC needed to cause disease was described to be very low ( $<100$ organisms), therefore minimal exposures can lead to disease (33). 


\section{Reservoir of Shiga toxin-producing E. coli}

STEC represent the only pathogenic group of $E$. coli that has a definite zoonotic origin. The major natural reservoir is ruminants in which the bacteria usually do not cause disease but are excreted in high numbers via the faeces. Cattle have been reported to be the main source of STEC 0157 and contaminated bovine meat is considered the most important source for STEC infections (4). Unpasteurized milk and its products can be contaminated and STEC is therefore regarded as a hazard in these products, too. Produce such as leafy greens, herbs and fruits have the potential to be contaminated with STEC via untreated manure, contaminated irrigation water, improper hygiene of workers or failed sanitation of equipment. Already long before the serious outbreak caused by STEC O104:H4 in Germany, sprouts were considered an important source of the pathogen. Contamination usually occurs on the seeds and during sprouting STEC present find ideal conditions for growth. STEC survival is markedly reduced in dry environments; however, infections have been caused by products with low water activity such as cookie dough, hazelnuts and fermented meat products $(34,35)$. Survival of STEC with an initial population of $5.5 \mathrm{log} \mathrm{cfu} / \mathrm{g}$ in buttermilk powder for 16 weeks at $21^{\circ} \mathrm{C}$ was described (36). Next to foodborne transmission as the most frequent mode of transmission, waterborne transmission direct contact with animals and person-to-person transmission are possible causes for infection (37).

\section{Cronobacter spp.}

Cronobacter spp. are Gram-negative, non-spore forming, motile rods, which also belong to the Enterobacteriaceae. The genus Cronobacter, formerly known as Enterobacter sakazakii, includes seven species: Cronobacter sakazakii, Cronobacter malonaticus, Cronobacter turicensis, Cronobacter muytjensii, Cronobacter condimenti and Cronobacter dublinensis and Cronobacter universalis (38). Cronobacter spp. is known as opportunistic foodborne pathogen of humans. It is of particular risk for children below the age of 28 days. Among these, infants with a low birth weight, born prematurely and which are immunocompromised are the most vulnerable (39). Cronobacter spp. was first linked to a case of meningitis in neonates in 1958 in England (40). Since this first reported case, there have been about 162 reported cases of infections and 29 deaths in infants up to 2008 (41). Most of the cases of disease were documented in new-borns in hospitals and intensive care units. Although the incidence of infection is low, the prognosis is poor and mortality rates are significant (20-80\%) (42). The estimated annual incidence rate for Cronobacter spp. infections is 1 per 100,000 in children $<12$ months but significantly higher in children with low birth weights $<2500 \mathrm{~g}$ (8.7 per 100,000) (41). Cronobacter spp. infections cause life-threatening meningitis, septicaemia and necrotizing 
enterocolitis and can lead to serious irreversible neurological sequelae in surviving children (43). Although epidemiological evidence for the number of cells needed to cause an infection is missing, a value of 1000 cell has been suggested (44) but this will depend on the physiological state of the organism, the health status of the host and the food matrix. Cronobacter spp. infections have also occurred in adults but usually these patients were already suffering from underlying fatal conditions.

\section{Sources of Cronobacter spp.}

The perceived source is infant formula and milk powder. When 141 different powdered infant formula originating from 35 countries were examined in 1988, 20 samples contained Cronobacter spp. in a range from 0.36 to $66 \mathrm{cfu}$ per $100 \mathrm{~g}$ (45). More recent data show that levels have decreased considerably to $-3.84 \pm 0.696 \log$ $\mathrm{cfu} / \mathrm{g}$ (46). Since the bacteria cannot survive the pasteurisation process during the production of infant formula, the presence of the bacteria in the finished product most probably originates from heat sensitive ingredients added after pasteurization or as a recontamination during the filling process from the production environment. $35 \%$ of the milk powder factories sampled by Kandhai et al. showed presence of Cronobacter spp. (47). In addition to contamination of the product at the factory level, extrinsic contamination via utensils such as blenders and spoons has been described (48). Nevertheless, the organism has been isolated from a wide range of environments and foods. The ubiquitous distribution was demonstrated by frequent isolation from households and vacuum cleaners (47). The presence of Cronobacter spp. in foods with low $\mathrm{a}_{\mathrm{w}}$ can be partly explained by its pronounced ability to survive in dry food products and environments. Several authors have described long survival times in powders $(49,50)$. Depending on the storage temperature of the powder, Cronobacter was still present in detectable levels after 22 weeks of storage (51). As levels of Cronobacter spp. in infant formula were reported to be very low, multiplication of the organism needs to take place in order to reach realistic probability to cause infection. Use of water below $70^{\circ} \mathrm{C}$ for the reconstitution of the formula and the extended uncooled storage of the reconstituted formula are main factors that can lead to bacterial growth.

\section{Testing for foodborne pathogens}

Microbiological testing is one of the tools that can be applied to assess whether a food safety risk management system is giving the level of control it was supposed to deliver and can provide industry and regulatory authorities with concrete evidence if control is used correctly (52). The most important microbiological tests 
performed on foods are for the presence and or quantity of certain pathogenic bacteria. Routine testing is generally limited to such organisms that are so-called "moderate hazards". These are for example Salmonella Typhimurium, Bacillus cereus, Staphylococcus aureus etc. (53). Bacteria regarded as "severe hazards" such as Clostridium botulinum, Salmonella Typhi etc. are not subject of routine testing (53). No conceivably practicable food-testing regime could give a statistically acceptable level of assurance regarding the danger that these organisms represent. Safety of these products must be ensured with measures other than microbiological testing. In the food industry, the hazard analysis and critical control points (HACCP) system is used to identify, evaluate and control the significant hazards in a food product. The decision on what pathogenic organism in a food to test for must rely mainly on epidemiology. Sometimes there is also a need to test for pathogens that occur in significant numbers in a food even though they will receive a heat treatment that will destroy the pathogens. The reason is generally the probability of cross contamination to other food products (15).

\section{Reasons for microbiological testing}

Microbial testing is an integrated part of managing of microbial safety in the food chain. There are different reasons to test for pathogens in food and depending on the responsible party one or the other might be more important:

\section{HACCP implementation:}

A HACCP system for controlling microbiological contamination can rely on appropriate microbiological criteria. Microbiological data can be collected to identify the points in the process where hazards originate and where hazards are reduced or eliminated. Therefore, microbiological testing is a necessary part of HACCP implementation (54). In an established HACCP system, microbiological testing can play a valuable role as a means for the verification of the system. With the help of microbiological data, producers can identify where the process is not properly controlled.

\section{Regulatory requirements:}

Food business operators are obliged to meet microbiological criteria. These can exist for the local market, import or export. Also business to business specifications can exits. This includes testing against values determined for the criteria by the means of sampling, the analysis of samples and the implementation of corrective actions. In Europe, microbiological criteria are laid down in commission regulation (EC) No 2073/2005 on microbiological criteria for foodstuffs. A microbiological 
criterion provides a metric for the presence for a particular microorganism or their metabolites for a certain food product at a specified step in the production chain. The likelihood of exposure to the consumer and its vulnerability are included as well when defining a microbiological criterion. Samples are taken from a batch of food and tested for the presence/quantity of the relevant bacteria. The results of the test will determine if, according to the microbiological criteria, the batch of food or the performance of a process is acceptable or not (55). The regulation lays down food safety criteria for certain important foodborne bacteria such as Salmonella and Listeria monocytogenes (56). Microbiological criteria apply to products placed on the market during their entire shelf life. The criteria also state the unit size for analysis, the reference method and the sampling plans. For example, the food safety criterion for Cronobacter spp. in dried infant formulae and dried dietary foods for special medical purposes intended for infants below six months is absence in $10 \mathrm{~g}$ with 30 samples to be taken. New microbiological criteria for Shiga toxin-producing E. coli serotypes O156, O26, O111, O103, O145 and O104:H4 in sprouted seeds were laid down in 2013 as a consequence of the STEC outbreak in 2011 in Germany.

\section{Surveillance and outbreak investigation:}

Microbiological testing is applied to determine regional, national and international situations of pathogen contamination in certain food products. Such data have been used to compare safety conditions of products from different regions and countries. These may have results on import and export regulations. Testing may also be applied in cases were methods for decontamination are assessed. In addition, epidemiological data after a foodborne outbreak need to be collected. Not only will samples of the presumptive responsible food be examined, but also samples of the remaining batch and the environment of the production facility. If possible, the responsible agent should be isolated and characterized.

In the end, microbiological end product testing for the confirmation of product safety is not a practical option. Due to statistical considerations, sample numbers needed for analysis would be much too high. In addition, end product testing is restricted to detecting failures but not their causes. Therefore, testing should only be used as a support for a sound process control (52).

\section{Methods for the detection of foodborne pathogens}

Pathogens in food might not be well adapted to the environment represented by the foods and are often damaged due to food processing. The stressed state and cellular damage may hamper their detection. Conventional bacterial testing methods rely 
on specific microbiological media to isolate and enumerate viable bacterial cells in foods. Cultural methods are reliable, efficient, easily adaptable, usually inexpensive and detect only living cells. They are able to deliver both qualitative and quantitative information on the microorganism within in the food. Additionally an isolate of the organism can be obtained. Generally, culture-based methods are designed to be able to detect a single bacterial cell in a sample which size can vary from $10 \mathrm{~g}$ to $375 \mathrm{~g}$ or more (57). Since the direct detection of a single microbial cell in such a large sample is impossible, most methods rely on the multiplication of the pathogens in order to reach a detection threshold. The general approach consists of sequential steps of cultural enrichment, selective and differential plating and confirmation (Figure 2). Cultural enrichment is frequently divided into pre-enrichment and selective enrichment. In the following, the steps in cultural detection will be described with focus on the previously mentioned pathogens.
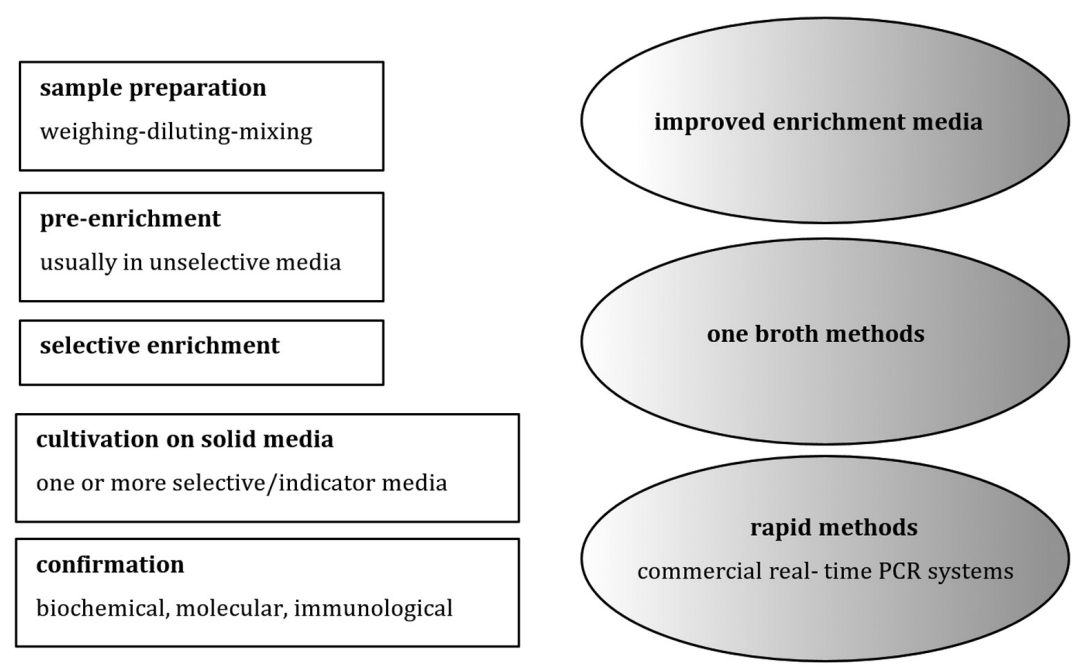

Figure 2. Culture based detection of pathogens from food and possible strategies for improvement discussed in this thesis.

\section{Pre-enrichment}

Key to the reliability of most methods for the detection of Gram-negative foodborne pathogens (Salmonella, Cronobacter and Shiga toxin-producing E. coli) is the ability to recover low numbers of stressed cells from any kind of food matrix and promote growth to a detectable level. The first step that is common to most current detection methodologies (cultural, molecular and immunological) aims at the resuscitation of cells in a non-selective medium. Next to the resuscitation of stressed cells the pre-enrichment is designed to offer an environment that allows for growth of the 
target microorganisms and that also allows for survival once growth has ceased for example by avoiding drastic $\mathrm{pH}$ changes through the presence of a suitable buffer.

Bacterial cells may encounter various types of stress during food production and storage such as heat, freezing, desiccation or extreme $\mathrm{pH}$ and individual cells might have experienced metabolic or physical injury. Sublethal injury has been reported to change the metabolism of bacteria by causing the degradation of ribosomal DNA and RNA, which can lead to failure in recovery of the cells and therefore false negative results (58). Other effects of injury can be an extended lag time, restricted temperature range for growth and increased sensitivity to selective agents (59). Despite the physiological impediment, stressed bacteria remain important because they keep their ability to contaminate and cause infection.

Buffered peptone water is one of the most widely used pre-enrichment broths for Salmonella in a wide range of foods. It is the required medium in many published reference methods including detection of Cronobacter spp. in infant formula (ISO/ TS 22964:2006) (60) and STEC in sprouts (ISO/TS 13136:2012) (61). In order to provide conditions for the resuscitation and growth of cells prior to the selective enrichment, BPW buffers the $\mathrm{pH}$ of the growth system against changes caused by the growth and metabolism of microorganism and those brought about by the food sample (62). The success of pre-enrichment is also depending on the quality of the medium. It was shown that there are some inconsistencies in the performance of BPW and that the ISO standard formulation results in performance variations not just from manufacturer to manufacturer but also from batch to batch (unpublished data by Heike Margot). A comparison of 18 different commercially brands of buffered peptone water showed differences in performance regarding buffering capacity, growth of unstressed bacteria and recovery of dry-stressed cells (unpublished data by Heike Margot). The performance of BPW brands depended heavily on the matrix and the organism tested (unpublished data by Heike Margot). During a comparison of two commercially available preparations of buffered peptone water with regards to their ability to promote recovery and growth of sub-lethally injured $S$. enterica, there was a significantly higher recovery rate of stressed cells with one brand of buffered peptone water. However, the performance of BPW in food was mostly dependent on the food type with the type and level of background flora present being the most important influential factors (62). Different studies have investigated the effect of changing the composition of BPW and modification of the incubation conditions during enrichment (temperature, time, etc.) $(63,64)$. Gray et al. (65) investigated the effect of variation between classes of casein, gelatine and peptones from different sources. They concluded that the variation in peptone has a substantial influence when looking at growth and enumeration of bacteria. For STEC, pre-enrichment 
methods were developed based on meat industry requirements. However, these methods are inadequate for the recovery of STEC from vegetables, flour and other low $\mathrm{a}_{\mathrm{w}}$ matrices (66). The supplementation of growth factors such as additional iron and sodium pyruvate, along with low levels of inhibiting agents primarily against Gram-positive background flora (8- hydroxyquinoline and sodium deoxycholate) enhanced the recovery of desiccation stressed Cronobacter spp. from low $\mathrm{a}_{\mathrm{w}}$ matrices (67). Products containing starter cultures and probiotic cultures present a special challenge to pathogen detection. Strong acidification of the enrichment caused by lactic acid producing bacteria can lead to inactivation of target bacteria and subsequently false-negative results (68).

\section{Selective enrichment}

The second step, the selective enrichment, should promote growth of the recovered bacteria and inhibit the background flora. The second enrichment step can be performed in selective or differential media. The selection can be achieved by the addition of a certain carbon source or supplementation with antibiotics or salts. Commonly used media for the selective enrichment of Salmonella include: Rappaport-Vassiliadis (RV) enrichment broth, Muller-Kauffman tetrathionate broth (MKTTn) and selenite cystine broth. Selective factors in Rappaport-Vassilliadis enrichment broth are malachite green, magnesium chloride and a slightly reduced $\mathrm{pH}$. The selectivity relies on high osmotic pressure, acid $\mathrm{pH}$, malachite green dye and incubation at $41.5^{\circ} \mathrm{C}$. Muller-Kauffman tetrathionate broth contains tetrathionate, brilliant green and bile. In the medium, bile salts and brilliant green inhibit the growth of Gram-positive bacteria, an alkaline $\mathrm{pH}$ is produced by calcium carbonate and iodine and sodium thiosulfate combined produce tetrathionate. Selenite is the selective compound in selenite cystine broth (69). Because these media differ in their selectivity (Rappaport-Vassilliadis $>$ Muller-Kauffman tetrathionate $>$ selenitecystine broth) they are usually used in parallel. RV broth and MKTTn are usually used for the detection of Salmonella from food and animal feed according to ISO/TS-6579: 2012 (70), whereas RV and selenite broth are applied for the isolation of Salmonella from human faeces. Differential or indicator media use the presence of certain dyes or chemicals from which the target bacteria produce characteristic visible changes to the medium. An example is Cronobacter screening broth (CSB), which contains sucrose and the $\mathrm{pH}$ indicator bromocresol blue to distinguish Cronobacter from most other Enterobacteriaceae (71). The necessity of applying a selective enrichment will mostly depend on characteristics of the food product, particularly on its microbial flora. In products with a high number of competing organisms, in which the target bacteria are likely to be stressed, both a non-selective and selective enrichment step 
will be necessary. For products with low levels of background flora, a one-broth enrichment strategy in an unselective enrichment broth can be sufficient.

\section{Detection by culturing}

To determine if the target is present in the selective enrichment culture, its presence needs to be confirmed on one or more selective agar media or with other methods. These media contain nutrients, selective agents and one or more differential biochemical reaction systems to differentiate the target bacteria from the other flora. Isolation media can be distinguished according to their function. Selective agar media allow the growth of the target bacteria while supressing the growth of other bacteria in the sample. This is achieved by the addition of selective compounds such as antibiotics, tellurite, bile salts etc. Examples for selective agar media are: MacConkey agar for the selection of coliforms or Baird-Parker agar for the isolation of Staphylococcus aureus. Indicator or differential media allow distinction of one microorganism from another growing on the same medium. Indicator media make use of the biochemical characteristics of a microorganism when growing in the presence of certain nutrients or indicators. When these compounds are added to the medium they visibly indicate the defining characteristics of the target bacteria. Brilliant Green agar is differential for lactose fermentation and indicates growth of Salmonella. Some media can be both selective and indicator media (e.g. MacConkey). If the enrichment is not selective enough or the food sample contains high numbers of background bacteria, the isolation of the target colony can be difficult due to overgrowth. Because it mostly cannot be excluded that the presence of typical colonies on selective agar media is due to growth of closely related microorganisms the identity still needs to be confirmed with biochemical or serological tests. The isolation of the organism is necessary for the identification and typing especially during outbreak scenarios and for epidemiological investigations.

\section{Requirements for microbiological methods}

When designing, considering the purchase and evaluating such a new method, several factors have to be considered.

Accuracy: The method must be able to correctly identify the target organism and differentiate it from closely related bacteria. For many pathogens, the ability to detect 1 cell in $25 \mathrm{~g}$ of product is demanded. In this case, the analysis only needs to be qualitative. The accuracy of a method is described with the two terms sensitivity and specificity. The sensitivity is the proportion of a target that can be detected. It is calculated with this equation: 
Sensitivity $(\%)=$ number of true positives $(p) /(p+$ number of false negatives $) * 100$

The sensitivity of a certain method will be lower when a present target will not be detected (false-negative result). False-negative results can result in a health risk for the consumer.

The specificity is defined as the ability of a method to discriminate between the target and other organisms.

$$
\text { Specificity }(\%)=\text { number of true negatives }(n) /(n+\text { number of false positives }) * 100
$$

A false-positive result caused by a positive result in the absence of the target will lower the specificity. False-positive results can have substantial financial consequences for the manufacturer if safe products are discarded. Since multiple samples are analysed in a sampling plan, even a rather low false positive rate can still result in a quite high rate of false positives overall.

Speed: Rapid methods for the detection of pathogens should be able to deliver a result faster than the reference methods. Yet, there are rapid methods that need an enriched culture in which the bacteria are resuscitated and did multiply. Most of the detection methods need $10^{4}-10^{5} \mathrm{cfu} / \mathrm{ml}$ for a reliable result. The need for enrichment and laborious sample preparation in advance to the application of rapid methods remains one of the challenges to target.

Costs: Standard cultural detection methods are usual not very expensive. If a rapid method is considered to replace the standard method, the costs per test should be calculated and compared. The purchase of the instrument usually causes the highest initial financial investment. Reagents and material supply can be costly, too. However, if labour costs can be reduced, application of the method may still be less expensive on the long term. In addition, earlier availability of the testing results will allow taking corrective measures faster, which in turn can lessen possible economic damage.

Simplicity: Rapid methods are often supposed to be used at the manufacturing site, however personnel may not be trained to use complex methods. Therefore the methods should be user friendly with little sources of possible errors. The number of operation steps should be limited and well adapted to the workflow and possibly automated to avoid sources of cross-contamination. The results should be displayed in an obvious way and if necessary protected from manipulation (72).

Validation: If an alternative rapid method is to be used in a laboratory accredited according to ISO 17025 and supposed to replace a reference method, it has to be validated to show that the new method performs better or at least equal to the standard method. Method validation is defined as the establishment of the 
performance characteristics of a method and provision of the objective evidence that the performance of the alternative method meets the requirements (73). In a first phase of the validation process, the alternative method is compared against the reference method by an expert laboratory. Afterwards, in a ring trial with several laboratories, the alternative method will be tested with a selection of food categories. The validation can be carried out for a limited number of food categories. The level of contamination and inhibiting ingredients may vary significantly between matrices. Therefore, the validation before the implementation, testing the relevant products, is very important to ensure the effectiveness of the method (74). One protocol for the validation of alternative methods is described in the ISO standard 16140 (75).

\section{Rapid Methods}

The cultural detection of foodborne pathogens is still often regarded as the gold standard and is the ISO reference methods for many pathogens (ISO 6579:2002 horizontal method for the detection of Salmonella (70), ISO/TS 22964:2006 milk and milk products-detection of Cronobacter spp. (60) etc.). However, these methods are very time and labour-intensive and require large volumes of liquid and solid media. The dependence of the organisms to grow in different culture media during pre-enrichment, selective enrichment, selective plating and identification may require several days before the result is obtained. Thus, conventional microbiological methods are not adequate for quick assessments of the microbiological safety of foods (76). Both the food industry and the legal authorities are therefore interested in methods that can deliver information on the microbiological status of food products as quickly and as reliable as possible. Over the last few decades, standard culturebased methods for the detection of pathogens have been modified and improved, with special attention to the reduction of time to detection. This is generally achieved by the replacement of the selective and differential enrichment and plating by more rapid immunological and molecular methods. In the food industry, rapid methods are mainly used for the fast screening of large numbers of samples of which the majority is expected to be negative. For food producers, screening of products with rapid methods is cost-effective, on the other hand the possibility of false-negative results remain a concern. Positive tested samples during screening are only regarded as presumptive positive results and need to be confirmed. The confirmation of presumptive positive samples is an important part of food testing since it can avoid the destruction of safe products due to false positive results (75). During outbreaks or for regulatory purposes, confirmation may go as far as isolating, identifying and subtyping of the microorganism. PCR based methods are often used for this purpose. 


\section{Commercial test systems}

Since the advent of rapid methods in food testing, a great number of commercially available methods have been developed to simplify and automate the identification of bacteria. Commercial rapid methods can be comprised of various different detection technologies using DNA, antibodies and enzymes. The technologies range from differential plating media to the application of specialised instruments such as real-time PCR platforms and microarrays (76). Some of the commercial methods are automated to reduce hands-on manipulations and allow parallel testing of several samples. The introduction of easy-to use detection kits with close-tube formats has promoted the application of molecular methods in routine laboratories and in food production facilities. Most test systems can be miniaturized and thus take up less space in the laboratory. The widespread application of miniaturized biochemical kits has facilitated the cumbersome biochemical identification. Commercial test systems are often proprietary methods that have a registered trademark or brand name, which is owned and marketed by a commercial company. Usually, some of the components and the exact mechanism of the method are confidential (73). Most commercial real-time PCR systems work with an undisclosed DNA target for example. The methods discussed in this thesis are described in more detail in the following section.

\section{Real-time PCR}

Amplification of nucleic acid by the polymerase chain reaction (PCR) was regarded as the most promising alternative to conventional cultural methods in food analysis ten years ago $(77,78)$. Today, conventional PCR has been superseded by real-time PCR that is now widely used in both research and diagnostic laboratories. Real-time PCR combines the amplification of bacterial DNA with simultaneous visualization of the amplification products by contiously measuring the fluorescent signal of a highly specific probe or intercalating dye. The fluorescent intensity is proportional to the amount of PCR amplicon. In contrast to simple PCR, no gel electrophoresis is needed, which saves time and reduces the risk of contamination. There are several fluorescent systems for real-time PCR with the most common being SYBR Green, Taqman probes and molecular beacon. Since SYBR Green binds to all doublestranded DNA products created during PCR, its specificity is reduced compared to the other detection systems. Probe based PCR assays like Taqman on the other hand are based on a specific hybridization probe that has a reporter fluorophore dye on the 5'end and a quencher molecule on the 3'end. When the probe in its native state is exposed to a light source, the emission of the reported dye is absorbed by the quencher molecule due to their close proximity. During the PCR amplification, 
the Taq polymerase extends the primer and approaches the annealed probe. The reporter is cleaved off which results in increased fluorescence. Multiple different targets can be detected in a single PCR reaction using multiple Taqman probes specific to pathogen marker genes (multiplex detection) (56). Molecular beacon assays also rely on probes but use a different chemistry. The target recognition portion of the beacon is flanked by complimentary DNA sequences. On the 5 end the beacon is labelled with a fluorescence reporter, a quencher sits at the opposite site. The resulting hairpin loop structure brings both the fluorophore and the quencher in close proximity, which leads to a quenched fluorescent signal. The hairpin loop dissociates when the molecular beacon binds the specific sequence in the target amplicon and the increasing distance of reporter and quencher allow the reporter to emit a signal (57). A wide selection of commercial real-time PCR systems for the detection of Salmonella and STEC were compared in the course of this PhD project.

Controls: One difficulty in the application of real-time PCR for food testing is the presence of various compounds that can have detrimental effects on the PCR reaction. Sample matrix associated inhibitors such as gelatine, fat, polyphenols etc. are known PCR inhibitors (79). In addition, malfunction of the cycler, errors made with the preparation of PCR mixtures or poor activity of the polymerase may impede with the PCR, which can result in amplification failure or decreased specificity and sensitivity of the system (80). These are the reasons why researchers and kit manufacturers have introduced internal amplification controls (IAC). These are markers for the failure of the amplification and signals for unreliable results that reduce the risk of obtaining false negative results. The IAC is a non-target DNA sequence that can be co-amplified simultaneously with the target sequence. In a PCR reaction containing an IAC, the control signal will be produced even when there is no target signal but the PCR reaction has worked. When there is neither a control nor a target signal, the PCR was unsuccessful (79). The presence of an IAC in PCR basedmethods for the detection of foodborne pathogens is a requirement specified by the CEN and the ISO (81). Another principal concern of food analysis is the occurrence of cross-contamination. The accidental contamination of the samples or the reagents with positive samples causes most false positive results. Cross contaminations can be reduced by the application of separated working areas for different steps in the preparation, filtered pipette tips and good laboratory practices. A negative control indicates that there is no contamination in the PCR assay (78).

Detection limit: The detection limit of any alternative method is one of the most important characteristics. Regulatory standards for many pathogens require the detection of one cell in a $25 \mathrm{~g}$ sample. The theoretical detection limit of a PCR reaction of one cell can be translated into $10^{3}$ to $10^{4} \mathrm{cfu} / \mathrm{ml}$ of sample enrichment. 
This is because the volume of enrichment used in the actual PCR reaction is usually very small and the sample enrichment contains other bacteria, food particles etc. These are the reasons why the detection limit of a real-time PCR system should always be determined in the respective matrix using the appropriate extraction method.

\section{One-broth methods}

Next to molecular methods, cultural methods have been modified in order to allow faster detection of pathogens. The pre-enrichment and selective enrichment step are the main time limiting factors in regards to turn around time for rapid methods (62). The usual sequence of enrichment and detection steps in the reference methods can be accelerated by omitting one of the two subsequent enrichment steps. The need for the application of a non-selective or selective enrichment step depends on the food matrix and its flora. Newly developed methods for the detection of Salmonella combine the enrichment in a selective broth with the isolation on a chromogenic agar. The enrichment broth is supposed to be selective enough to suppress competitive organisms without negatively affecting the recovery of stressed target cells. The chromogenic agar media should improve recovery of Salmonella by reduction of the background flora. With these methods, a negative Salmonella result can be obtained within two days. Presumptive positive colonies need to be confirmed with subsequent methods (26). Not only the selective enrichment can be skipped, onebroth enrichment protocols employing only a non-selective or minimally selective broth medium have been proposed that can be used in food matrices with little competitive flora (64).

\section{Immunological methods}

Immunological methods rely on the specific binding of an antibody to an antigen. For the detection of pathogens and their toxins, a variety of antibodies incorporated in different assays are available. Homogeneous or "marker-free" immunoassays make the antigen-antibody complex immediately visible, without the need for the separation of the bound from the unbound antibody. Examples are latex agglutination tests, which are widely used for the confirmation of presumptive positive results for Salmonella.

The most prevalent antibody-based assays for the detection of pathogens in food are ELISA based approaches. ELISA assays are heterogeneous immunoassays, which are based on the separation of the unbound antibody from the bound antibody. In a typical sandwich assay, the capture antibody is immobilized on a solid plate. After 
the sample is added, the unbound sample is removed and the reporter antibody conjugate is added. The reported antibody is usually labelled with horseradish peroxidase. The removal of the unbound reporter conjugate is followed by the addition of the reporting substrate. The intensity of the reporter signal is related to the amount of the antigen in the sample. Commercial immunoassays include a variety of reporting systems and can be performed in minimally equipped labs (72). Another application of immunological methods in commercial systems is the application of immunocapture-based separation. This technique includes the immunological binding of the target, followed by its physical separation from an enrichment culture. During immunomagnetic separation, samples are mixed with beads that are coated with antibodies. The target in the sample binds the immunomagnetic beads, which can be removed from the sample by applying a magnetic field. The beads can be plated or the isolated organisms can be added to a PCR reaction. This technique is used for the isolation of a range of pathogens (Listeria monocytogenes, Salmonella, E. coli O157) from food products. Since antibody techniques are easily automated and cost-effective they are very suitable for commercial testing systems. An example is the Vitek Immuno Diagnostic Assay System (VIDAS, BioMerieux). The instrument performs all steps of a sandwich ELISA and reports the result.

\section{Objectives of the thesis}

This $\mathrm{PhD}$ thesis was conducted pursuing the following objectives:

- Evaluating methods for more rapid and sensitive detection of foodborne pathogens to guide laboratories contemplating about replacing conventional methods with a rapid alternative.

- Optimization of the pre-enrichment medium with a view to recovery and growth of Gram-negative foodborne pathogens for the application across the relevant ISO standards.

- Improvement of the detection procedure of Shiga toxin-producing E. coli from sprouted seeds and gaining better insight in enrichment ecology by application of a microbiome analysis of the natural sprout flora.

- Determination of the impact of an extended lag phase of stressed single Cronobacter spp. cells on the probability of detection in powdered infant formula. 


\section{Outline of the thesis}

The research conducted in the course of this $\mathrm{PhD}$ project addressed various aspects of the detection methodology for Gram-negative pathogens in food products. The different steps from enrichment to final detection were considered as well as factors influencing these.

As described in the introduction, traditional cultural methods for pathogen detection are time and labour-intensive. Due to their increased availability and affordability rapid methods for the most prevalent pathogens are getting more popular and their number on the market increases. However, the selection of the most suitable detection system for a laboratory or a food manufacturer is not easy and needs to be supported by experimental data. In Chapter 2, the accuracy of commercially available real-time PCR assays for the detection of Salmonella was compared. Inclusivity and exclusivity were assessed with pure cultures. The extraction method resulting in the least inhibition was selected. Subsequently, the detection limit was determined in four food products. The convenience of use for the methods was evaluated since in commercial laboratories it is essential that those methods are efficient, fast and easy to use.

Not only molecular techniques are used in commercial rapid methods, the modification of cultural methods by skipping the selective enrichment step also allows for a more rapid detection. Rapid cultural methods using only one selective enrichment step and isolation on chromogenic agar media for the detection of Salmonella are compared in Chapter 3. Three methods from different manufactures were tested in regards to their ability to correctly identify Salmonella and to differentiate the target from closely related organisms. The doubling time in the selective enrichment broths was determined. The limit of detection was compared to a reference method using four food matrices.

In Chapter 4, seven commercial real-time PCR assays for the detection of the $s t x$ genes were evaluated. Since the presence of certain Shiga toxin subtypes is considered to be a good indicator for STEC virulence, detection systems were tested for their ability to correctly detect all known $s t x_{1}$ and $s t x_{2}$ subtypes. In addition, the convenience of use for the application in food microbiology was assessed.

Even though rapid detection methods gained great popularity in the detection of foodborne pathogens, most, if not all, rapid methods also include a pre-enrichment step, which inevitably increases the time to result to at least $18 \mathrm{~h}$. Gram-negative foodborne pathogens can be present in low numbers and often in a stressed state. During the enrichment these cells should be resuscitated and protected from overgrowth by the background flora. The evaluation of the effects of changing 
the composition of the pre-enrichment medium buffered peptone water (BPW) on the growth of stressed and unstressed Salmonella, STEC and Cronobacter spp. is described in Chapter 5. BPW was supplemented with an available iron source and sodium pyruvate, along with low levels of 8-hydroxyquinoline and sodium deoxycholate to improve resuscitation of desiccation stressed cells and at the same time inhibit growth of Gram-positive competing bacteria. The use of this modified broth in a one-broth enrichment strategy was tested with pure cultures and with food matrices. Furthermore the detection limit of the current ISO standard method for the detection of Salmonella and STEC from sprouted seeds after enrichment in the broth variants was determined.

The fact that sprouted seeds are a challenging matrix for current detection methods was already described in chapter 5. In Chapter 6 the problem of detecting low numbers of STEC in this matrix was addressed. Different broth media (EE-broth, BGB, mTSB + Novobiocin and BPW) used for the enrichment of STEC were compared with respect to their ability to promote the growth of stressed and unstressed STEC from different serotypes. Sprouts were spiked with low levels of stressed cells and the ability of the media to recover the cells from the matrix was tested. To get a better insight in the background flora on sprouts and its development during enrichment, the microbiome of sprouts was characterized with next-generation sequencing.

In products were the initial contamination level is very low and cells are stressed due to unfavourable conditions, the physiological state of the individual cell has an important influence on the growth behaviour and consequently on the detection. One of the consequences that stress can have on cells is an increase of the lag time. In Chapter 7 the influence of stress on the lag time of stressed single Cronobacter spp. cells is described. Cronobacter strains of different species were subjected to heat, acid and desiccation stress, diluted to single cells and their lag time was recorded. The inactivation caused by the stress was tested and lag time and inactivation data were used to build scenarios visualizing the effects on the detection of desiccation stressed Cronobacter spp.

Chapter 8 contains a summarizing discussion and conclusions. 


\section{References}

1. World Health Organization. 2008. Foodborne disease outbreaks: guidelines for investigation and control. Available at http://www.who.int/foodsafety/publications/foodborne_disease/outbreak_ guidelines.pdf last access 27 August, 2015.

2. Centres for Disease Control and Prevention. 2010. Surveillance for foodborne disease outbreaks. United States. Morbidity and Mortality Weekly Report 59: 973-979.

3. Scallan, E., Hoekstra, RM., Angulo, FJ., Tauxe, RV., Widdowson, MA., Roy, SL., Jones, JL., Griffin, PM. 2011. Foodborne illness acquired in the United States-major pathogens. Emerging Infectious Diseases 17: 7-15.

4. The European Union summary report on trends and sources of zoonoses, zoonotic agents and foodborne outbreaks in 2013. EFSA, European Centre for Disease Prevention and Control 2015; 13(1): 3991-4165.

5. World Health Organization. 2008. Foodborne disease outbreaks: guidelines for investigation and control. Available at www.who.int/foodsafety/publications/foodborne_disease/outbreak_ guidelines.pdf last access January 15, 2016.

6. The federal office of public health, Switzerland, 2013. Foodborne outbreaks in Switzerlandcurrent statistics, future developments, practical guidelines for the investigation of outbreaks and a historical review. Available at www.blv.admin.ch/themen/04678/04711/04779/index.html last access August 07, 2015.

7. Ahmed, SM., Hall., AJ., Robinson, AE., Verhoef, L., Premkumar, P., Parashar, UD., Koopmans, M., Lopman, BA. 2014. Global prevalence of norovirus in cases of gastroenteritis: a systematic review and meta-analysis. The Lancet Infectious Diseases 14: 725-730.

8. Behravesh, CB., Williams, IT., Tauxe, RV. 2012. Emerging foodborne pathogens and problems: Expanding prevention efforts before slaughter or harvest. Improving food safety through a onehealth approach: workshop summary. http://www.ncbi.nlm.nih.gov/books/NBK114501/

9. Lynch, MF., Tauxe, RV., Hedberg, CW. 2009. The growing burden of foodborne outbreaks due to contaminated fresh produce: Risks and opportunities. Epidemiology and Infection 137: 307-315.

10. Rossvoll, E., Langsrud, S., Bloomfield, S. Moen, B., Heir, E., Moretro, T. 2015. The effects of different hygiene procedure in reducing bacterial contamination in a model domestic kitchen. Journal of Applied Microbiology 119: 582-593.

11. Jay, JM., Loessner, MJ., Golden, DA. 2005. Modern food microbiology. Food Science Text Series p. 657.

12. Tindall, BJ., Grimont, PAD., Garrity, GM., Euzeby, JP. 2005. Nomenclature and taxonomy of the genus Salmonella. International Journal of Systematic and Evolutionary Microbiology 55: 521-524.

13. Buxton, JA., Fyfe, M., Berger, S., Cox, MB., Northcott, KA., Multiprovincial Salmonella typhimurium case-control study group. 2002. Reactive arthritis and other sequelae following sporadic Salmonella typhimurium infection on British Columbia, Canada: a case control study. Journal of Rheumatology 10: $2154-8$.

14. Crump, JA., Luby, SP., Mintz, ED. 2004. The global burden of typhoid fever. Bulletin of the World Health Organization 82: 346-353.

15. Christian, JHB. 1989. Public health microorganisms testing in perspective- in Foodborne microorganisms of public health significance Fourth Edition. AIFST Food Microbiology Group p. 3-15.

16. Adams, MR., Moss, MO. 1995. Food Microbiology. Royal Society of Food Chemistry.

17. Gunn, JS., Marshall, JM., Baker, S., Dongol, D., Charles, RC., Ryan, ET. 2014. Salmonella chronic carriage: epidemiology, diagnosis, and gallbladder persistence. Trends in Microbiology 22: 648-655.

18. EFSA panel on Biological Hazards. 2013. Scientific opinion on the risk posed by pathogens in food of non-animal origin. EFSA Journal 11:1-138. 
19. Angelo, KM., Chu, A., Nguyen, TA., Bottichio, L., Wise, M., William, I., Seelman, S., Bell, R., Fatica, M., Lance, S., Baldwin, S., Shannon, K., Lee, H., Trees, E., Strain, E., Gieraltowski, L. 2015. Outbreak of Salmonella Newport infections linked to cucumber-United States, 2014. Morbidity \& Mortality Weekly Report 6: 144-157.

20. Herman, KM, Hall, AJ., Gould, LH. 2015. Outbreaks attributed to fresh leafy vegetables, United States, 1973-2012. Epidemiology and Infection 20: 1-11.

21. Cavallaro, E., Date, K., Medus, C., Meyer, S., Miller, B., Kim, C., Nowicki, S., Cosgrove, S., Sweat, D., Phan, Q., Flint, J., Daly, ER., Adams, J., Hyytia-Trees, E., Gerner-Smidt, P., Hoeckstra, RM., Schwensohn, C., Langer, A., Sodha, SV., Rogers, MC., Angulo, FJ., Tauxe RV., Williams, IT., Behravesh, CBT, 2011. Salmonella Typhimurium infections associated with peanut products. New England Journal of Medicine 365: 601-610.

22. Brockman, SO., Piechotowski, I., Kimmig, P. 2004. Salmonella in sesame seed products. Journal of Food Protection 67: 178-180.

23. Werber D., Dreesman, J., Feil., F., van Treeck, U., Fell., G., Ethelberg, S., Hauri, AM., Roggentin, P., Prager, R., Fisher, IST., Behnke, SC., Bartelt, E., Weise, E., Ellis, A., Siitonen, A., Andersson, Y., Tschäpe, H., Kramer, MH., Ammon, A. 2005. International outbreak of Salmonella Oranienburg due to German chocolate. BMC Infectious Diseases 5: 7.

24. Koch, J., Schrauder, A., Alpers, K., Werber, D., Frank, C., Prager, R., Rabsch, W., Broll, S., Feil, F., Roggentin, P., Bockemühl., J., Tschäpe, H., Ammon, A., Stark, K. 2005. Salmonella Agona outbreak from contaminated aniseed, Germany. Emerging Infectious Diseases 11: 1124-1127.

25. Ilic, S., Duric, P., Grego, E. 2010. Salmonella Senftenberg infections and fennel seed tea, Serbia. Emerging Infectious Diseases 16: 893-895.

26. Margot, H., Stephan, R., O’Mahony, E., Iversen, C. 2013. Comparison of rapid cultural methods for the detection of Salmonella species. International Journal of Food Microbiology 163: 47-50.

27. Archer, J., Jervis, ET., Bird, J., Gaze, JE. 1998. Heat resistance of Salmonella Weltevreden in lowmoisture environments. Journal of Food Protection 61: 969-973.

28. Kaper, JB., Nataro, JP., Mobley, HLT. 2004. Pathogenic Escherichia coli. Nature Reviews 2: 12-140.

29. Riley, LW., Remis, RS., Helgerson, SD., McGee, HB., Wells, JG., Davis, BR., Hebert, RJ., Olcott, ES., Johnson, LM., Hargrett, NT., Blake, PA., Cohen, ML. 1983. Hemorrhagic colitis associated with a rare Escherichia coli serotype. New England Journal of Medicine 308: 681-685.

30. Tarr, PI., Gordon, CA., Chandler, WL. 2005. Shiga-toxin-producing Escherichia coli and haemolytic uraemic syndrome. Lancet 365: 1073-1086.

31. Bosilevac, JM., Koohmaraie, M. 2011. Prevalence and characterization of non-O157 Shiga toxinproducing Escherichia coli isolated from commercial ground beef in the United States. Applied and Environmental Microbiology 77: 2103-2112.

32. Swiss National Reference Centre for enteropathogenic bacteria and Listeria. 2014. Annual Report enteropathogenic Escherichia coli.

33. Thorpe, CM. 2004. Shiga toxin-producing Escherichia coli infection. Clinical Infectious Diseases. Available at http://cid.oxfordjournals.org/ last access August 05, 2015.

34. Neil, KP., Biggerstaff, G., MacDonald, JK., Trees, E., Medus, C., Musser, KA., Stoika, SG., Zink, D., Sotir, MJ. 2011. A novel vehicle for transmission of Escherichia coli O157:H7 infections to humans: multistate outbreaks of $E$. coli O157:H7 infections associated with consumption of ready-to-bake commercial cookie dough-United States 2009. Clinical Infectious Diseases 54: 511-518.

35. Centres for Disease Control and Prevention. 2011. Investigative update: multistate outbreak of $E$. coli O157:H7 infections associated with in-shell hazelnuts. Available at http://cdc.gov/ecoli/2011/ hazelnutsO157/archive/030511.html last access August 27, 2015.

36. Beuchat, LR., Komitopoulou, E., Beckers, H. Betts, RP., Bourdichon, F., Fanning, S., Joosten, HM., Ter Kuile, BH. 2012. Low-water activity foods: increased concern as vehicles of foodborne pathogens. Journal of Food Protection 76: 150-172. 
37. Erickson, MC., Doyle, MP. 2007. Food as vehicle for transmission of Shiga toxin-producing Escherichia coli. Journal of Food Protection 70: 2426-2449.

38. Iversen, C., Mullane, N., McCardell, B., Tall., BD., Lehner, A., Fanning, S., Stephan, R., Joosten, H. 2008. Cronobacter gen. nov., a new genus to accommodate the biogroups of Enterobacter sakazakii, and proposal of Cronobacter sakazakii gen. nov., comb. nov., Cronobacter malonaticus sp. nov., Cronobacter turicensis sp. nov., Cronobacter muytjensii sp. nov, Cronobacter dubliensis sp. nov., Cronobacter genomspecies 1, and of three subspecies, Cronobacter dubliensis subsp. dubliensis subsp. nov., Cronobacter dubliensis subsp. lausannensis subsp. nov. and Cronobacter dubliensis subsp. lactardii subsp. nov. International Journal of Systematic and Evolutionary Microbiology 45: 195-204.

39. Bowen, AB., Braden, CR. 2006. Invasive Enterobacter sakazakii disease in infants. Emerging Infectious Diseases 12: 1185-1189.

40. Urmenyi, AC., Franklin AW. 1961. Neonatal death from pigmented coliform infection. Lancet 1961: 313-315.

41. Food and Agricultural Organization of the United Nations (FAO) and the World Health Organization (WHO) (FAO/WHO). 2008. Enterobacter sakazakii (Cronobacter spp.) in powdered follow up formulae. Available at www.fao.org/3/a-i0453e.pdf last access August 05, 2015.

42. Hunter, CJ., Petrosyan, M., Ford, H., Prasadarao, NV. 2008. Enterobacter sakazakii: an emerging pathogen in infants and neonates. Surgical Infections 9: 533-539.

43. Lai, KK. 2001. Enterobacter sakazakii infections among neonates, infants, children and adults: case reports and a review of the literature. Medicine (Baltimore) 80: 113-122.

44. Iversen, C., Forsythe, S. 2003. Risk profile of Enterobacter sakazakii, an emergent pathogen associated with infant milk formula. Trends in Food Science and Technology 14: 443-454.

45. Muytjens, HL., Roelofs-Willemse, H., Jaspar, GH. 1988. Quality of powdered substitutes for breast milk with regard to members of the family Enterobacteriaceae. Journal of Clinical Microbiology 26: 743-746.

46. Jongenburger, I., Reij, MW., Boer, EPJ., Gorris, LGM., Zwietering, MH. 2011. Actual distribution of Cronobacter spp. in industrial batches of powdered infant formula and consequences for performance of sampling strategies. International Journal of Food Microbiology 151: 62-69.

47. Kandhai, MC., Reij, MW., Gorris, LGM., Guillaume-Gentil O., Van Schothorst, M. 2004. Occurrence of Enterobacter sakazakii in food production and households. The Lancet 363: 39-40.

48. Noriega, FR., Kotloff, KL., Martin, MA., Schwalbe, RS. 1990. Nosocomical bacteremia caused by Enterobacter sakazakii and Leuconostoc mesenteroides resulting from extrinsic contamination of infant formula. The Paediatric Infectious Disease Journal 9: 447-449.

49. Breeuwer, P., Lardeau, A., Peterz, M., Joosten, H. 2003. Desiccation and heat tolerance of Enterobacter sakazakii. Journal of Applied Microbiology 95: 967-973.

50. Edelson-Mammel, SG., Buchanan, RL. 2005. Survival of Enterobacter sakazakii in a dehydrated powdered infant formula. Journal of Food Protection 67: 60-63.

51. Kandhai, MC., Reij, MW., Van Schothorst, M., Gorris, LGM., Zwietering, MH. 2010. Inactivation rates of Cronobacter spp. and selected other bacterial strains in powdered infant formulae stored at different temperatures. Journal of Food Protection 75: 839-848.

52. Van Schothorst, M., Zwietering, MH., Ross, T., Buchanan, RL., Cole, MB, International Commission on Microbiological Specifications for Foods (ICMSF). 2009. Relating microbiological criteria to food safety objectives and performance objectives. Food Control 20: 967-979.

53. European Commission Health and Consumer Protection Directorate-General. 2012. Working document on microbial contaminant limits for microbial pest control products. Available at http:// ec.europa.eu/food/plant/pesticides/guidance_documents/docs/wd_on_microbial_contaminant_ limits_en.pdf last access 16 November, 2015.

54. Brown, MH., Gill, CO., Hollingsworth, J., Nickelson, R., Seward, S., Sheridan, JJ., Stevenson, T., Sumner, JL., Theno, DM., Usborne, WR., Zink, D. 2000. The role of microbiological testing in systems for assuring the safety of beef. International Journal of Food Microbiology 62: 7-16. 
55. CAC (Codex Alimentarius Commission). 1997. Principles for establishment and application of microbiological criteria for foods. CAC/GL 21-1997.

56. Commission Regulation (EC) No 2073/2005 of 15 November 2005 on microbiological criteria for foodstuffs. Official Journal of the European Union 2073: 1-26.

57. Dwivedi, HP., Jaykus, LA. 2011. Detection of pathogens in foods: the current state-of-the-art and future directions. Critical Reviews in Microbiology 37: 40-63.

58. Taskila, S., Osmekhina, E., Tuomola, M., Ruuska, J., Neubauer, P. 2011. Modification of buffered peptone water for improved recovery of heat-injured Salmonella typhimurium. Journal of Food Science 76: 157-162.

59. Stephens, PJ., Mackey, BM. 2002. Recovery of stressed microorganisms. Culture Media for Food Microbiology 22: 25-47.

60. ISO/TS 22964 (International Organization for Standardisation). 2006. Milk and milk products detection of Enterobacter sakazakii. International Organization for Standardization, Geneva, Switzerland.

61. ISO/TS 13136 (International Organization for Standardisation). 2012. Microbiology of food and animal feed. Real-time polymerase chain reaction (PCR)-based method for the detection of foodborne pathogens. Horizontal method for the detection of Shiga toxin-producing Escherichia coli (STEC) and the determination of O157, O111, O26, 0103 and 0145 serogroups. International Organization for Standardization, Geneva, Switzerland.

62. Baylis, CL., MacPhee S., Betts, RP. 2000. Comparison of two commercial preparations of buffered peptone water for the recovery and growth of Salmonella bacteria from foods. Journal of Applied Microbiology 89: 501-510.

63. Andrews, WH: 1986. Resuscitation of injured Salmonella spp. and coliforms from foods. Journal of Food Protection 49: 62-75.

64. Margot, H., Stephan, R., O’Mahony, E., Iversen, C. 2013. Comparison of rapid cultural methods for the detection of Salmonella species. International Journal of Food Microbiology 163: 47-50.

65. Gray, VL., Müller, CT., Watkins, ID., Lloyd, D. 2006. Peptones from diverse sources: pivotal determinants for growth dynamics. Journal of Applied Microbiology 104: 554-565.

66. Sata, S., Fujisawa, T., Osawa, R., Iguchi, A., Yamai, A., Shimada, T. 2003. An improved enrichment broth for isolation of Escherichia coli O157, with specific reference to starved cells, from radish sprouts. Applied and Environmental Microbiology 69: 1858-1860.

67. Weber, C., Stephan, R., Druggan, R., Joosten, H. Iversen, C. 2009. Improving the enrichment procedure for Enterobacteriaceae detection. Food Microbiology 26: 565- 572.

68. Joosten, H., Bidlas, E., Garofalo, N. 2006. Salmonella detection in probiotic products. International Journal of Food Microbiology 110: 104-7.

69. Phyllis, E. 2002. Food Microbiology: The Laboratory. The Food Processors Institute. Washington D.C., United States of America.

70. ISO/TS 6579 (International Organization for Standardisation). 2002. Microbiology of food and animal feed. Horizontal method for the detection enumeration and serotyping of Salmonella. International Organization for Standardization, Geneva, Switzerland.

71. Iversen, C., Druggan, P., Schumacher, S., Lehner, A., Feer, C., Gschwend, L., Joosten, H., Stephan, R. 2008. Development of a novel screening method for the isolation of "Cronobacter" spp. (Enterobacter sakazakii). Applied and Environmental Microbiology 74: 2550-2553.

72. De Boer, E., Beumer, RR. 1999. Methodology for detection and typing of foodborne microorganisms. International Journal of Food Microbiology 50: 119-130.

73. Jasson, V., Jacxens, L., Luning, P., Rajkovic, A., Uyttendale, M. 2010. Alternative microbial methods: An overview and selection criteria. Food Microbiology 27: 710-730.

74. Malorny, B., Tassios, P. Radstrom, P., Cook, N., Wagner, M., Hoorfar, J. 2003. Standardization of diagnostic PCR for the detection of foodborne pathogens. International Journal of Food Microbiology 83: $39-48$. 
75. ISO 16140 (International Organization for Standardisation). Microbiology of food and feeding stuffs. Protocol for the validation of alternative methods (EN ISO 16140). European Committee for Standardization, AFNOR, Paris, France.

76. Hoorfar, J. 2011. Rapid Detection, characterization and enumeration of foodborne pathogens. Acta Pathologica, Microbiologica et Immunologica Scandinavica 119: 1-24.

77. Malorny, B., Tassios, PT., Radstrom, P., Cook, N., Wagner, M., Hoorfar, J. 2003. Standardization of diagnostic PCR for the detection of foodborne pathogens. International Journal of Food Microbiology 83: 39-48.

78. Rodriguez-Lazaro, D., Cook, N., Hernandez, M. 2014. Real-time PCR in food science: PCR Diagnostics. Current Issues in Molecular Biology 15: 39-44.

79. Wilson, IG. 1997. Inhibition and facilitation of nucleic acid amplification. Applied and Environmental Microbiology 63: 3741-3751.

80. Hoorfar, J., Cook, N., Malorny, B., Wagner, M., DeMedici, D., Abdulmawjood, A., Fach, P. 2004. Diagnostic PCR, making internal amplification control mandatory. Letters in Applied Microbiology 38: 79-80.

81. ISO 22174:2005. Microbiology for food and feeding stuffs-polymerase chain reaction (PCR) for the detection of food borne pathogens-General requirements and definitions. International Organization for Standardization, Geneva, Switzerland. 


\section{Chapter}

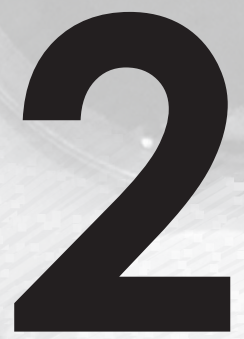

Inclusivity, exclusivity and limit of detection of commercially available real-time PCR assays for the detection of Salmonella

Heike Margot, Roger Stephan, Salvatore Guarino,

Balamurugan Jagadeesan, David Chilton, Emer O’Mahony,

Carol Iversen 


\section{Abstract}

The traditional cultural detection of Salmonella spp. is both time and labourintensive. Salmonella is often a release criterion for the food industry and time to result is therefore an important factor. Storage of finished products and raw materials can be costly and may adversely impact available shelf life. The application of real-time PCR for the detection of Salmonella spp. in food samples enables a potential time-saving of up to four days. The advancement of real-time PCR coupled with the development of commercially available systems in different formats has made this technology accessible for laboratories in an industrial environment. Ideally these systems are reliable and rapid as well as easy to use.

The current study represents a comparative evaluation of seven commercial real-time PCR systems for the detection of Salmonella. Forty-nine target and twenty-nine non-target strains were included in the study to assess inclusivity and exclusivity. The limit of detection for each of the method was determined in four different food products. All systems evaluated were able to correctly identify the 49 Salmonella strains. Nevertheless, false positive results (Citrobacter spp.) were obtained with four of the seven systems. In milk powder and bouillon powder, the limit of detection was similar for all systems, suggesting a minimal matrix effect with these samples. Conversely, for black tea and cocoa powder some systems were prone to inhibition from matrix components. Up to $100 \%$ of the samples were inhibited using the proprietary extracts but inhibition could be reduced considerably by application of a DNA clean-up kit. 


\section{Introduction}

The ISO standard cultural method for the detection of Salmonella spp. involves a non-selective pre-enrichment in buffered peptone water, followed by a selective enrichment in Rappaport-Vasilliadis Soya broth and Muller-Kauffmann Tetrathionate-Novobiocin broth and plating onto selective and differential agars. Two selective solid media are inoculated; xylose lysine deoxycholate agar (XLD agar) and any other solid selective/differential medium of choice that is complementary to XLD. Presumptive positive colonies must then be confirmed biochemically and serologically (1). It can take up to 5 working days to receive a confirmed positive result. Although still considered as the "gold standard", cultural methods are labour-intensive and time-consuming. The application of molecular based methods, such as real-time PCR, can significantly reduce the manpower and time required to detect pathogens such as Salmonella. In recent years, increasingly rapid and specific PCR based methods have been developed to identify Salmonella contamination in environmental and food samples and to confirm the identity of isolated Salmonella cultures. Even though PCR is a valuable tool for scientists, allowing for fast and effective analysis of samples from different origins, inhibition is the most common reason of PCR failure when adequate copies of DNA are present (2). Inhibition of PCR can be caused by various compounds present in the food matrix, in the growth media and in the reagents used for extraction. Rossen et al. (3) tested a wide range of components for the maximum amount that can be added to a PCR reaction without causing inhibition. Their findings showed that concentrated protein, unrelated DNA and levels of $\mathrm{MgCl}_{2}$ potentially have a negative effect on PCR sensitivity. PCR inhibition mechanisms can be grouped into three categories: inhibiting substances can affect cell lysis during DNA extraction, capture or degrade nucleic acids or interfere with the Taq DNA polymerase activity (4). Known PCR inhibitors include proteinases, calcium ions, polyphenolics, tannins, humic acid, complex poly-saccharides, collagen, bile salts, heme, haemoglobin, myoglobin, urea, lactoferrin, immunoglobulin G, melanin and eumelanin (5). Approaches for the prevention of inhibition will include either a clean-up of the extracted DNA or a dilution of the sample. However, dilution of the sample requires laborious sample manipulation and may result in template depletion if template DNA concentrations are low (4). DNA clean-up kits often include a filter column that removes inhibitors like polyphenolics, humic acids, tannins etc. from nucleic acid solutions with little work effort and minimal impact on DNA concentration. The establishment of realtime PCR and commercialization of detection kits facilitates application of PCR for routine testing. However, evaluation data of these systems are so far very limited and restricted to the testing of single systems $(6,7)$. Therefore, the objective of the present study was to evaluate in parallel seven commercially available real-time PCR 
based systems for the detection of Salmonella. A limit of detection (LOD) approach was used with food samples known to be challenging for PCR, e.g. containing inhibitory compounds. In addition, for food matrices where inhibition of the PCR reaction was apparent, the performance of different extraction methods for sample clean up prior to PCR were compared. Moreover, the tests were also compared in view of their convenience and applicability for use in a routine testing laboratory.

\section{Materials and methods}

\section{Food samples}

Skimmed milk powder, a bouillon powder containing Mediterranean herbs, black tea and cocoa powder were used in the study. These food samples were chosen, as they are known to contain compounds that can potentially inhibit the PCR reaction.

\section{Bacterial strains}

A total of 49 Salmonella enterica subsp. enterica strains, covering a range of 39 serotypes, and 29 non-Salmonella were used for inclusivity and exclusivity testing respectively. The non-Salmonella strains included species with similar growth requirements and typically isolated from similar sources to Salmonella. The strains were grown on plate count agar (PCA, Oxoid) at $37^{\circ} \mathrm{C}$ for $24 \mathrm{~h}$. The bacterial strains were stored at $4^{\circ} \mathrm{C}$ in $1 / 2$ tryptose soy agar (TSA, Oxoid). Salmonella Tennessee strain S511, an isolate from a pet food factory in France, was selected for the LOD experiments. Previous experiments confirmed that this strain can be detected with all PCR systems evaluated. One colony of S511 grown on PCA was transferred to $5 \mathrm{~mL}$ of brain heart infusion broth (BHI, Oxoid) and incubated overnight at $37^{\circ} \mathrm{C}$. The cell counts of the overnight culture were determined by plate counting on PCA. Before spiking of the sample, the overnight culture was diluted in physiological saline solution $(0.9 \% \mathrm{NaCl})$ to achieve the desired inoculation level.

\section{Inoculation and enrichment}

A total of 22 portions ( $25 \mathrm{~g}$ ) of each food type were weighed aseptically into stomacher bags and the appropriate enrichment diluent was added. The $25 \mathrm{~g}$ samples of skimmed milk powder were enriched in $225 \mathrm{~mL}$ of buffered peptone water (BPW, Oxoid). Cocoa powder was enriched in $225 \mathrm{~mL}$ of skimmed milk supplemented with brilliant green to a final concentration of $0.018 \mathrm{~g} / \mathrm{L}$. The $25 \mathrm{~g}$ portions of black 
tea and bouillon powder with Mediterranean herbs were each enriched in $900 \mathrm{~mL}$ of BPW; this higher dilution is routinely used in commercial testing laboratories as it has been found to be necessary to prevent growth inhibition of the target organism in these matrices. For the LOD experiments the sample homogenates were inoculated with $100 \mu \mathrm{L}$ of the diluted inoculum in different concentrations. Six replicate samples were spiked with one of three inoculums to give estimated counts of $0.3 \mathrm{cfu} / 25 \mathrm{~g}, 1 \mathrm{cfu} / 25 \mathrm{~g}$, or $3 \mathrm{cfu} / 25 \mathrm{~g}$. Two replicates, inoculated with ca. 10 $\mathrm{cfu} / 25 \mathrm{~g}$ served as a positive control. Two replicates were not inoculated to serve as negative controls and to detect if the sample matrices caused false positive results, e.g. due to auto-fluorescence. The samples were mixed by kneading the stomacher bag for approximately $20 \mathrm{~s}$ by hand and incubated at $37^{\circ} \mathrm{C}$ for 16 to $18 \mathrm{~h}$. The concentration of the inoculum was estimated by plating on PCA.

\section{Detection systems evaluated}

The current study represents a comparative evaluation of seven diagnostic systems namely ADIAFOOD® Salmonella (AES chemunex, Bruz cedex, France) applied on the Stratagene MX3005P, BAX® system Q7 real-time Salmonella (DuPont Qualicon, Wilmington, USA) applied on the BAX system Q7, BIOTECON foodproofC Salmonella Detection Kit (Biotecon Diagnostics, Potsdam, Germany) applied on the Lightcycler ${ }^{\circledR}$ 2.0, BioControl Assurance GDS ${ }^{\circledR}$ TM Salmonella (BioControl, Bellevue, USA) applied on the GDS Rotor Gene ${ }^{\circledR}$, Genedisc ${ }^{\circledR}$ Shiga Toxic E. coli and Salmonella spp. (Pall GeneDisc ${ }^{\circledR}$ Technologies, Bruz, France) applied on the GeneDisc ${ }^{\circledR}$ Cycler, BioRad iQ-Check ${ }^{\circledR}$ Salmonella 2 (Biorad, Marnes-la-Coquette, France) applied on the MiniOpticon $^{\mathrm{TM}}$ and MicroSeq ${ }^{\circledR}$ Salmonella spp. detection kit (Applied Biosystems, Foster City, USA) applied on the 7500 Fast Real-Time PCR System.

\section{DNA extraction}

\section{Inclusivity/exclusivity}

Strains used for inclusivity/exclusivity testing were grown overnight on PCA at 37 ${ }^{\circ} \mathrm{C}$. One colony from PCA was added to $450 \mu \mathrm{L}$ of lysis buffer comprising $20 \mathrm{~mL}$ Tris-HCL pH 8.51 M (12.1 g Tris-(hydroxymethyl)- Aminomethan (Sigma-Aldrich, Buchs, Switzerland), distilled water to $100 \mathrm{~mL}$ ); $100 \mu \mathrm{L}$ Tween 20 (Merck, Darmstadt, Germany); 48 mg Proteinase K (Sigma-Aldrich, Buchs Switzerland, P6556), distilled water to $200 \mathrm{~mL}$ and heated for $40 \mathrm{~min}$ at $60^{\circ} \mathrm{C} \pm 1$ followed by $20 \mathrm{~min}$ at $95^{\circ} \mathrm{C} \pm$ 1 in a heating block (Thermomixer Comfort, Eppendorf). Subsequently the lysate was added to the PCR reaction according to the volume of sample recommended to be added to the assay reagents by the individual manufacturer's instructions. For 
the BAX ${ }^{\circledR}$ system Q7 real-time Salmonella assay, a colony from PCA was added to 5 $\mathrm{mL}$ brain heart infusion broth (BHI) and incubated overnight at $37^{\circ} \mathrm{C}$. The extraction was then performed as described in the manufacturer's protocol.

\section{Comparison of commercial DNA extraction/DNA clean-up kits}

In addition to the use of the proprietary methods proposed by the RT-PCR kit manufacturers, different commercially available sample preparation and nucleic acid clean up kits were evaluated for their ability to overcome the PCR inhibition caused by certain food matrices. Manual extraction and clean-up kits from both PCR and non PCR manufacturers were evaluated, including PrepSEQ ${ }^{\mathrm{TM}}$ Rapid Spin Sample Preparation Kit and PrepSEQ ${ }^{\mathrm{TM}}$ Rapid Spin Sample Preparation Kit Extra Clean (Applied Biosystems), foodproof ${ }^{\circledR}$ StarPrep one Kit (Biotecon), the Food Extraction Pack 01 (Pall GeneDisc ${ }^{\circledR}$ Technologies), DNEasy ${ }^{\circledR}$ mericon Food Kit, both 2 and $200 \mathrm{~g}$ protocols (Qiagen, Hombrechtikon, Switzerland), Masterpure ${ }^{\mathrm{TM}}$ Complete DNA and RNA purification kit (Epicentre, Madison, USA) and OneStep ${ }^{\mathrm{TM}}$ PCR Inhibitor Removal Kit (Zymo Research, Irvine, CA, USA). In addition two automated systems, MagMAX ${ }^{\mathrm{TM}}$ Express-96 Magnetic Particle Processor (Applied Biosystems) and QIAsymphony SP (Qiagen) were also included in the comparison. Matrices known to contain inhibitory compounds (tea, chocolate and Mediterranean herb mix) were inoculated with high levels of Salmonella $\left(10^{4} \mathrm{cfu} / 25 \mathrm{~g}\right)$ and enriched overnight in BPW as described above along with an uninoculated control sample. The $\mathrm{cfu} / \mathrm{mL}$ of the inoculated sample after enrichment was estimated using plate counts on XLD agar to ensure the Salmonella had grown. Duplicate $1 \mathrm{~mL}$ aliquots from the uninoculated control sample and duplicate aliquots from the inoculated samples were subjected to heat lysis at $97^{\circ} \mathrm{C} \pm 2$ with no inhibitor removal step. Aliquots from the inoculated sample were also processed in duplicate according to the instructions for each of the commercial extraction methods. The DNA and protein concentrations of each of the extracts were measured using a spectrophotometer (BioPhotometer, Eppendorf). Aliquots from each of the extractions were diluted to equivalent DNA concentrations. Each of the diluted and undiluted extracts were tested using the BIOTECON foodproof@ Salmonella Kit, BioControl GDS® Salmonella kit, Genedisc ${ }^{\circledR}$ Shiga Toxic E. coli and Salmonella spp. kit and MicroSeq ${ }^{\circledR}$ Salmonella kit on their respective PCR cyclers. The $\mathrm{C}_{t}$ values for each extraction method were compared. In addition, the ease of use of each extraction method was evaluated, including cost, time-to-result and hands-on time. A follow-up evaluation of Pall GenDisc ${ }^{\circledR}$ Food Extraction Pack 01, Applied Biosystems PrepSEQ ${ }^{\mathrm{TM}}$ Rapid Spin Sample Preparation Kit and Zymo OneStep ${ }^{\mathrm{TM}}$ PCR Inhibitor Removal Kit involved extraction of DNA from a range of samples including different varieties of teas, coffees, chocolates, nuts, vegetables, fresh produce, herbs and spices $(n=107)$. 
The extraction methods were applied alone and in combination. Inhibitor removal was evaluated using BioContol GDS ${ }^{\circledR}$, PALL Genedisc ${ }^{\circledR}$ Technologies and Applied Biosystems MicroSeq ${ }^{\circledR}$ kits on their respective PCR cyclers.

\section{Proprietary DNA extraction from inoculated food samples}

DNA from enriched samples was extracted using the proprietary extraction method of the PCR kit or with the method recommended by the supplier. A separate extraction kit is not supplied with BAX® system Q7 real-time Salmonella, Assurance GDS® TM Salmonella and iQ-Check ${ }^{\circledR}$ Salmonella 2, however an extraction step is an integral part of these methods. For the other systems the following extraction kits were recommended and used according to manufacturer's instructions: PrepSEQ ${ }^{\mathrm{TM}}$ Rapid Spin Sample Preparation Kit (Applied Biosystems), foodproof $®$ Sample Preparation Kit I (Biotecon Diagnostics) and the Extraction Pack Food 01 (Pall GeneDisc ${ }^{\circledR}$ Technologies). In some cases the suppliers gave special recommendations deviating from the instruction manual. For DNA extraction from milk powder with the ADIAFOOD ${ }^{\circledR}$ Salmonella the first centrifugation steps were excluded, whereas for the extraction from cocoa powder and black tea an additional washing step was advised. An additional washing step was also performed for the cocoa powder and tea samples with the MicroSeq ${ }^{\circledR ~ S a l m o n e l l a ~ s p p . ~ d e t e c t i o n ~ k i t . ~}$

\section{Real-time PCR amplification}

The PCR amplifications were carried out as described in the manufacturer's instructions. For inclusivity/exclusivity testing each strain was tested once unless there was a false positive, false negative or invalid result. In this case the extract of the strain was tested again in duplicate. For the testing of the artificially inoculated food samples, the performance of each PCR system was first evaluated using the extract of the recommended proprietary extraction method. For cocoa powder and black tea, extracts that exhibited inhibition were retested after dilution. In addition, based on results from the comparison of extraction methods, a combined extraction protocol of Extraction Pack Food 01 followed by Zymo OneStep ${ }^{\mathrm{TM}}$ PCR Inhibitor Removal kit was also used and tested on each PCR system. Initial experiments showed that the BAX® system Q7 real-time Salmonella and the Assurance GDS® TM Salmonella method did not function with extracts other than from their proprietary extraction procedures. 


\section{Data analysis}

The amplification results were analysed using the software provided by the kit supplier. All PCR systems included an internal positive control that would indicate possible inhibition problems during the reaction. For the inclusivity/exclusivity testing the positive/ negative calls of the PCR software were used as a final result. Percentage inclusivity and exclusivity was calculated for the Salmonella and nonSalmonella strains respectively. Based on the PCR results of the inoculated matrices the limits of detection were calculated for each PCR system with each matrix and extract as per Wilrich and Wilrich (8). $\mathrm{LOD}_{50}$ in $\mathrm{cfu} / \mathrm{g}$ stands for the (average) contamination level that gives a positive result in $50 \%$ of the cases.

\section{Results and discussion}

\section{Inclusivity/exclusivity}

All PCR systems evaluated were able to correctly identify the 49 Salmonella strains (Table 1). Serotypes tested were isolated from food products or from clinical specimens and were previously used for evaluating cultural methods for Salmonella detection. A total of 29 non-Salmonella isolates were analyzed with each PCR system. BAX ${ }^{\circledR}$ system Q7 real-time Salmonella, foodproof(C Salmonella Detection Kit and MicroSeq ${ }^{\circledR}$ Salmonella spp. detection kit gave 100\% negative results for these strains. Four systems, namely the ADIAFOOD ${ }^{\circledR}$ Salmonella, Genedisc ${ }^{\circledR}$ Shiga Toxic E. coli and Salmonella spp., Assurance GDS ${ }^{\circledR}$ TM Salmonella and iQ-Check® Salmonella 2 incorrectly identified Citrobacter murliniae strains as Salmonella (Table 2). The Citrobacter spp. strains, which gave false positive results with certain systems, were isolated from fresh vegetables and were identified using both MALDI-TOF MS and $16 \mathrm{~S}$ rDNA sequencing as C. murliniae. The problem of false positive results caused by Citrobacter strains in commercially available real-time PCR systems for the detection of Salmonella spp. has not been reported previously. However, the close relationship of the two genera is known to be a challenge for cultural and biochemical differentiation (9). 
Table 1. Inclusivity results for each real-time system evaluated

\begin{tabular}{|c|c|c|c|c|c|c|c|c|}
\hline Salmonella strains & $\mathrm{N}^{\mathrm{a}}$ & 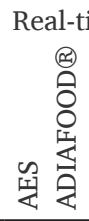 & 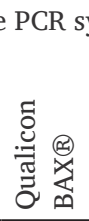 & 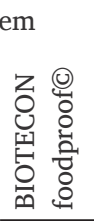 & 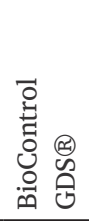 & = & 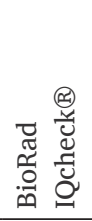 & 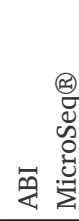 \\
\hline Salmonella Agona & 1 & + & + & + & + & + & + & + \\
\hline Salmonella Albany & 1 & + & + & + & + & + & + & + \\
\hline Salmonella Anatum & 3 & + & + & + & + & + & + & + \\
\hline Salmonella Ank & 1 & + & + & + & + & + & + & + \\
\hline Salmonella Bergen & 1 & + & + & + & + & + & + & + \\
\hline Salmonella Bracknell & 1 & + & + & + & + & + & + & + \\
\hline Salmonella Cerro & 1 & + & + & + & + & + & + & + \\
\hline Salmonella Chittagong & 1 & + & + & + & + & + & + & + \\
\hline Salmonella Congo & 1 & + & + & + & + & + & + & + \\
\hline Salmonella Denver & 1 & + & + & + & + & + & + & + \\
\hline Salmonella Derby & 1 & + & + & + & + & + & + & + \\
\hline Salmonella Ekotedo & 1 & + & + & + & + & + & + & + \\
\hline Salmonella Enteritidis & 2 & + & + & + & + & + & + & + \\
\hline Salmonella Farmsen & 1 & + & + & + & + & + & + & + \\
\hline Salmonella Gambe & 1 & + & + & + & + & + & + & + \\
\hline Salmonella Ibandan & 1 & + & + & + & + & + & + & + \\
\hline Salmonella Infantis & 2 & + & + & + & + & + & + & + \\
\hline Salmonella Kentucky & 1 & + & + & + & + & + & + & + \\
\hline Salmonella Kibi & 1 & + & + & + & + & + & + & + \\
\hline Salmonella Kinondoni & 1 & + & + & + & + & + & + & + \\
\hline Salmonella Limete & 1 & + & + & + & + & + & + & + \\
\hline Salmonella Maritzburg & 1 & + & + & + & + & + & + & + \\
\hline Salmonella Mbandanka & 1 & + & + & + & + & + & + & + \\
\hline Salmonella Napoli & 2 & + & + & + & + & + & + & + \\
\hline Salmonella Nashua & 1 & + & + & + & + & + & + & + \\
\hline Salmonella Oranienburg & 1 & + & + & + & + & + & + & + \\
\hline Salmonella Panama & 1 & + & + & + & + & + & + & + \\
\hline Salmonella Plymouth & 1 & + & + & + & + & + & + & + \\
\hline Salmonella Rissen & 1 & + & + & + & + & + & + & + \\
\hline Salmonella Salamae & 1 & + & + & + & + & + & + & + \\
\hline Salmonella Sundsvall & 1 & + & + & + & + & + & + & + \\
\hline Salmonella Tennessee & 2 & + & + & + & + & + & + & + \\
\hline Salmonella Thompson & 1 & + & + & + & + & + & + & + \\
\hline Salmonella Typhimurium & 5 & + & + & + & + & + & + & + \\
\hline Salmonella Uno & 1 & + & + & + & + & + & + & + \\
\hline Salmonella Virchow & 1 & + & + & + & + & + & + & + \\
\hline Salmonella Wagadugu & 1 & + & + & + & + & + & + & + \\
\hline Salmonella Wagama & 1 & + & + & + & + & + & + & + \\
\hline Salmonella Wagenia & 1 & + & + & + & + & + & + & + \\
\hline Inclusivity \% & & 100 & 100 & 100 & 100 & 100 & 100 & 100 \\
\hline
\end{tabular}

${ }^{\text {a }} \mathrm{N}$, number of strains. 
Table 2. Exclusivity results for each real-time PCR system evaluated Non-Salmonella strains Real-time PCR system

\begin{tabular}{|c|c|c|c|c|c|c|c|}
\hline & 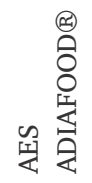 & 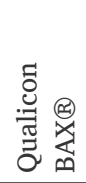 & 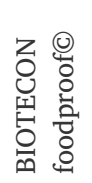 & 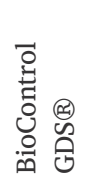 & 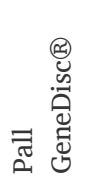 & 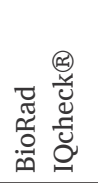 & 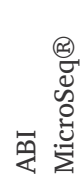 \\
\hline Citrobacter murliniae & + & - & - & + & + & + & - \\
\hline Citrobacter spp. & + & - & - & - & - & - & - \\
\hline Citrobacter spp. & - & - & - & - & - & - & - \\
\hline Citrobacetr spp. & - & - & - & - & - & - & - \\
\hline Cronobacter malonaticus & - & - & - & - & - & - & - \\
\hline Cronobacter muytjensii & - & - & - & - & - & - & - \\
\hline Cronobacter sakazakii & - & - & - & - & - & - & - \\
\hline Cronobacter sakazakii & - & - & - & - & - & - & - \\
\hline Cronobacter turicensis & - & - & - & - & - & - & - \\
\hline Enterobacter amnigenus & - & - & - & - & - & - & - \\
\hline Enterobacter asburiae & - & - & - & - & - & - & - \\
\hline Enterobacter asburiae & - & - & - & - & - & - & - \\
\hline Enterobacter cloacae & - & - & - & - & - & - & - \\
\hline Enterobacter homaechei & - & - & - & - & - & - & - \\
\hline Enterococcus faecalis & - & - & - & - & - & - & - \\
\hline Escherichia coli & - & - & - & - & - & - & - \\
\hline Escherichia coli & - & - & - & - & - & - & - \\
\hline Hafnia alvei & - & - & - & - & - & - & - \\
\hline Klebsiella oxytoca & - & - & - & - & - & - & - \\
\hline Listeria innocua & - & - & - & - & - & - & - \\
\hline Micrococcus luteus & - & - & - & - & - & - & - \\
\hline Pantoea spp. & - & - & - & - & - & - & - \\
\hline Proteus mirabilis & - & - & - & - & - & - & - \\
\hline Providencia alcalifaciens & - & - & - & - & - & - & - \\
\hline Pseudomonas aeruginosa & - & - & - & - & - & - & - \\
\hline Pseudomonas fluorescens & - & - & - & - & - & - & - \\
\hline Serratia liquefaciens & - & - & - & - & - & - & - \\
\hline Serratia plymuthica & - & - & - & - & - & - & - \\
\hline Shigella flexneri & - & - & - & - & - & - & - \\
\hline Exclusivity \% & 93.1 & 100 & 100 & 96.6 & 96.6 & 96.6 & 100 \\
\hline
\end{tabular}

\section{Salmonella detection in different food matrices}

\section{Comparison of commercial DNA extraction/DNA clean-up kits}

Salmonella counts from the inoculated samples were in the range of $4.5 \times 10^{8}-$ $1.5 \times 10^{9} \mathrm{cfu} / \mathrm{ml}$, indicating that there was no growth inhibition of the Salmonella during the enrichment. The automated DNA extraction systems are advantageous for processing large numbers of samples in parallel. Of the manual extraction kits, the purest DNA extract was obtained with the Masterpure ${ }^{\mathrm{TM}}$ Complete DNA and RNA 
purification kit (Epicentre). However, this was the most expensive, the most labourintensive and had the longest time to result. Purity of DNA obtained was determined by measuring absorbance at 260 and $280 \mathrm{~nm}$ and calculation of A260/280. The least labour-intensive of the manual extraction kits, with also the fastest time to result and lowest cost, was the OneStep ${ }^{\mathrm{TM}}$ PCR Inhibitor Removal Kit (Zymo Research). RT-PCR detection of Salmonella in the heat-lysed extracts from the uninoculated and inoculated samples was unsuccessful with indication of IPC (internal positive control) inhibition or questionable amplification. Salmonella was detected in the inoculated sample using the different extraction methods with $C_{t}$ values in the range of 7-30 depending on the extraction method and on the RT-PCR detection method used. The difference in $\mathrm{C}_{\mathrm{t}}$ values was related to the DNA concentration in the extracts and the volume of template used in the particular RT-PCR assays. In these experiments there was no evidence of inhibitor compounds affecting the PCR amplifications indicating that all extraction methods successfully removed sufficient amounts of inhibitors. The pattern of $C_{t}$ values for each of the extracts was similar across all RT-PCR systems indicating that there was no relationship between performance of the extraction method and performance of the RT-PCR method (data not shown). Pall GeneDisc ${ }^{\circledR}$ Food Extraction Pack 01, Applied Biosystems PrepSEQ ${ }^{\mathrm{TM}}$ Rapid Spin Sample Preparation Kit and Zymo OneStep ${ }^{\text {TM }}$ PCR Inhibitor Removal Kit were chosen for follow-up evaluation based on cost, ease of use and time-to-result. Successful PCR results were obtained with the majority of the 107 samples following the application of GeneDisc ${ }^{\circledR}$ Food Extraction Pack 01. For several varieties of tea the most successful results were obtained using a combination of GeneDisc ${ }^{\circledR}$ Food Extraction Pack 01 followed by additional application of Zymo OneStep ${ }^{\mathrm{TM}}$ PCR Inhibitor Removal Kit to the extract.

\section{PCR inhibition with proprietary methods}

With the black tea matrix, inhibition problems were apparent for the GeneDisc ${ }^{\circledR}$ Shiga Toxic E. coli and Salmonella spp. (40.9\% inhibition), iQ-Check ${ }^{\circledR}$ Salmonella 2 (100\% inhibition) and MicroSeq ${ }^{\circledR}$ Salmonella spp. detection kit (63.6\% inhibition) systems despite an extensive DNA extraction with the PrepSEQ ${ }^{\mathrm{TM}}$ Rapid Spin Sample Preparation Kit. The application of a 1:10 dilution to extracts from the MicroSeq ${ }^{\circledR}$ Salmonella spp. and iQ-Check ${ }^{\circledR}$ Salmonella 2 kits decreased inhibition to $0 \%$ and $13.6 \%$ respectively. However, dilution of samples is not ideal because the target DNA may be diluted to a level below the limit of detection (4). A clean-up of extracts from the Extraction Pack Food 01 with the Zymo OneStep ${ }^{\mathrm{TM}}$ tubes was found to reduce inhibition from the tea samples ran on the GeneDisc ${ }^{\circledR}$, iQ-Check ${ }^{\circledR}$ and MicroSeq ${ }^{\circledR}$ systems to $9.1 \%, 54.5 \%$ and $18.2 \%$, respectively. Almost all cocoa powder samples were inhibited when the proprietary extraction methods of ADIAFOOD ${ }^{\circledR}$ Salmonella 
and iQ-Check ${ }^{\circledR}$ Salmonella 2 were used (90.9\% and 100\% respectively). A dark colour was observed in the DNA samples, potentially indicating the presence of inhibitors. Less inhibition was observed with Extraction Pack Food 01 extracts from cocoa samples following a clean-up with the Zymo OneStep ${ }^{\mathrm{TM}}$ tubes $(0 \%$ inhibition for ADIAFOOD ${ }^{\circledR}$ Salmonella and 4.5\% for iQ-Check ${ }^{\circledR}$ Salmonella 2).

\section{Limits of detection $\left(L O D_{50}\right)$}

The $\mathrm{LOD}_{50}(\mathrm{cfu} / \mathrm{g})$ for Salmonella Tennessee strain S511 in the four different food matrices as determined with the extracts of the proprietary extraction methods are summarized in Table 3. For black tea and cocoa powder, the $\mathrm{LOD}_{50}(\mathrm{cfu} / \mathrm{g}$ ) are also given for the extracts using the Extraction Pack Food 01 combined with Zymo OneStep $^{\text {TM }}$. For the milk powder and the bouillon powder samples, values for the limit of detection were similar for all methods. Salmonella was detected at low levels in these matrices without inhibition problems despite the presence of lipids/proteins and tannins/phenolics, respectively. The use of combined extraction with Extraction Pack Food 01 followed by Zymo OneStep ${ }^{\mathrm{TM}}$ tubes, compared to use of proprietary extraction with/without dilution, did not provide consistent improvements in $\mathrm{LOD}_{50}(\mathrm{cfu} / \mathrm{g})$ for black tea and chocolate samples. However the amount of sample used for proprietary extraction and the amount of DNA extract added to the PCR reaction differed between methods and the amount of template added from the combined extraction could not be normalized for direct comparison. PCR assays need to be developed in conjunction with specific extraction protocols for these difficult matrices. Microbiological criteria for foodstuffs typically require absence of Salmonella in $25 \mathrm{~g}$ samples, and the analytical methods that are used to verify this are expected to give a positive result if only one cell is present, which corresponds with a $\mathrm{LOD}_{50}$ of ca. $0.03 \mathrm{cfu} / \mathrm{g}$. In milk powder, the ADIAFOOD® Salmonella, Genedisc ${ }^{\circledR}$ Shiga Toxic E. coli and Salmonella spp., MicroSeq ${ }^{\circledR}$ Salmonella spp. detection kit and iQ-Check ${ }^{\circledR}$ Salmonella 2 gave an LOD50 of less than 0.04 . With bouillon powder, only the iQ-Check ${ }^{\circledR}$ Salmonella 2 gave an $\mathrm{LOD}_{50}$ of less than 0.04. Following a 10-fold dilution of black tea extracts, the ADIAFOOD ${ }^{\circledR}$ Salmonella, MicroSeq ${ }^{\circledR}$ Salmonella spp. detection kit and iQ-Check ${ }^{\circledR}$ Salmonella 2 were able to detect $0.04 \mathrm{cfu} / \mathrm{g}$. The BAX® system Q7 real-time Salmonella and foodproof@ Salmonella Detection Kit methods were also capable of detecting 0.04 cfu/g. BAX® system Q7 real-time Salmonella, ADIAFOOD ${ }^{\circledR}$ Salmonella, Genedisc ${ }^{\circledR}$ Shiga Toxic E. coli and Salmonella spp. and MicroSeq ${ }^{\circledR}$ Salmonella spp. detection kit methods gave detection limits below $0.04 \mathrm{cfu} / \mathrm{g}$ with cocoa powder samples. However, a sample clean-up with the Zymo OneStep ${ }^{\text {TM }}$ clean-up tubes necessary for the MicroSeq ${ }^{\circledR}$ Salmonella spp. detection kit to reach this level. Regarding the food matrices tested in this work, inhibition was most probably caused by polyphenols as 
both black tea and cocoa powder contain high levels of these substances. Tannins, which are oligomeric compounds with free phenolic groups, can oxidize to form quinones that bind to the Taq DNA polymerase and inactivate the enzyme, resulting in decreased amplification efficiency (10). The fact that inhibition was significantly minimized by the application of the Zymo OneStep ${ }^{\mathrm{TM}}$ clean-up tubes implies that the filter successfully retained inhibitory substances. DNA purification is recommended when testing samples that contain a high content of inhibitory substances such as food constituents and environmental compounds $(11,12)$. In this study, it was shown that a DNA clean-up step can significantly reduce inhibition in samples from tea and cocoa powder.

Table 3. Limit of detection in cfu/g with upper and lower $95 \%$ confidence limit

\begin{tabular}{|c|c|c|c|c|c|c|c|c|}
\hline \multirow[b]{3}{*}{$\begin{array}{l}\text { Real-time PCR } \\
\text { method }\end{array}$} & \multicolumn{8}{|c|}{ Food sample } \\
\hline & \multicolumn{2}{|c|}{ Milk powder } & \multicolumn{2}{|c|}{ Bouillon powder } & \multicolumn{2}{|c|}{ Black tea } & \multicolumn{2}{|c|}{ Cocoa powder } \\
\hline & $\mathrm{LOD}_{50}$ & $95 \% \mathrm{Cl}$ & $\mathrm{LOD}_{50}$ & $95 \% \mathrm{Cl}$ & $\mathrm{LOD}_{50}$ & $95 \% \mathrm{Cl}$ & $\mathrm{LOD}_{50}$ & $95 \% \mathrm{Cl}$ \\
\hline \multirow[t]{2}{*}{ AES ADIAFOOD ${ }^{\circledR}$} & 0.031 & $0.015-0.064$ & 0.062 & $0.029-0.134$ & $0.007^{a}$ & $0.003-0.016$ & $0.037^{a}$ & $0.018-0.075$ \\
\hline & & & & & $0.009^{\mathrm{b}}$ & $0.004-0.021$ & $0.022^{\mathrm{b}}$ & $0.010-0.045$ \\
\hline Qualicon BAX® & 0.044 & $0.021-0.091$ & 0.076 & 0.034-0.171 & 0.04 & $0.019-0.081$ & 0.017 & $0.008-0.035$ \\
\hline BIOTECON & 0.056 & $0.026-0.119$ & 0.076 & $0.034-0.171$ & 0.014 & $0.006-0.029$ & 0.082 & $0.036-0.188$ \\
\hline foodproof(C) & & & & & $0.234^{\mathrm{b}}$ & $0.069-0.800$ & $0.037^{\mathrm{b}}$ & 0.018-0.075 \\
\hline BioControl GDS $®$ & 0.044 & $0.021-0.091$ & 0.076 & $0.034-0.171$ & 0.09 & $0.038-0.211$ & 0.067 & $0.031-0.148$ \\
\hline \multirow[t]{2}{*}{ Pall GeneDisc $®$} & 0.031 & $0.015-0.064$ & 0.076 & $0.034-0.171$ & 0.101 & $0.042-0.245$ & 0.024 & $0.012-0.049$ \\
\hline & & & & & $0.022^{\mathrm{b}}$ & $0.011-0.046$ & $0.017^{\mathrm{b}}$ & $0.008-0.035$ \\
\hline \multirow[t]{2}{*}{ BioRad IQcheck ${ }^{\circledR}$} & 0.015 & $0.007-0.031$ & 0.038 & $0.019-0.078$ & $0.016^{\mathrm{a}}$ & $0.007-0.033$ & 0.014 & 0.006-0.029 \\
\hline & & & & & $0.067^{\mathrm{b}}$ & $0.030-0.146$ & $0.031^{\mathrm{b}}$ & $0.015-0.063$ \\
\hline \multirow[t]{2}{*}{ ABI MicroSeq ${ }^{\circledR}$} & 0.031 & $0.015-0.064$ & 0.056 & 0.026-0.119 & $0.030^{\mathrm{a}}$ & $0.015-0.062$ & $0.051^{\mathrm{a}}$ & 0.024-0.107 \\
\hline & & & & & $0.053^{\mathrm{b}}$ & $0.025-0.111$ & $0.031^{\mathrm{b}}$ & $0.015-0.063$ \\
\hline
\end{tabular}

aDA was extracted using the proprietary extraction kit with the exception of 1:10 dilution applied to DNA extracts.

bDNA was extracted using the Food Extraction Pack 01 followed by the Zymo OneStep ${ }^{\mathrm{TM}}$ PCR Inhibitor Removal Kit.

\section{Convenience of use}

With real-time PCR systems continuously replacing cultural Salmonella testing in commercial laboratories, it is essential that the methods are efficient, fast and easy to use. Ideally a minimum number of handling steps, for example opening of tubes, pipetting steps and centrifugation, should be required to perform a test. Moreover, there should be little danger of cross contamination when several samples are processed at a time. The number of required centrifugation and pipetting steps varied across the platforms tested in this study. Methods requiring several centrifugation steps or manual IMS (immunomagnetic separation) with a lot of extraction 
consumables and reaction tubes were regarded as laborious and not particularly user friendly. These protocols placed a limitation on the number of samples that could be processed at one time and were considered quite complex for high throughput routine analysis. Advantages associated with some of the systems investigated in this study included the ability to perform DNA extraction in the PCR cycler without the requirement for additional heating equipment. Some systems provide reaction tubes pre-filled with dehydrated reagents, the addition of the template being the only requirement. This type of system offers both timesaving and the potential to prevent false results due to pipetting errors or contamination of reagents. Differences were also noticed in the flexibility of the systems. If a method can be run on more than one type of real-time PCR instrument, this may be seen as advantageous. For most of the kits tested here, the proprietary instrument must be purchased. Some platforms are completely closed systems where analysis of the acquired data or change of the temperature profile is not possible for the user. In conclusion, this study shows that there are a number of newly developed commercially available real-time PCR platforms for the detection of Salmonella spp., which allow rapid detection of low levels of Salmonella in complex matrices. Citrobacter spp. strains were shown to be of continued concern even with molecular detection methods for Salmonella. Increasing data being made available through the genome sequencing projects underway, can be expected to uncover superior diagnostic markers, which could then be considered for inclusion in future versions of these diagnostic assays. However, it is a constant challenge to include all potential competitive organisms during method development and cooperation with method users, expands access to natural food isolates. With the increasing availability and affordability of improved nucleic acid extraction procedures and advent of automated technologies which are capable of providing results with minimal manual intervention, PCR based technologies are poised to find even more usage in the food industry. 


\section{References}

1. ISO International Standard 6579, 2002. Microbiology of food and animal feeding stuffs, Horizontal Method for the detection of Salmonella spp. Fourth ed. 07-15.

2. Aleaddini, R. 2011. Forensic implications of PCR inhibition- a review. Forensic Science International. Genetics 6: 297-305.

3. Rossen, L., Norskov, P., Holmstrom, K., Rasmussen, OF. 1992. Inhibition of PCR by components of food samples, microbial diagnostic assays and DNA-extraction. International Journal of Food Microbiology 17: 37-45.

4. Kontanis, EJ., Reed, FA. 2006. Evaluation of real-time PCR amplification efficiencies to detect PCR inhibitors. Journal of Forensic Sciences 51: 795-804.

5. Rådström, P., Knutsson, R., Wolffs, P., Lövenklev, M., Löfström, C. 2004. Pre-PCR processing: strategies to generate PCR-compatible samples. Molecular Biotechnology 26: 33-146.

6. Bennet, AR., Greenwood, D., Tennant, C., Banks, JG., Betts, RP. 1998. Rapid and definitive detection of Salmonella in food by PCR. Letters in Applied Microbiology 26: 437-441.

7. Cheung, PY., Chan, CW., Wong, W., Cheung, TL., Kam, KM. 2004. Evaluation of two real-time polymerase chain reaction pathogen detection kits for Salmonella spp. in food. Letters in Applied Microbiology 39: 509-515.

8. Wilrich, PT., Wilrich, C. 2009. Estimation of the POD function and the LOF of a qualitative microbiological measurement method. Journal of AOAC International 92: 1763-1772.

9. Bennet, AR., MacPhee, S., Betts, R., Post, D. 1999. Use of pyrrolidonyl peptidase to distinguish Citrobacter from Salmonella. Letters in Applied Microbiology 28: 175- 178.

10. Young, CC., Burghoff, RL., Keim, LG., Minak-Bernero, V., Lute, JR., Hinton, SM. 1993. Polyvinylpyrrolidone-agarose gel electrophoresis purification of polymerase chain reactionamplifiable DNA from soils. Applied and Environmental Microbiology 59: 1972-1974.

11. Bessetti, J. 2007. An introduction to PCR inhibitors. Promega Corporation.

12. Wilson, IG. 1997. Inhibition and facilitation of nucleic acid amplification. Applied and Environmental Microbiology 63: 3741-3751. 


\section{Chapter}

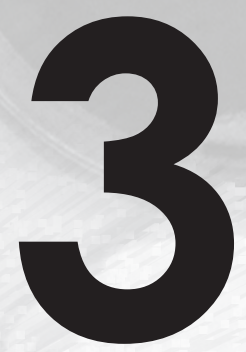

\section{Comparison of rapid cultural methods for the detection of Salmonella species}

Heike Margot, Roger Stephan, Emer O'Mahony, Carol Iversen 


\section{Abstract}

Three newly developed rapid cultural methods (Rapid Salmonella, Precis ${ }^{\mathrm{TM}}$ Salmonella, IBISA Salmonella) for the detection of Salmonella spp. were compared to a reference method. All methods performed comparably on inclusivity/exclusivity testing. Similar limits of detection were observed for all methods with milk, cocoa and bouillon matrices. Some tea varieties appeared to disturb the normal colour formation of all selective agars tested. 


\section{Introduction}

Traditional culture methods for the isolation and identification of Salmonella from food involve enrichment in a primary non-selective broth, such as lactose broth or buffered peptone water (BPW). This is followed by secondary selective enrichments in two media chosen from Rappaport-Vassiliadis (Soya) broth (RV(S)), selenite cystine broth and/or a tetrathionate broth. After plating on two selective agars, the suspect colonies are confirmed biochemically and serologically $(1,2)$. The complete procedure requires at least three days to obtain a negative result and up to seven days for a confirmed positive result. Cultural methods have the advantage that they are capable of detecting viable cells, however the testing of large sample numbers is time consuming and labour-intensive (3). Production lots often need to be held in storage for several days during Salmonella testing. Therefore, the demand exists for faster yet still reliable and sensitive methods. The close relationship with other genera such as Escherichia coli, Cronobacter and Citrobacter spp. presents another challenge to the cultural detection of Salmonella spp. These organisms compete in the enrichment media and/or can cause false positive reactions in Salmonella tests. Particularly in foods with a high initial background flora, low levels of Salmonella might be overgrown by the competing bacteria $(4,5)$. Newly developed cultural methods combine a single enrichment in a selective broth at an elevated temperature followed by isolation on a chromogenic agar. Background organisms are suppressed by the selective agents in the broth and agar and/or can be differentiated from Salmonella via the colour reaction on the selective agar. Elimination of the nonselective enrichment step means the risk of overgrowth of Salmonella by competitors is reduced and that a negative result can be obtained in $44-48 \mathrm{~h}$.

\section{Material and methods}

The inclusivity/exclusivity and the ability to recover Salmonella from difficult food matrices were evaluated for the following rapid cultural methods: Rapid Salmonella (Bio-Rad, Marnes-la-Coquette, France), Precis ${ }^{\mathrm{TM}}$ Salmonella (Oxoid, Pratteln, Switzerland) and IBISA Salmonella (AES chemunex, Bruz cedex, France). Rapid Salmonella and IBISA Salmonella include a supplement to BPW, which contains both nutrients to resuscitate injured Salmonella and inhibiting substances against competitor organisms. The Precis ${ }^{\mathrm{TM}}$ method includes the ONE Broth-Salmonella, which is a complete selective enrichment medium. After the enrichment in the respective broths, aliquots are streaked on Rapid'Salmonella agar, Brilliance ${ }^{\mathrm{TM}}$ Salmonella agar and IBISA agar. Salmonella can be differentiated from non-target bacteria based on colony color and positive results are confirmed with a latex test. 
The reference method used was based on ISO 6579:2002 using BPW, RVS, XLD and ChromID (bioMérieux, Marcy l'Etoile, France) for the detection of Salmonella species, this version of the standard method has been validated using ISO 16140 (MicroVal certificate number MV2007-LR06).

\section{Strains}

Forty-nine Salmonella enterica subsp. enterica strains and 32 non-Salmonella strains were used to determine inclusivity (sensitivity) and exclusivity (specificity) in the different media. The strains were chosen to provide a variety of serovars/species commonly found in food products and included strains that had given unexpected results in previous method evaluation studies. All strains were natural isolates obtained from our in-house collections.

\section{Determination of doubling times}

For the investigation of doubling times in the four enrichment broths (ONE broth-Salmonella, BPW + Rapid'Salmonella supplement, BPW + IBISA Salmonella supplement, BPW and RVS), overnight cultures of six Salmonella strains, as well as one strain each of Cronobacter sakazakii, Shigella flexneri, E. coli and Citrobacter freundii were grown in Tryptic Soy Broth (TSB, Oxoid) at $37^{\circ} \mathrm{C}$ and serially diluted to $1: 10^{-6}$ in $9 \mathrm{ml}$ of the recommended broth for each method. A $400 \mu \mathrm{L}$ aliquot of each dilution from 1:10-2 to $1: 10^{-6}$ was pipetted into duplicate wells of a Bioscreen C honeycomb plate. The plates were incubated in a Bioscreen $\mathrm{C}$ optical density reader (iLF bioserve e. K., Langenau, Germany) for $24 \mathrm{~h}$ at $41.5^{\circ} \mathrm{C}$ and the $\mathrm{OD}_{600 \mathrm{~mm}}$ of the wells was measured every $15 \mathrm{~min}$. The strains were similarly prepared in BPW and were incubated in the Bioscreen $\mathrm{C}$ for $24 \mathrm{~h}$ at $37^{\circ} \mathrm{C}$. The doubling time for each strain was calculated using the regression equation for the linear trend line.

\section{Limit of detection}

For the determination of the limit of detection (LOD), four different food matrices (skimmed milk powder, sugar free cocoa, black tea and bouillon powder with Mediterranean herbs) were artificially inoculated. The LODp is the contamination level (cfu/g) leading to a positive result with a specified probability, $\mathrm{p}$. The $\mathrm{LOD}_{50}$ and $\mathrm{LOD}_{95}$ were calculated for each method with four different food matrices, specifying the smallest quantity of Salmonella that can be detected with a probability of $50 \%$ or 95\%, respectively. An overnight culture of Salmonella Tennessee strain S511 was diluted to achieve inoculation levels of approximately $3 \mathrm{cfu} / 25 \mathrm{~g}, 1 \mathrm{cfu} / 25 \mathrm{~g}$ and 0.3 $\mathrm{cfu} / 25 \mathrm{~g}$, with six replicates per inoculation level. Two $25 \mathrm{~g}$ portions of uninoculated 
sample served as negative controls and one positive control was inoculated with approximately $10 \mathrm{cfu} / 25 \mathrm{~g}$. For the skimmed milk and sugar free cocoa powder matrices, $25 \mathrm{~g}$ of each food product was enriched in $225 \mathrm{~mL}$ of the specific broth for each method. For the black tea and Mediterranean bouillon powder matrices, $25 \mathrm{~g}$ of the sample was added to $900 \mathrm{~mL}$ of broth. This higher dilution is routinely used in commercial testing laboratories as it has been found to be necessary to prevent growth inhibition of the target organism from the herb, spices and salt content of these matrices. For the rapid cultural methods, the enrichments were incubated for $16-20 \mathrm{~h}$ at $41.5^{\circ} \mathrm{C}$ before streaking $10 \mu \mathrm{L}$ onto a selective medium. For the reference method, primary enrichment was carried out in BPW, with $100 \mathrm{~mL}$ of a $10 \%$ solution of non-fat dry milk (NFDP) added to the BPW for enrichment of cocoa powder. All BPW enrichments were incubated for $16-20 \mathrm{~h}$ at $37^{\circ} \mathrm{C}$, before transfer of $0.1 \mathrm{~mL}$ to $10 \mathrm{~mL}$ of RVS broth, followed by incubation at $41.5^{\circ} \mathrm{C}$ for $18-24 \mathrm{~h}$. A $10 \mu \mathrm{L}$ aliquot was then streaked onto selective agar. Based on the qualitative results statistical analysis was carried out by application of the EXCEL sheet PODLOD. xls (6). The $\mathrm{LOD}_{50}$ with confidence limits for each method with each matrix were calculated.

\section{Results \& discussion}

\section{Inclusivity/exclusivity}

All methods performed with 100\% specificity and sensitivity. Where growth of nonSalmonella strains occurred, these could be differentiated from target Salmonella strains by the colony colour (see Tables 1 and 1b). On the IBISA agar, some Salmonella serovars only showed weak growth. Non-target organisms, which showed growth similar to Salmonella in the selective broths (Cronobacter malonatius and Cronobacter muytjensii) did not grow on the chromogenic agar plates of the three alternative methods. 
Table 1a. Inclusivity result for each method evaluated

\begin{tabular}{|c|c|c|c|c|c|c|}
\hline \multirow[t]{2}{*}{$\underline{\text { Salmonella strains }}$} & \multirow[t]{2}{*}{$\mathrm{N}$} & \multirow{2}{*}{ 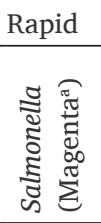 } & \multirow{2}{*}{ 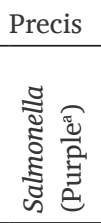 } & \multirow{2}{*}{ 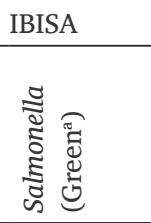 } & \multicolumn{2}{|c|}{ Reference method } \\
\hline & & & & & 角苞 & 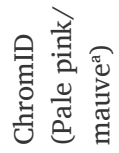 \\
\hline Salmonella Agona & 1 & + & + & + & + & + \\
\hline Salmonella Albany & 1 & + & + & + & + & + \\
\hline Salmonella Anatum & 3 & + & + & + & + & + \\
\hline Salmonella Ank & 1 & + & + & + & + & + \\
\hline Salmonella Bergen & 1 & + & + & + & + & + \\
\hline Salmonella Bracknell & 1 & + & + & + & (clear) & + \\
\hline Salmonella Cerro & 1 & + & + & + & + & + \\
\hline Salmonella Congo & 1 & + & + & + & + & + \\
\hline Salmonella Chittagong & 1 & + & + & + & + & + \\
\hline Salmonella Denver & 1 & + & + & + & + & + \\
\hline Salmonella Derby & 1 & + & + & + & + & + \\
\hline Salmonella Enteritidis & 2 & + & + & + & + & + \\
\hline Salmonella Ekotedo & 1 & + & + & + & (clear) & + \\
\hline Salmonella Farmsen & 1 & + & + & + & + & + \\
\hline Salmonella Gambe & 1 & + & + & + & (clear) & + \\
\hline Salmonella Ibandan & 1 & + & + & + & + & + \\
\hline Salmonella Infantis & 2 & + & + & + & + & + \\
\hline Salmonella Kentucky & 1 & + & + & + & (clear) & + \\
\hline Salmonella Kibi & 1 & + & + & + & + & + \\
\hline Salmonella Kinondoni & 1 & + & + & + & + & + \\
\hline Salmonella Limete & 1 & + & + & + & + & + \\
\hline Salmonella Maritzburg & 1 & + & + & + & + & + \\
\hline Salmonella Mbandanka & 1 & + & + & + (weak) & + & + \\
\hline Salmonella Napoli & 2 & + & + & + & + & + \\
\hline Salmonella Nashua & 1 & + & + & + (weak) & (clear) & + \\
\hline Salmonella Oranienburg & 1 & + & + & + & (clear) & + \\
\hline Salmonella Panama & 1 & + & + & + & + & + \\
\hline Salmonella Plymouth & 1 & + & + & + & + & + \\
\hline Salmonella Rissen & 1 & + & + & + & + & + \\
\hline Salmonella Salamae & 1 & + & + & + (weak) & (clear) & + \\
\hline Salmonella Sundsvall & 1 & + & + & + & + & + \\
\hline Salmonella Tennessee & 2 & + & + & + (weak) & + & + \\
\hline Salmonella Thompson & 1 & + & + & + & + & + \\
\hline Salmonella Typhimurium & 5 & + & + & + (weak) & (clear) & + \\
\hline Salmonella Uno & 1 & + & + & + & + & + \\
\hline Salmonella Virchow & 1 & + & + & + & + & + \\
\hline Salmonella Wagadugu & 1 & + & + & + & + & + \\
\hline Salmonella Wagama & 1 & + & + & + & + & + \\
\hline Salmonella Wagenia & 1 & + & + & + & (clear) & + \\
\hline Inclusivity $\%$ & & $100 \%$ & $100 \%$ & $100 \%$ & $100 \%$ & \\
\hline
\end{tabular}

Footnotes: -. No growth, +, typical growth, + (weak), weak growth, N, number of strains tested,

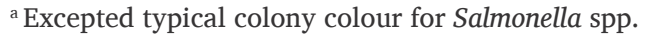


Table 1b. Exclusivity result for each method evaluated

\begin{tabular}{|c|c|c|c|c|c|}
\hline \multirow[t]{2}{*}{ Organism } & \multirow{2}{*}{ 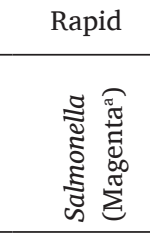 } & \multirow{2}{*}{ 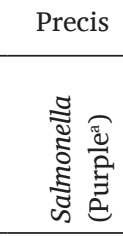 } & \multirow{2}{*}{ 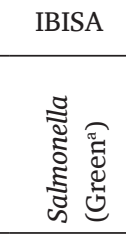 } & \multicolumn{2}{|c|}{ Reference Method } \\
\hline & & & & 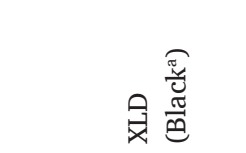 & 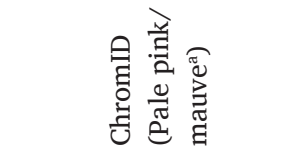 \\
\hline Enterobacter hormaechei & Green & Green & - & Atypical (yellow) & Atypical (turquoise) \\
\hline S. flexneri & - & - & - & - & Atypical (white) \\
\hline Enterobacter asburiae & - & Green & - & - & Atypical (turquoise) \\
\hline Proteus mirabilis & - & - & - & - & Atypical (beige) \\
\hline Providencia alcalifaciens & - & Beige & - & - & - \\
\hline Cronobacter turicensis & Dark blue & - & Purple & Atypical (yellow) & Atypical (dark blue) \\
\hline Hafnia alvei & - & - & - & Atypical (clear) & Atypical (turquoise) \\
\hline Klebsiella oxytoca & - & Green & - & Atypical (yellow) & Atypical (blue green) \\
\hline C. sakazakii & - & - & Black & - & Atypical (green) \\
\hline Enterobacter cloacae & - & - & - & - & - \\
\hline C. malonaticus & - & - & - & Atypical (beige) & Atypical (blue) \\
\hline C. muytjensii & - & - & - & Atypical (yellow) & Atypical (blue purple) \\
\hline E. coli & - & - & - & Atypical (yellow) & Atypical (turquoise) \\
\hline E. coli & - & - & - & Atypical (clear) & Atypical (turquoise) \\
\hline Serratia liquefaciens & - & - & - & - & - \\
\hline Enterobacter amnigenus & - & - & - & - & Atypical (turquoise) \\
\hline C. sakazakii & - & - & - & Atypical (white) & Atypical (dark blue) \\
\hline E. asburiae & - & Green & - & Atypical (yellow) & Atypical (turquoise) \\
\hline Serratia plymuthica & - & - & - & - & - \\
\hline C. freundii & - & Beige & - & Atypical (yellow) & Atypical (turquoise) \\
\hline C. freundii & Rosé & Beige & - & Atypical (yellow) & Atypical (turquoise) \\
\hline C. freundii & - & Beige & - & Atypical (clear) & Atypical (turquoise) \\
\hline C. freundii & - & - & - & - & Atypical (turquoise) \\
\hline Enterococcus faecalis & - & - & - & - & - \\
\hline Micrococcus luteus & - & - & - & - & - \\
\hline Pseudomonas aeruginosa & - & - & - & - & - \\
\hline Pseudomonas fluorescens & - & - & - & - & - \\
\hline Listeria innocua & - & - & - & - & - \\
\hline Pantoea spp. & - & - & - & - & - \\
\hline Exclusivity \% & $100 \%$ & $100 \%$ & $100 \%$ & $100 \%$ & \\
\hline
\end{tabular}

- , no growth.

${ }^{a}$ Expected typical colony for Salmonella spp. 
Table 2. Doubling time (minutes) in base broth for each isolation method

\begin{tabular}{llllll}
\hline Organism & $\begin{array}{l}\text { Rapid } \\
\text { Salmonella }\end{array}$ & $\begin{array}{l}\text { Precis } \\
\text { Salmonella }\end{array}$ & $\begin{array}{l}\text { IBISA } \\
\text { Salmonella }\end{array}$ & BPW & RVS broth \\
\hline Salmonella & 35.3 & 27.3 & 28.4 & 21.9 & 29.7 \\
(average \pm STDEV) & \pm 16.4 & \pm 8.5 & \pm 8.8 & \pm 1.9 & \pm 6.3 \\
C. sakazakii & 44.94 & 26.94 & 21.49 & 18.62 & 43.70 \\
S. flexneri & - & - & - & 24.43 & - \\
E. coli & - & - & - & 15.66 & - \\
C. freundii & - & 36.20 & 41.15 & 25.04 & - \\
\hline
\end{tabular}

-, no growth

\section{Growth rates in the selective broths}

The growth rate of Salmonella in BPW, RVS and in broths from the Precis Salmonella and IBISA Salmonella methods were found to be in a similar range (Table 2). For all rapid method broths the growth of $E$. coli and $S$. flexneri was inhibited. The doubling time of $C$. sakazakii ranged from $18.62 \mathrm{~min}$ in BPW to $44.94 \mathrm{~min}$ in Rapid Salmonella selective broth. RVS and Rapid Salmonella inhibited the growth of the C. freundii strain. Doubling times for this strain in the other broths ranged from 25.04 to $41.15 \mathrm{~min}$. Cronobacter and Citrobacter are the main background organisms that pose problems for the isolation of Salmonella. The organisms can generally grow on Salmonella selective agar, but do not produce typical Salmonella colony morphologies. Therefore false positive colonies should not be a cause for concern. However, the potential exists for false negative results due to overgrowth of the target organisms from the competing flora.

\section{Detection limit in the food matrix}

For the milk powder, cocoa powder and Mediterranean bouillon powder, all methods could detect levels of contamination ranging from $<0.008-0.144 \mathrm{cfu} / \mathrm{g}$ of product. For black tea the $\mathrm{LOD}_{50}$ ranged from 0.051 to $0.219 \mathrm{cfu} / \mathrm{g}$. When black tea was enriched with the different broths and isolated on the selective agars, atypical coloration of the colonies made it difficult to interpret the results on the plates (Table 3). Further analysis was performed with different tea varieties by overnight enrichment of $25 \mathrm{~g}$ in $900 \mathrm{~mL}$ BPW inoculated with approximately 10 cfu of Salmonella Congo S617. The enrichment was then streaked on 6 different selective agars for presence/absence testing. The selective agars were: XLD, BGA, chromID $^{\mathrm{TM}}$ Salmonella (bioMérieux), Rapid Salmonella (BioRad), Precis ${ }^{\mathrm{TM}}$ Salmonella (Oxoid) and IBISA Salmonella (AES chemunex). Two tea varieties appear to contain ingredients, which disturb the normal color formation of all selective agars tested. In conclusion, newly developed rapid cultural methods present a time saving of $48 \mathrm{~h}$ 
for the cultural detection of Salmonella spp. in food samples. This saving is achieved by omitting the non-selective enrichment step and using a fast latex agglutination test for the confirmation of presumptive positive colonies. The tested methods were as sensitive and specific as the reference method when pure cultures of target and non-target strains were tested. Difficult matrices such a black tea can pose a problem with false negative results due to atypical colony colours.

Table 3. Limit of detection (cfu/g) with upper and lower $95 \%$ confidence limits

\begin{tabular}{|c|c|c|c|c|c|c|c|c|}
\hline \multirow[t]{3}{*}{ Method } & \multicolumn{8}{|c|}{ Food Sample } \\
\hline & \multicolumn{2}{|c|}{ Milk powder } & \multicolumn{2}{|c|}{ Bouillon powder } & \multicolumn{2}{|c|}{ Black tea } & \multicolumn{2}{|c|}{ Cocoa powder } \\
\hline & LOD50 & $\begin{array}{l}\text { Confidence } \\
\text { Limit }\end{array}$ & LOD50 & $\begin{array}{l}\text { Confidence } \\
\text { Limit }\end{array}$ & $L O D 50$ & $\begin{array}{l}\text { Confidence } \\
\text { Limit }\end{array}$ & LOD50 & $\begin{array}{l}\text { Confidence } \\
\text { Limit }\end{array}$ \\
\hline Reference & 0.039 & $0.018-0.084$ & 0.009 & $0.004-0.020$ & 0.110 & $0.054-0.224$ & 0.057 & $0.027-0.120$ \\
\hline $\begin{array}{l}\text { Rapid } \\
\text { Salmonella }\end{array}$ & 0.144 & $0.070-0.296$ & 0.039 & $0.017-0.089$ & 0.062 & $0.030-0.129$ & 0.082 & $0.040-0.168$ \\
\hline $\begin{array}{l}\text { Precis } \\
\text { Salmonella }\end{array}$ & 0.057 & $0.027-0.119$ & 0.036 & $0.016-0.079$ & 0.051 & $0.024-0.107$ & 0.088 & $0.043-0.181$ \\
\hline IBISA & 0.024 & $0.011-0.056$ & 0.007 & $0.003-0.015$ & 0.219 & $0.100-0.477$ & 0.068 & $0.033-0.142$ \\
\hline
\end{tabular}




\section{References}

1. ISO International Standard 6579, 2002. Microbiology of Food and Animal Feeding Stuffs. Horizontal Method for the Detection of Salmonella spp., 4th edition. (07-15).

2. Bacteriological Analytical Manual, 2011. Chapter 5 Salmonella November 2011 version US FDA. http://www.fda.gov/Food/ScienceResearch/LaboratoryMethods/Bacteriological AnalyticalManualBAM/ucm070149.htm.

3. Maciorowski, K.G., Herrera, P., Jones, T., Pillai, S.D., Ricke, S.C. 2006. Cultural and immunological detection methods for Salmonella spp. in animal feeds-a review. Veterinary Research Communications 30: 127-137.

4. D‘Aoust, J.Y., Sewell, A.M., Warburton, D.W. 1992. A comparison of standard cultural methods for the detection of foodborne Salmonella. International Journal of Food Microbiology 16: 41-50.

5. Bennet, A.R., MacPhee, S., Betts, R., Post, D. 1999. Use of pyrrolidonyl peptidase to distinguish Citrobacter from Salmonella. Letters in Applied Microbiology 28: 175-178.

6. Wilrich, C., Wilrich, P. 2009. Estimation of the POD function and the LOD of a qualitative microbiological measurement method. Journal of AOAC International 92: 1763-1772. 


\title{
Chapter
}

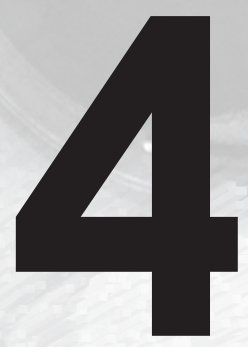

Evaluation of seven different commercially available real-time PCR methods for the detection of Shiga toxin 1 and 2 gene subtypes

\author{
Heike Margot, Nicole Cernela, Carol Iversen, \\ Claudio Zweifel, Roger Stephan
}




\section{Abstract}

Following the recent outbreak of Shiga toxin-producing Escherichia coli (STEC) 0104:H4 infection in Germany, the demand for fast detection of STEC has again increased. Various real-time PCR-based methods enabling detection of Shiga toxin genes (stx) have been developed and can be used for applications in food microbiology. The present study was conducted to evaluate the reliability of seven commercially available real-time PCR systems for detection of $s t x_{1}$ and $s t x_{2}$ subtypes. For this purpose, pure cultures of 18 STEC strains harbouring all known $s t x_{1}$ and/or $s t x_{2}$ subtypes were tested. Only one of the seven real- time PCR systems detected all known $s t x_{1}$ and $s t x_{2}$ subtypes. Six systems failed to detect the $s t x_{2 f}$ subtype. One system missed $s t x_{2}$ subtypes reported in association with severe human disease. Because the presence of certain $s t x$ genes (subtypes) is considered an important indicator of STEC virulence, systems differentiating between the $s t x_{1}$ and $s t x_{2}$ gene groups provide added value. Reliable and fast detection of $s t x$ genes is of major importance for both diagnostic laboratories and the food industry. 


\section{Introduction}

Shiga toxin-producing Escherichia coli (STEC), also called verocytotoxin-producing E. coli (VTEC), strains are recognized as a major cause of foodborne illnesses. STEC strains are responsible for a number of human diseases, including diarrhea, hemorrhagic colitis, and the life-threatening hemolytic uremic syndrome (HUS) (4). Since the STEC O104:H4 infection outbreak in Germany in 2011, the demand for reliable and fast detection of STEC has increased (9). STEC strains are characterized by the production of one or more Shiga toxins. Based on cytotoxicity neutralization assays and sequence analysis of Shiga toxin genes, two main Stx groups (Stx1 and Stx2) have been described (6). According to new nomenclatures, the Stx1 group consists of the Stx1a, Stx1c, and Stx1d subtypes. The Stx2 group is more heterogeneous and includes the Stx2a, Stx2b, Stx2c, Stx2d, Stx2e, Stx2f, and Stx2g subtypes. STEC strains pathogenic for humans tend to produce Stx2 and have other virulence traits such as the adhesion factor intimin. In STEC strains from HUS patients, genes encoding Stx2a or Stx2c (mainly in combination with eae genes encoding intimin) are frequently found, and Stx2d-producing strains also have been isolated from HUS patients (5). Testing for Shiga toxin genes (stx) is used for diagnosis of STEC infections in humans and for detection of STEC in foods, although Hafnia alvei and Citrobacter freundii may also harbor stx. Nevertheless, the presence of $s t x$ and in particular certain stx subtypes (especially in association with other virulence factors such as intimin) is considered a better indicator for STEC virulence than is the serotype. Persson et al. (5) were not able to find an association between HUS and individual $O$ groups after investigating 20 human STEC infection cases in Denmark. Boerlin et al. (1) found that $s t x_{2}$-positive strains were five times more likely to be linked with severe illness than were $s t x_{2}$-negative isolates of the same serotype. The aim of the present study was to evaluate the reliability of seven commercially available real-time PCR systems for detection of all known $s t x_{1}$ and $s t x_{2}$ subtypes. For this purpose, pure cultures of 18 STEC strains harboring various $s t x_{1}$ and/or $s t x_{2}$ subtypes were tested. The convenience of the performance of the seven real-time PCR protocols for application in food microbiology also was assessed.

\section{Materials and Methods}

\section{STEC strains}

Eighteen target strains carrying various $s t x_{1}$ and/or $s t x_{2}$ subtypes were used (Table 1). Sixteen strains were obtained from the World Health Organization (WHO) Collaborating Centre for Reference and Research on Escherichia and Klebsiella in 
Denmark (Statens Serum Institute, Copenhagen, Denmark), and these strains have been used recently in the 2nd International External Quality Assurance program. The two additional strains were obtained from the collection of the Institute for Food Safety and Hygiene (Vetsuisse Faculty University of Zurich, Zurich, Switzerland). Strains were grown on plate count agar (Oxoid AG, Pratteln, Switzerland) for $24 \mathrm{~h}$ at $37^{\circ} \mathrm{C}$.

\section{Real-time PCR systems evaluated}

The following commercially available real-time PCR systems were evaluated: GeneDisc STEC and E. coli O157 applied on the GeneDisc Cycler (Pall GeneDisc Technologies, Bruz, France), the Assurance GDS STEC applied on the GDS Rotor Gene (BioControl, Bellevue, WA), the Mericon VTEC $s t x_{1} /{ }_{2}$ applied on the Qiagen Rotor-gene Q (Qiagen, Hombrechtikon, Switzerland), the LightMix Kit EHEC applied on the LightCycler 2.0 (Roche Diagnostics AG, Rotkreuz, Switzerland), the iQ Check STEC VirX (Bio-Rad, Marnes-la- Coquette, France) applied on the MiniOpticon, the BAX System STEC Suite Screening Assay applied on the BAX System Q7 (DuPont, Qualicon, Wilmington, DE), and the ABI Custom TaqMan VT1/VT2 Assay (Applied Biosystems, Carlsbad, CA) applied on the 7500 Fast real-time PCR system.

\section{Detection of $s t x_{1}$ and $s t x_{2}$ subtypes}

Pure culture experiments were performed to evaluate the reliability of the seven realtime PCR systems for detection of $s t x_{1}$ and/or $s t x_{2}$ subtypes. Boiled lysates prepared from colonies of the 18 STEC strains grown on plate count agar were used as templates. A colony was added to $450 \mathrm{ml}$ of lysis buffer containing $20 \mathrm{ml}$ of $1 \mathrm{M}$ Tris $\mathrm{HCl}$ (pH 8.5), $100 \mathrm{ml}$ of Tween 20 (Merck, Darmstadt, Germany), $48 \mathrm{mg}$ of Proteinase K (SigmaAldrich, Buchs Switzerland), and distilled water to $200 \mathrm{ml}$. Suspensions were heated for $40 \mathrm{~min}$ at $60^{\circ} \mathrm{C} \pm 1$ and then for $20 \mathrm{~min}$ at $95^{\circ} \mathrm{C} \pm 1$ in a heating block. The amount of lysate used in each assay was adapted according to the required template volume and diluted with lysis or resuspension buffer supplied with the kits. PCR assays were performed according the manufacturer's instructions. When the first run yielded negative results for certain stx subtypes, the run was repeated with a reduced lysate concentration.

\section{Convenience in performance}

Because the evaluated real-time PCR systems are intended to be used by diagnostic laboratories, convenience in performance is also of importance. Thus, the systems were evaluated with regard to sample preparation time, running time for STEC detection, and ease of data analysis. 


\section{Results and Discussion}

\section{Detection of $s t x_{1}$ and $s t x_{2}$ subtypes}

The Assurance GDS STEC, LightMix Kit EHEC, and ABI Custom TaqMan VT1/VT2 assays report results itemized for the $s t x_{1}$ and $s t x_{2}$ groups. The GeneDisc STEC and $E$. coli O157, Mericon VTEC stx ${ }_{1}{ }_{2}$, BAX STEC Suite Screening, and iQ Check STEC VirX assays do not allow differentiation between the $s t x_{1}$ and $s t x_{2}$ groups. With exception of the LightMix Kit EHEC system, all tested systems included an internal control. Results for detection of the different $s t x_{1}$ and $s t x_{2}$ subtypes by the seven evaluated commercial real-time PCR-based systems are shown in Table 1. The ABI Custom TaqMan VT1/VT2 Assay correctly detected all $s t x_{1}$ and $s t x_{2}$ subtypes in the first run. All other systems yielded negative results for at least $s t x_{2 f}$. The iQ Check STEC VirX, GeneDisc STEC and E. coli O157, and Mericon VTEC $\operatorname{stx}_{1} / 2$ assays yielded correct positive results in the first run for strains harbouring all $s t x_{1}$ and $s t x_{2}$ subtypes except $s t x_{2 f}$ However, in the Mericon VTEC stx ${ }_{1} / 2$ Assay, the colour compensation was not ideal because negative results were occasionally indicated as uncertain. The Assurance GDS STEC assay did not detect the stx $\mathrm{x}_{2 \mathrm{~b}}$ subtype in the first run, but in the second run with a decreased amount of template, all $s t x_{1}$ and $s t x_{2}$ subtypes (except $\left.s t x_{2 f}\right)$ were detected. The LightMix Kit EHEC assay was unable to detect $s t x_{2 \mathrm{a}}, s t x_{2 \mathrm{f}}$, and $s t x_{2 g}$, and some of the results obtained were inconsistent, especially with regard to strains harbouring $s t x_{1 \mathrm{a}}$ and $s t x_{2 \mathrm{~b}}$ (Table 1 ). This system should separately detect $s t x_{1}$ and $s t x_{2}$ subtypes by yielding different peaks for the $s t x_{1}\left(55.3^{\circ} \mathrm{C}\right)$ and $s t x_{2}\left(66.3^{\circ} \mathrm{C}\right)$ melting curves. Despite performing several runs with different concentrations of lysate as template and diluted template, for some strains and stx subtypes (C147$10, s t x_{1 \mathrm{c}}$ and $s t x_{2 \mathrm{~b}}$; C154-10, stx $x_{1 \mathrm{c}}$ and $s t x_{2 \mathrm{~b}}$; Sf133-1, stx ${ }_{1 \mathrm{c}}$ 1093-00, $s t x_{1 \mathrm{a}}$ and $\left.s t x_{2 \mathrm{a}}\right)$ it was not possible to obtain a definite result because the respective melting curves showed only one peak at $60^{\circ} \mathrm{C}$. In addition, three strains (C148-10, C157-10, C15810) harbouring only $s t x_{1 a}$ were indicated as positive for $s t x_{2}$. Because this system does not include an internal control, it was not possible to detect potential PCR inhibitors. The BAX System STEC Suite Screening system was not able to detect $s t x_{1 \mathrm{~d}}$, $s t x_{2 b}$ and $s t x_{2 f}$ in any of three replicated runs. Five of the seven evaluated real-time PCR assays detected all $s t x_{1}$ subtypes ( $s t x_{1 a^{3}}, s t x_{1 \mathrm{c}}$ and $s t x_{1 \mathrm{~d}}$ ) and $s t x_{2}$ subtypes $s t x_{2 \mathrm{a}^{\prime}}$, $s t x_{2 \mathrm{~b}}, s t x_{2 \mathrm{c}}, s t x_{2 \mathrm{~d}}, s t x_{2 \mathrm{e}}$, and $s t x_{2 g}$. Because strains harbouring $s t x_{2 \mathrm{a}}, s t x_{2 \mathrm{c}}$ and $s t x_{2 \mathrm{~d}}$ have been reported in association with outbreaks and severe human illness $(2,3,5)$, the ability of a system to detect these subtypes is of great importance. Six of the seven evaluated real-time PCR assays met this requirement. However, $s t x_{2 a}$ was always detected in strains also harbouring $s t x_{1 \mathrm{a}}$. The lack of reactivity for the $s t x_{2 \mathrm{f}}$ subtype has been reported previously and explained by the divergence of the $s t x_{2 \mathrm{f}}$ nucleotide 
sequence (2). The Stx $2 \mathrm{f}$ toxin is also not detected by some immunological kits. STEC strains harbouring $s t x_{2 \mathrm{f}}$ have been isolated from pigeons (7), but such strains seem to be only rarely associated with severe human diseases (8). An additional desirable trait in an STEC detection system is differentiation between $s t x_{1}$ and $s t x_{2}$ groups. The presence of $s t x_{2}$ in STEC strains significantly increases the likelihood of disease progression to HUS, whereas STEC isolates carrying $s t x_{1}$ are mainly found in healthy humans or patients with uncomplicated diarrhea (1).

\section{Convenience in performance}

For testing of pure cultures, all kits could be used with lysates from a simple heating step. The LightMix Kit EHEC system can be run on a standard real-time PCR machine, whereas for the Assurance GDS STEC, the BAX System STEC Suite Screening, the iQ Check STEC VirX, the GeneDisc STEC and E. coli O157, and the ABI Custom TaqMan VT1/VT2 assays the respective instrument must be purchased. However, these tests can also be used for the analysis of several other microorganisms. Another advantage of assays such as the BAX System STEC Suite Screening assay or the Assurance GDS STEC system is that no separate work station or room for DNA extraction is needed. Hands-on times also are shorter, even though there are differences in the running time for PCR amplification and detection. Reliable and fast detection of STEC is of major importance for diagnostic laboratories. Only one of the seven commercially available real-time PCR-based assays evaluated in the present study detected all known $s t x_{1}$ and $s t x_{2}$ subtypes and therefore could detect STEC strains with all combinations of $s t x$ subtypes. One system missed $s t x_{2}$ subtypes reported in association with severe human disease. Because the presence of certain Shiga toxin genes (subtypes) is considered an important indicator of STEC virulence, systems differentiating between the $s t x_{1}$ and $s t x_{2}$ groups provide added value. 


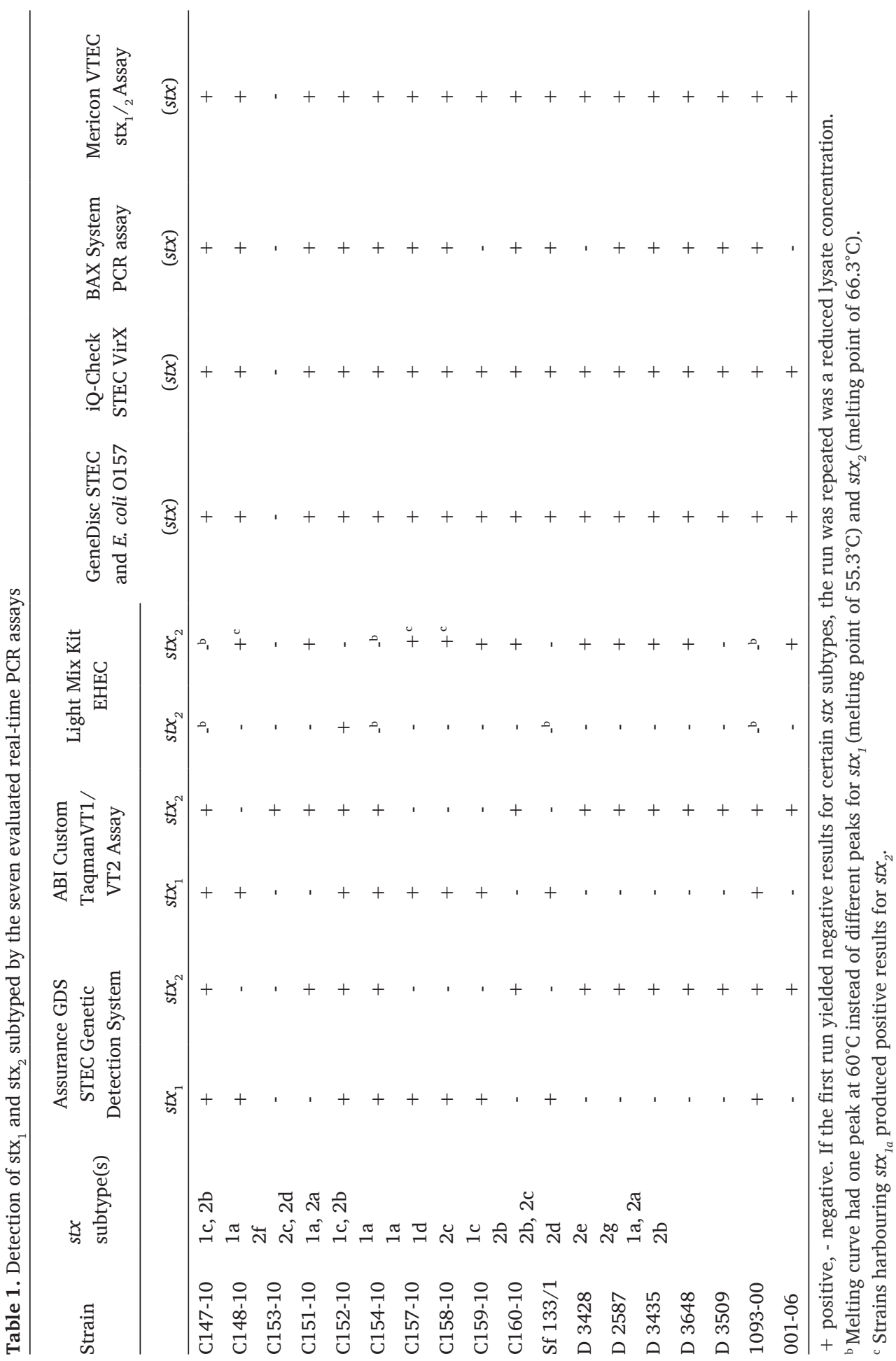




\title{
Acknowledgment
}

\author{
We thank F. Scheutz (WHO Collaborating Centre for Reference and Research on \\ Escherichia and Klebsiella in Denmark) for providing STEC strains.
}

\section{References}

1. Boerlin, P., McEwen, SA., Boerlin-Petzold, F., Wilson, JB., Johnson, RP., Gyles, CL. 1999. Associations between virulence factors of Shiga toxin-producing Escherichia coli and disease in humans. Journal of Clinical Microbiology 37:497-503.

2. Feng, PC., Jinneman, K., Scheutz, F., Monday, SR. 2011. Specificity of PCR and serological assays in the detection of Escherichia coli Shiga toxin subtypes. Applied and Environmental Microbiology 77: 6699-6702.

3. Friedrich, AW., Bielaszewska, M., Zhang, WL., Pulz, M., Kuczius, T., Ammon, A., Karch, H. 2002. Escherichia coli harbouring Shiga toxin 2 gene variants: frequency and association with clinical symptoms. Journal of Infectious Diseases 185:74-84.

4. Karch, H., Tarr, PI., Bielaszewska, M. 2005. Enterohaemmorrhagic Escherichia coli in human medicine. International Journal of Microbiology 295: 405-418.

5. Persson, S., K. E. Olsen, S. Ethelberg, and F. Scheutz. 2007. Subtyping method for Escherichia coli Shiga toxin (verocytotoxin) 2 variants and correlations to clinical manifestations. Journal of Clinical Microbiology 45:2020-2024.

6. Scheutz, F., Teel, LD., Beutin, L., Piérard, D., Buvens, G., Karch, H., Mellmann, A., Caprioli, ATozzoli, R., Morabito, S., Strockbine, SN., Melton-Celsa, AR., Sanchez, M., Persson, S., O’Brien, AD. 2012. Multicenter evaluation of a sequence-based protocol for subtyping Shiga toxins and standardizing Stx nomenclature. Journal of Clinical Microbiology 50:2951-2963.

7. Schmidt, H., Scheef, J., Morabito, S., Caprioli, A., Wieler, LH., Karch, H. 2000. A new Shiga toxin 2 variant (Stx2f) from Escherichia coli isolated from pigeons. Applied and Environmental Microbiology 66:1205-1208.

8. Van Duynhoven, YT., Friesema, IH., Schurman, T., Roovers, A., van Zwet, AA, Sabbe, LJM., van den Zwaluw, WK., Notermans, DW., Mulder, B., van Hannen, EJ., Heilmann, FGC., Buiting, A., Jansen, R., Koositra-Smid, AM. 2008. Prevalence, characterization and clinical profiles of Shiga toxinproducing Escherichia coli in the Netherlands. Clinical Microbiology and Infection 14:437-455.

9. Werber, D., Krause, G., Frank, C., Fruth, A., Flieger, A., Mielke, M., Schaade, L., Stark, L. 2012. Outbreaks of virulent diarrheagenic Escherichia coli-are we in control? BMC Medicine 10:11. 


\section{Chapter}

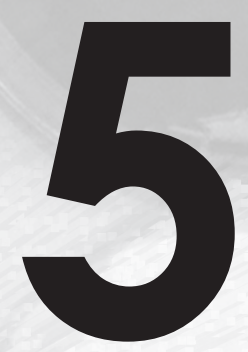

\section{Evaluation of different buffered peptone water (BPW) based enrichment broths for detection of Gram-negative foodborne pathogens from various food matrices}

Heike Margot, Marcel H. Zwietering, Han Joosten, Emer O`Mahony, Roger Stephan 


\section{Abstract}

This study evaluated the effects of changing the composition of the preenrichment medium buffered peptone water (BPW) on the growth of stressed and unstressed Gram-negative foodborne pathogens in a one-broth enrichment strategy. BPW supplemented with an available iron source and sodium pyruvate, along with low levels of 8-hydroxyquinoline and sodium deoxycholate (BPW-S) improved the recovery of desiccated Cronobacter spp. from powdered infant formula. Growth of Salmonella and STEC was comparable in all BPW variants tested for different food matrices. In products with high levels of Gram-negative background flora (e.g. sprouts), the target organisms could not be reliably detected by PCR in any of the BPW variants tested unless the initial level exceeded $10^{3} \mathrm{cfu} / 10 \mathrm{~g}$ of sprouts. Based on these results we suggest BPW-S for a one-broth enrichment strategy of stressed Gram-negative foodborne pathogens from dry products. However, a onebroth enrichment strategy based on BPW variants tested in this evaluation is not recommended for produce with a high level of Gram-negative background flora due to very high detection limits. 


\section{Introduction}

Key to the reliability of all methods for the detection of Gram-negative foodborne pathogens (e.g. Salmonella, Cronobacter and Shigatoxin-producing Escherichia coli) is the capability to recover low numbers of stressed cells from any kind of food matrix to a detectable level. These methods usually consist of three consecutive steps. The pre-enrichment step, that is common to most current detection methodologies (cultural, molecular and immunological), aims at the resuscitation/recovery of cells in a non-selective medium such as buffered peptone water (BPW). The second step, a selective enrichment, should promote growth of the recovered target bacteria. The last step, the actual detection of the pathogen can be accomplished with either cultural or molecular methods. Gram-negative foodborne pathogens are usually present in relatively low numbers, sometimes accompanied by a high number of closely related competitor organisms (1). In addition, cells maybe sub-lethally injured by food processing or intrinsic factors of the food matrix (2). The purpose of the pre-enrichment step is to allow stressed target microorganisms to resuscitate and grow in either a non-selective or moderately selective environment. At this stage, the target organisms can be overgrown by the background flora in the food product due to absent selectivity of the medium, which can lead to false negative results. The selective enrichment should promote growth of the recovered target bacteria. The necessity of applying a selective enrichment will mostly depend on the characteristics of the food product, particularly on its microbial flora. In products with a high number of competing organisms, in which the target bacteria are likely to be stressed, both a non-selective and selective enrichment step will be necessary. For products with low levels of background flora, a one-broth enrichment strategy in an unselective enrichment broth can be sufficient. Since the pre- enrichment and selective enrichment step are the main time limiting factors in regard to turn around time for rapid methods (1), a moderately selective one-broth enrichment strategy can decrease the total time until results are available.

The success of the pre-enrichment step is however not only depending on the food product but also on the quality of the medium. Preliminary work has shown that there are some inconsistencies in the performance of BPW and that the ISO standard formulation results in performance variations not just from manufacturer to manufacturer but also from batch to batch. A comparison of 18 different commercial brands of buffered peptone water showed differences in performance regarding buffering capacity, growth of unstressed bacteria and recovery of dry-stressed cells (unpublished data). The performance of the BPW brands depended heavily on the matrix and the organism tested. Baylis et al. (1) compared two commercially available preparations of buffered peptone water with regard to their ability to 
promote recovery and growth of sub-lethally injured Salmonella enterica. There was a significantly higher recovery rate stressed of cells with one brand of buffered peptone water however, the performance of BPW in food was mostly dependent on the food type with the type and level of background flora present being the most important influential factors. Strain variability also exerted an influence on the recovery of stressed cells. Different studies have investigated an improvement of enrichment media by supplementation and by modification of the conditions during enrichment such as temperature, $\mathrm{pH}$, time etc. (3). Gray et al. (4) investigated the effect of variation between classes of casein, gelatine and peptones from different sources. They concluded that the variation in peptone has a substantial influence when looking at growth and enumeration of bacteria. For STEC, pre-enrichment methods were developed based on meat industry requirements that are, however, inadequate for the recovery of STEC from vegetables, flour and other low aw matrices (5). Weber et al. (6) showed that the supplementation of growth factors such as additional iron and sodium pyruvate, along with low levels of inhibiting agents primarily against Gram-positive background flora (8-hydroxyquinoline and sodium deoxycholate), enhances the recovery rate of stressed cells. Products containing starter cultures and probiotic cultures present a special challenge to pathogen detection. Strong acidification of the enrichment caused by lactic acid producing bacteria can lead to inactivation of target bacteria and subsequently false-negative results. Previous experimental work has shown that increased concentrations of buffer phosphates in BPW improved detection of pathogens in powders containing probiotics (unpublished data). For this reason, BPW with $3 \mathrm{x}$ and $6 \mathrm{x}$ increase in buffer phosphate concentration were included in the study. So far, there are only few studies evaluating the use of BPW with supplements in a one-broth enrichment. In particular, data obtained from experiments in the food matrix are scarce.

The aim of the current study was to compare different modifications of BPW with regard to their ability to promote growth of unstressed and stressed Gram-negative foodborne pathogens in different food matrices. 
Table 1. Strains used in this study

\begin{tabular}{|c|c|}
\hline Strain & Species \\
\hline N10 2100 & Salmonella Agona \\
\hline N10 2099 & Salmonella Rissen \\
\hline N10 2103 & Salmonella Hadar \\
\hline N10 2054 & Salmonella Livingstone \\
\hline S604 & Salmonella Anatum \\
\hline N10 1898 & Salmonella Senftenberg \\
\hline N10 1905 & Salmonella enterica O:rough \\
\hline N472 962 & Salmonella Typhimurium, monophasic \\
\hline N10 2043 & Salmonella Virchow \\
\hline N10 2148 & Salmonella London \\
\hline 40 & E. coli $\mathrm{O} 103$ \\
\hline K124 & E. coli O91:H10 \\
\hline N10 630 & E. coli O128ac:(H2) \\
\hline K406 & E. coli O116:(H28) \\
\hline 115903 & E. coli O55:H7 \\
\hline N10 632 & E. coli O111:(H8)b \\
\hline 185004 & E. coli O121:H19 \\
\hline 96803 & E. coli O26:H11 \\
\hline N10 635 & E. coli O26:H11 \\
\hline 33 & E. coli $\mathrm{O} 145$ \\
\hline E608 & Cronobacter malonaticus \\
\hline E465 & Cronobacter dublinensis \\
\hline E265 & Cronobacter malonaticus \\
\hline E288 & Cronobacter sakazakii \\
\hline E615 & Cronobacter malonaticus \\
\hline E151 & Cronobacter sakazakii \\
\hline E269 & Cronobacter sakazakii \\
\hline E266 & Cronobacter sakazakii \\
\hline E776 & Cronobacter sakazakii \\
\hline E532 & Cronobacter malonaticus \\
\hline
\end{tabular}




\section{Materials and methods}

\section{Bacterial strains}

Different S. enterica, Cronobacter spp. and Shigatoxin-producing Escherichia coli (STEC) strains were chosen as representatives for Gram-negative food borne pathogens (Table 1$)$. Working cultures were made from frozen $\left(-80^{\circ} \mathrm{C}\right.$ ) BHI (Oxoid CM1135, Basingstoke, United Kingdom) with 20\% glycerol stocks and maintained on blood agar plates (Difco Columbia blood agar base, 5\% sheep blood, CM0031 Oxoid) at $4^{\circ} \mathrm{C} \pm 1$. All strains were natural isolates, obtained from our in-house collection.

\section{Supplementation of BPW}

Buffered peptone water (BPW, Oxoid CM1049) was prepared according to the manufacturer's instructions. BPW-S was prepared by using BPW with the following supplements added before autoclaving: $40 \mu \mathrm{M}$ 8-hydroxyquinoline, $0.5 \mathrm{~g} / \mathrm{l}$ ammonium-iron (III) citrate, $0.1 \mathrm{~g} / 1$ sodium deoxycholate, $0.1 \mathrm{~g} / 1$ sodium pyruvate (all from Sigma-Aldrich, Buchs, Switzerland). $6 \times \mathrm{BPW}$ (quantities for $3 \times \mathrm{BPW}$ in brackets) was prepared by addition of $7.5 \mathrm{~g} / 1(3 \mathrm{~g} / 1) \mathrm{KH}_{2} \mathrm{PO}_{4}$ and $17.5 \mathrm{~g} / 1$ (7 g/l) $\mathrm{Na}_{2} \mathrm{HPO}_{4}$ (anhydrous) (Sigma-Aldrich) to BPW. $6 \times$ BPW-S contains both additional buffer salts and supplements of BPW-S. Throughout this work, buffered peptone water from a single batch was used to avoid lot-to-lot variations.

\section{Recovery of dry stressed cells}

Each ten strains of Cronobacter spp., STEC and $S$. enterica were grown overnight in $9 \mathrm{ml} \mathrm{BHI} \mathrm{(Oxoid)} \mathrm{at} 37^{\circ} \mathrm{C}$. Grown cultures were centrifuged at 13,000 $\mathrm{g}$ for 10 min. The supernatant was discarded and the pellet was resuspended in $1 \mathrm{ml} \mathrm{BPW}$. The cell suspension with cell counts of approximately $10^{9}-10^{10} \mathrm{cfu} / \mathrm{ml}$ was serially tenfold diluted in BPW. $10 \mu \mathrm{l}$ of each dilution were pipetted in eight wells of a 96-well microtiter plate using one plate per strain resulting in $10^{7}-10^{8} \mathrm{cfu} /$ well in the first row. Cell counts of the culture were determined with plate counts on tryptic soy agar (BD Diagnostic Systems, Heidelberg, Germany). After two days of storage in a desiccator containing silica gel at room temperature, one complete plate was rehydrated with $200 \mu \mathrm{l}$ BPW, BPW-S or $3 \times$ BPW per well and incubated $16 \pm 2 \mathrm{~h}$ at $37^{\circ} \mathrm{C}$. The most probable number (MPN) of microorganisms that had survived the drying process and were able to grow in the enrichment broth was determined based on the number of wells in which growth was observed using the 
Bacteriological Analytical Manual Online MPN table (http://www.fda.gov/Food/ FoodScienceResearch/LaboratoryMethods/ucm109656.htm).

\section{Application of desiccation stress}

In food matrices with a low $\mathrm{a}_{\mathrm{w}}$, pathogens are expected to have encountered desiccation stress. To achieve a more realistic scenario, cells used for spiking were desiccation stressed before inoculation. The STEC K124 and 33, Cronobacter spp. E615 and E776, S. enterica N10 1905 and N472 962 strains were grown separately overnight in $30 \mathrm{ml} \mathrm{BHI} \mathrm{(Oxoid)} \mathrm{at} 37^{\circ} \mathrm{C}$. After centrifugation for $12 \mathrm{~min}$ at 4000 $\mathrm{rpm}$ and the supernatant was discarded. The inside of the tube was dried with a sterile cotton swab. Small amounts of sterile $\mathrm{CaCO}_{3}$ (Sigma-Aldrich) were added to the pellet and mixed vigorously with a spatula until homogenously distributed. More $\mathrm{CaCO}_{3}$ was added to a final amount of approximately $15 \mathrm{~g}$ of powder. The powder was stored in a desiccator with silica gel for two days. The homogeneity of the powder was verified one day before the actual experiment by weighing five times $0.1 \mathrm{~g}$ of powder, diluting in $0.9 \%$ saline and plating on selective agar (Rapid' E. coli 2 agar for E. coli (Biorad, Marnes la Coquette, France), XLD agar for $S$. enterica (Oxoid), Brilliance Enterobacter sakazakii agar for Cronobacter spp. (Oxoid)). However, plating on selective agar might have resulted in lower cell counts than those actually found in the powder. To obtain the desired concentration, $0.1 \mathrm{~g}$ of the powder with bacteria was suspended in $0.9 \%$ saline, diluted if necessary and added to the enrichment. The spiking levels were checked by enumeration on selective agar.

\section{Growth of pathogens inoculated into food enrichments}

$10 \mathrm{~g}$ samples of skim milk powder, oat flakes, minced beef, soy sprouts and powdered infant formula (PIF) were diluted 1/10 with the different enrichment media and mixed in a stomacher for $30 \mathrm{~s}$ at medium intensity. Food products for one experiment were obtained from the same supplier, if possible originating from the same batch. The samples were inoculated with low levels of the target strain (aiming at $10^{1} \mathrm{cfu}$ in $100 \mathrm{ml}$ ) and incubated for $18 \pm 2 \mathrm{~h}$ at $37^{\circ} \mathrm{C}$. For spiking with cells with- out application of stress (for minced beef and sprouts), an overnight culture grown in BHI was diluted to the desired concentration and added to the diluted matrix. In the case of milk powder, oat flakes and PIF, the target strains were desiccation stressed before inoculation, using the protocol described in section "application of desiccation stress". Skimmed milk powder was inoculated with Salmonella, oat flakes were inoculated with STEC and Salmonella, minced beef was 
inoculated with STEC, soy sprouts were inoculated with STEC and S. enterica and powdered infant formula was inoculated with Cronobacter spp. Inoculum levels were confirmed by plate counts on tryptic soy agar. After 4, 8, 15, 20 and $24 \mathrm{~h}$ of incubation, samples of each enrichment broth were diluted in $0.9 \%$ saline and plated on the appropriate selective agar. To verify that the used food products were not naturally contaminated with $S$. enterica, Cronobacter spp. or STEC, negative controls were incubated and checked for the presence of pathogens by plating on selective agar or by Assurance GDS real-time PCR (Biocontrol, Bellevue, USA). Total aerobic counts and E. coli/coliform counts were determined in the un-inoculated samples by plating them on tryptic soy agar at regular intervals. Minced meat and sprout samples were additionally plated on Rapid' E. coli 2 agar (Biorad). All agar plates were aerobically incubated at $37^{\circ} \mathrm{C}$ for $24 \pm 2 \mathrm{~h}$. The $\mathrm{pH}$ of the negative control was measured at regular intervals in 6xBPW and BPW-S using a pH meter (Orion Star, Thermofisher Scientific, Reinach, Switzerland). To obtain data after more then 12 $\mathrm{h}$ incubation an identical second pre-enrichment broth was prepared in the late afternoon, also incubated at $37^{\circ} \mathrm{C}$, and sampled the next day. This approach may result in an increase of the variability.

\section{Recovery of STEC and Salmonella from sprouts}

Fresh soy sprouts were obtained from a local Asian supermarket. $10 \mathrm{~g}$ samples were diluted 1/10 with BPW, BPW-S and $6 \times \mathrm{BPW}$ and mixed in a Stomacher for $30 \mathrm{~s}$ at medium intensity. Sprouts were spiked with $10,10^{2}, 10^{3} \mathrm{cfu} / \mathrm{sample}$ with E. coli (strain K124) and a naturally nalidixic acid resistant Salmonella Kentucky (strain N08 2487) and incubated for $18 \pm 2 \mathrm{~h}$ at $37^{\circ} \mathrm{C}$. Plate counts were performed to confirm the inoculation level. After incubation, the samples were diluted and plated on selective media. Samples inoculated with STEC were plated on Rapid' $E$. coli 2 agar (Biorad) and samples inoculated with $S$. enterica were plated on Luria Bertani Agar $+256 \mu \mathrm{g} / \mathrm{ml}$ nalidixic acid sodium salt (Sigma- Aldrich). Plates were incubated for $24 \mathrm{~h}$ at $37^{\circ} \mathrm{C}$. In addition, presence of the pathogens was tested with the Assurance GDS real-time PCR. An uninoculated sample was used as a negative control.

\section{Statistical analysis}

Statistical analysis was performed using IBM SPSS. The effect of the enrichment media on the resuscitation of desiccation stressed cells was compared applying oneway ANOVA. A three-way ANOVA was used to compare the cell counts from the enriched cultures for the four enrichment media, five food matrices and the four organisms. 


\section{Results and discussion}

\section{Recovery of desiccated cells}

The MPN concentrations $(\log \mathrm{cfu} / \mathrm{ml}$ ) after rehydration and incubation for the tested strains using the three enrichment media are shown in Fig. 1. Salmonella strains were recovered to values reaching from $0.5 \log$ MPN to $4.6 \log$ MPN. The mean MPN counts were $3.6 \pm 1.2,3.7 \pm 1.3$ and $3.4 \pm 1.3$ in BPW, BPW-S and $6 \times$ BPW, respectively. Desiccated Salmonella strains did not show great variation in regards to the different media. Two strains remained at low cfu levels after rehydration and incubation, which indicates that growth after desiccation was more strain than media dependent. Desiccated STEC strains were recovered to highest concentrations in BPW (mean MPN count $4.1 \pm 0.2$ ), showing little strain variation. The mean concentrations in BPW-S and $3 \times$ BPW were up to $2.0 \log$ MPN and 0.6 $\log$ MPN lower, respectively. There was no statistical significant difference between the media $(\mathrm{P}=0.87)$. Highest concentrations for Cronobacter strains were recorded in BPW-S (mean MPN count $3.2 \pm 0.7$ ) and $6 \times \mathrm{BPW}$ (mean MPN count $3.3 \pm 0.9$ ) $(\mathrm{P}=0.06)$. However, strain variability resulted in differences in counts of up to $2.5 \log$ MPN. The strains showed least resuscitation in BPW (mean MPN count $2.5 \pm 0.5$ ). The positive effect of the combined supplementation of BPW with an iron source, sodium pyruvate and sodium deoxycholate on stressed Enterobacteriaceae was already described by Weber et al. (6). Nevertheless, recovery of desiccated STEC was significantly superior in BPW without supplements $(P<0.01)$. One of the supplements, sodium deoxycholate, is the selective component in bile salts and its use in culture media for the inhibition of Gram-positive organisms and selection of Gram-negatives is well recognized (7). However, the negative effect of bile on the detection of stressed pathogens has also been described (8); Hara-Kudo et al. (9). A concentration of $1.0 \mu \mathrm{g} / \mathrm{ml}$ sodium deoxycholate in an agar medium resulted in increased lag time and growth rate of $E$. coli and the interference with the flagellation was named as a possible reason by D'Mello and Yotis (8). Stephens and Joynson (10) reported decreased recovery of acid/salt stressed E. coli O157:H7 in tryptone soya broth when bile salts were added. These findings indicate that bile salts with sodium deoxycholate being the main ingredient can deteriorate the recovery of stressed $E$. coli cells (10). Sodium pyruvate protects stressed bacteria from reactive oxygen species (11). These can develop in the enrichment broth through auto-oxidation of reducing sugars and cause decreased recovery of stressed cells (12). Sodium pyruvate is able to facilitate the repair process in injured bacteria and can replace the function of catalase in these organisms. No negative effects on any of the organisms tested in our study are described in literature. Therefore the 
observed inhibitory effect in STEC is most probably not caused by this substance. 8-hydroxyquinoline (8-HQ) was added to the enrichment medium to replace vancomycin as an inhibitor for Gram-positive competitors as this compound is heat stable and alternatives to antibiotics are desirable (6).

a)

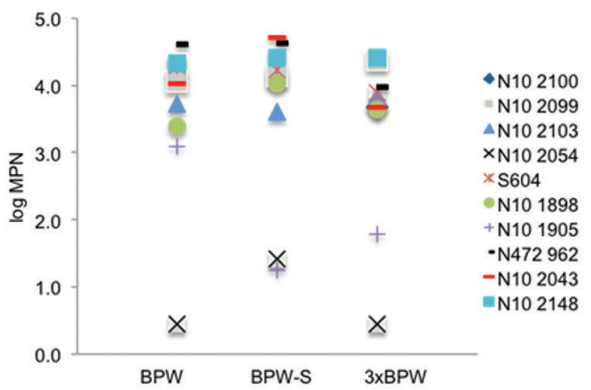

b)

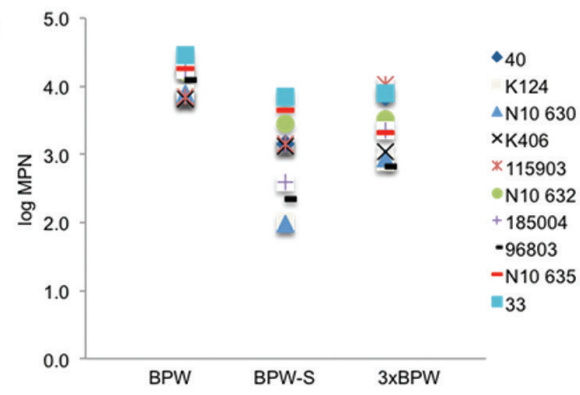

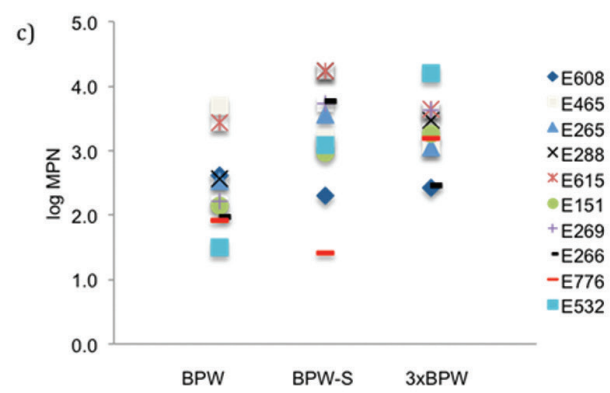

Figure 1. Log MPN of desiccation stressed cells after rehydration and incubation for $18 \pm 2 \mathrm{~h}$ at $37^{\circ} \mathrm{C}$ with different enrichment media. (a) 10 strains of $S$. enterica (b) 10 strains of STEC (c) 10 strains of Cronobacter spp.

\section{Maximum population density in the matrix}

The maximum population density for each matrix with standard deviation is shown in Fig. 2. All food matrices were inoculated with two strains of the same species and the experiments were performed in triplicate. In one experiment, one food product was spiked with one strain and diluted with all tested media. The spiking inoculum was identical for one experiment. However, spiking levels between different replicates can differ which is the main reason for the high standard deviation in some cases. When PIF was spiked with low levels of desiccation stressed Cronobacter, highest counts were seen in BPW-S in all experiments. Levels in the other enrichment media were on average $1 \mathrm{log} \mathrm{cfu} / \mathrm{ml}$ lower than in BPW-S. However, in two of the experiments, counts in $6 \times \mathrm{BPW}$ and $6 \times \mathrm{BPW}$-S were as high as in BPW-S. Overall, 
the cell counts of Cronobacter were not significantly different between the media $(P=0.06)$. Weber et al. (6) demonstrated the same improved recovery with ten Cronobacter spp. strains. They also showed that isolation from other naturally contaminated samples of different origin was enhanced. For skimmed milk powder, Salmonella strain N472 962 grew to $9 \log \mathrm{cfu} / \mathrm{ml}$ in all enrichment media. Variation was small in this case (mean standard deviation $=0.5$ ). Strain N101905 grew to lower counts in all media and experiments were yielding higher standard deviations (mean standard deviation $=1.3$ ). STEC strains 33 and K124 spiked into cereals grew to $9 \log \mathrm{cfu} / \mathrm{ml}$, independent of the enrichment medium. In contrast to the desiccation experiments, both STEC strains grew to same concentration in BPW and BPW-S. When $S$. enterica was spiked into cereals, growth of the target bacteria again was lower in $6 \times \mathrm{BPW}$ and $6 \times \mathrm{BPW}$-S than in BPW and BPW-S with high standard deviation. Minced meat was spiked with low levels of unstressed bacteria. STEC strain 33 grew to levels of $8 \log \mathrm{cfu} / \mathrm{ml}$ to $10 \log \mathrm{cfu} / \mathrm{ml}$ in BPW-S, $6 \times$ BPW and $6 \times$ BPW-S. Values in BPW were up to $2 \mathrm{log} \mathrm{cfu} / \mathrm{ml}$ lower. Minced meat was also spiked with $S$. enterica. For both strains, all four media showed the same maximum population density.

The general outcome of the matrix experiments is that both Salmonella and STEC strains (with the exemption of K124) did grow to comparable concentrations in all four enrichment media independent of the matrix. This indicates that the food matrix balances the effects of the media supplements, both positive and negative. The results also show that in the matrices tested, Salmonella, STEC and Cronobacter spp. can be isolated with a one-broth strategy with BPW-S. In food products in which one or more of these three targets have to be tested, one enrichment could be sufficient and omission of a selective enrichment allows time saving. $6 \times$ BPW was included in the study because previous experimental work showed that increased buffering capacity enhanced recovery of desiccated cells from products with a high number of lactic acid producing bacteria (e.g. probiotic culture powders) (data not published). We did not find, as expected, an additional benefit in the use of this medium for the products described here. 
a)

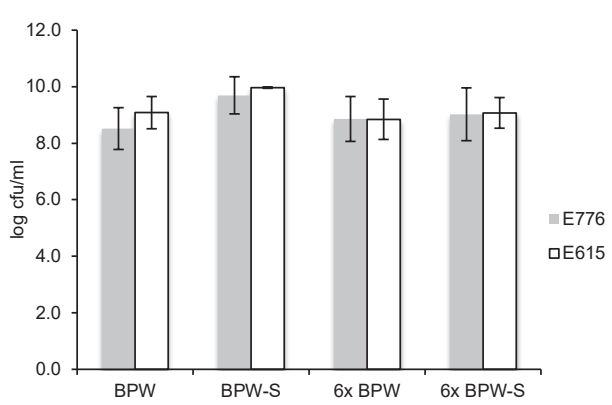

c)

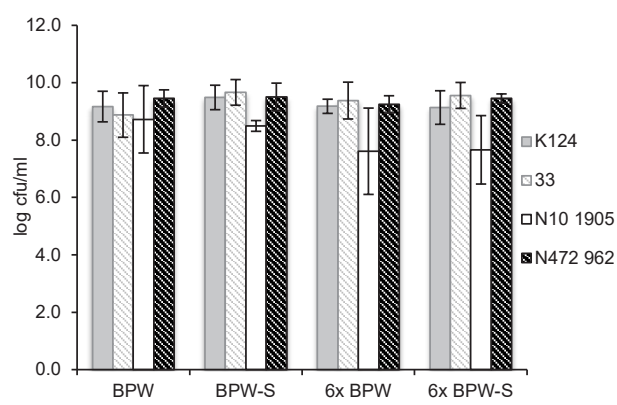

b)

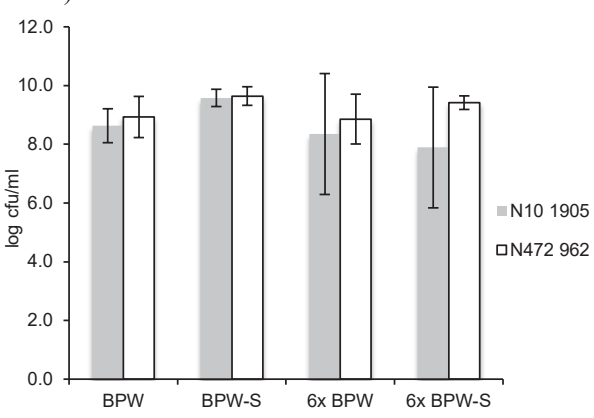

d)

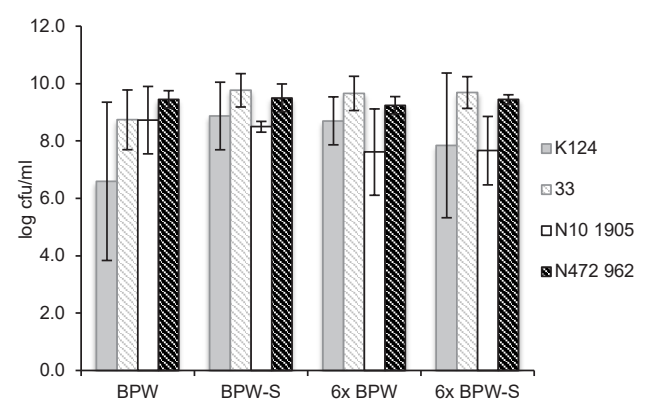

Figure 2. Maximum population density in the different enrichment media after incubation for $18 \pm 2 \mathrm{~h}$ at $37^{\circ} \mathrm{C}$. Spiking level was between $10^{1}$ and $10^{2} \mathrm{cfu} / 10 \mathrm{~g}$. (a) Cronobacter in powdered infant formula with strains E776 and E615, (b) Salmonella in milk powder with strains N10 1905 and N472 962, (c) Oat flakes with STEC strains K124 and 33, Salmonella strains N10 1905 and N472 962, (d) Minced meat with STEC strains K124 and 33. Salmonella strains N10 1905 and N472 962. Error bars are standard deviations.

\section{Growth in food matrices}

The growth of both the pathogens and the background flora was determined in BPW and BPW-S. PH in the enrichment was recorded. All food matrices were inoculated with low levels of the target organism. The target bacteria and the background flora reached approximately the same final concentration after $24 \mathrm{~h}$ for PIF, milk powder, oat flakes and minced meat (Fig. 3). For PIF and oat flakes the levels of the back- ground flora was $1 \log \mathrm{cfu} / \mathrm{ml}$ lower in BPW-S than in BPW throughout the incubation period. These are the products, which have a mainly Gram-positive flora. In PIF, the final number of Cronobacter was over 1 log higher in BPW-S. In the other food matrices, there was no obvious difference between the enrichment media in the growth of the selected pathogens. In PIF, oat flakes and minced meat the target organisms reached their final value after $15 \mathrm{~h}$. In milk powder it took 20 h until Salmonella reached the maximum numbers. Sprouts were spiked with a higher number of Salmonella to enable detection of the target bacteria after the incubation period. It is remarkable that starting from $0 \mathrm{~h}$ of incubation, the 
a)

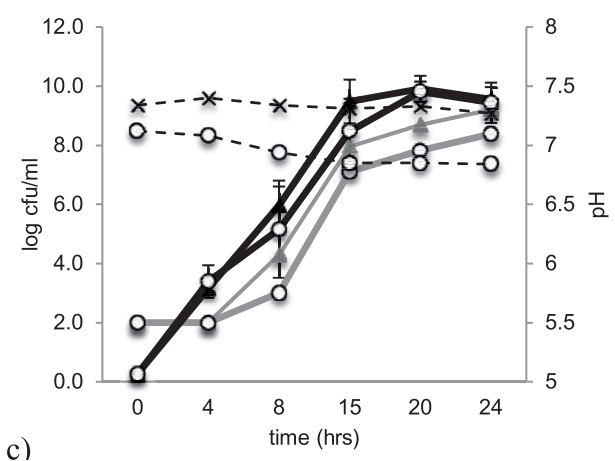

c)

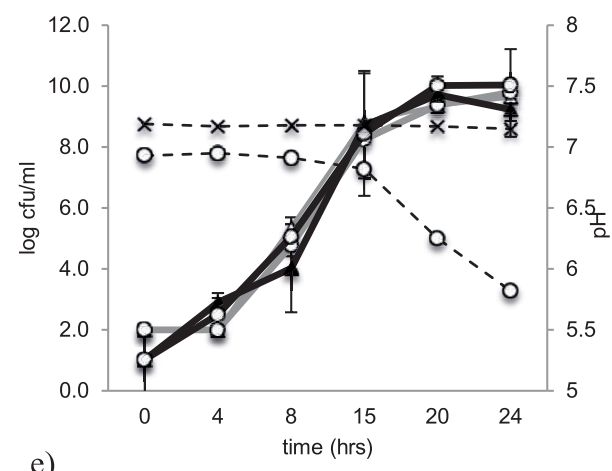

e)

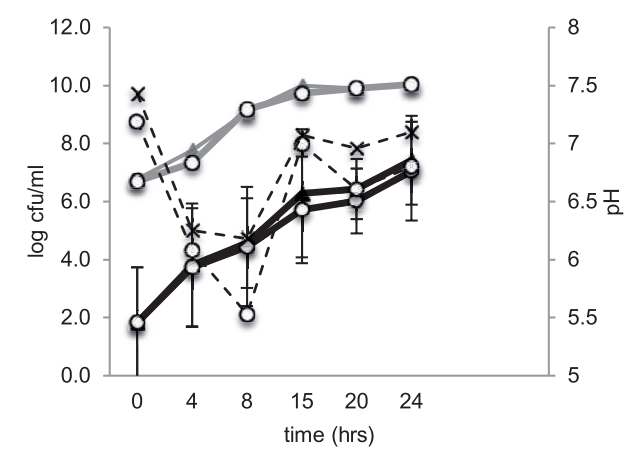

b)

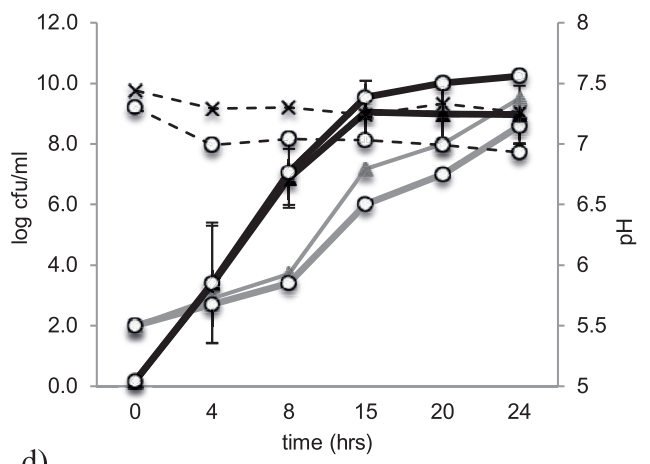

d)

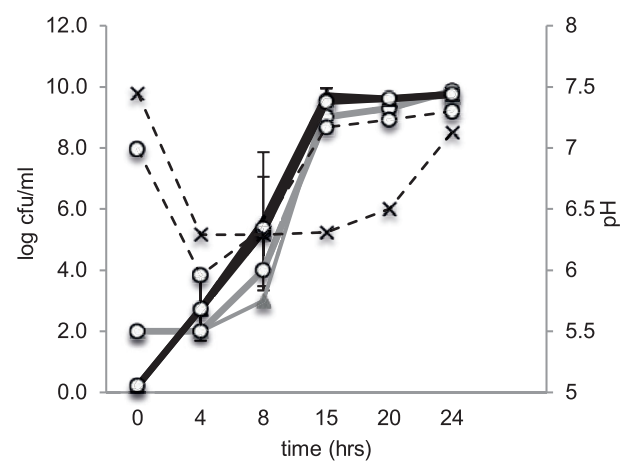

Figure 3. Growth of target bacteria and background flora in different enrichment media for various food matrices. Samples were incubated for $18 \pm 2 \mathrm{~h}$ at $37^{\circ} \mathrm{C}$. Dotted lines show pH (BPW-S $(\circ)$ and $6 \mathrm{xBPW}(\times))$. Counts of aerobic background flora are shown in grey and target bacteria in black (BPW ( $\Delta$ ), BPW-S (o)). (a) S. enterica in oat flakes, (b) Cronobacter spp. in PIF, (c) S. enterica in milk powder, (d) STEC in minced meat, (e) $S$. enterica in sprouts. Points are means of two trials with two strains. Error bars are standard deviations.

counts of the background flora are at least $3 \mathrm{log} \mathrm{cfu} / \mathrm{ml}$ steps higher throughout the enrichment period. Background flora counts in sprouts were very high and values of 7 to $8 \log \mathrm{cfu} / \mathrm{g}$ in sprouts have already been published by other researches (13). In contrast to the other matrices used in this study, the background flora of sprouts is mainly composed of Gram-negative organisms and therefore the inhibiting agents in the BPW variants are not effective because they were selected to suppress the Gram- positive flora. Inhibiting effects of the background flora on pathogens like E. coli $\mathrm{O} 157$ and Salmonella have been described previously $(14,15)$. An approach explaining this behaviour is the Jameson-effect. According to this model, two species 
compete for the resources in the environment during their growth. Growth of both populations stops when the resources are depleted or when metabolic products inhibiting growth have accumulated (16). It is possible that this model also applies in sprouts. However, since growth in our experiments was only determined up to 24 $\mathrm{h}$, the growth behaviour of Salmonella after this time is not known. In the enrichment of dry food products, $\mathrm{pH}$ values remained relatively stable. Only in milk powder did the $\mathrm{pH}$ in BPW-S decrease to 5.8. BPW with increased buffer concentration did not completely prevent $\mathrm{pH}$ decline but usually kept the $\mathrm{pH}$ about 1 point higher. However, $\mathrm{pH}$ decrease did in none of the products reach a level that would inhibit growth of the target bacteria.

\section{Detection limit in sprouts}

Since the abovementioned experiments indicated that low levels of Salmonella and STEC spiked into sprouts could not be recovered, the inoculation level was increased and enrichments were additionally tested with real-time PCR for the presence of the pathogens. These results are summarized in Table 2. Salmonella could not be detected by real-time PCR, when sprouts were inoculated with only 10 cfu. However, Salmonella counts were $10^{4}-10^{5} \mathrm{cfu} / \mathrm{ml}$, which indicates that there was growth of $S$. enterica during the enrichment. At an inoculation level of $10^{2} \mathrm{cfu}$, PCR results for Salmonella were only positive in 6xBPW. At an inoculation level of $10^{3} \mathrm{cfu}$, Salmonella was detected with PCR from BPW and 6xBPW and cultural isolation yielded a minimal value of $1.0 \times 10^{5} \mathrm{cfu} / \mathrm{ml}$. Nevertheless, levels of $4.0 \times 10^{5}$ $\mathrm{cfu} / \mathrm{ml}$ of Salmonella in BPW-S were not detected in the PCR, even though the test protocol included an immunomagnetic separation step. Hence, at an inoculation level of $10^{3} \mathrm{cfu}$ (levels of $\geq 10^{5} \mathrm{cfu} / \mathrm{ml}$ after the enrichment step), Salmonella could not be consistently detected. This, however, seems not to be due to the different enrichment broths which were evaluated. The high number of accompanying flora and the dilution steps which are applied in the PCR (only small volumes are used) are the reasons for a high detection limit, which seems to be between $10^{5}$ and $10^{6} \mathrm{cfu} / \mathrm{ml}$ after the enrichment step. Badosa et al. (18) have evaluated ISO enrichment real-time PCR methods with different selective enrichment media and found that Salmonella was only detected from sprouts in 50\% of the cases when the inoculation level was $10 \mathrm{cfu}$ in $25 \mathrm{~g}$. $1 \mathrm{cfu}$ was never detected even though a selective enrichment was performed after the enrichment in BPW. Their method was able to detect $1 \mathrm{cfu}$ in $25 \mathrm{~g}$ of other fresh produce. Filtered soy sprout extracts did result in positive detection for all inoculation levels, which suggest that the high levels of accompanying flora caused the failure of the detection (17). Taking the present data into account, the possible presence of a low dose of Salmonella in 25 
$\mathrm{g}$ of sprouts cannot be reliably detected with a one- broth enrichment strategy. A selective enrichment is necessary to promote selective growth of the target organism and to inhibit the background flora. However, members of the common sprout flora (such as Citrobacter spp.) can also grow in selective broths and can be misidentified as Salmonella on selective agar. STEC were neither detected with PCR nor when using Rapid' E. coli 2 agar with the lower inoculation levels. Isolation of the STEC strains on agar was only possible with an inoculation level of $10^{3} \mathrm{cfu}$. Still, the PCR result of the enrichment in BPW was negative. Differences in cultural detection between STEC and Salmonella can be explained by different selectivity of the agar media. The Salmonella strain was grown on LB agar supplemented with nalidixic acid, which suppressed growth of any background flora on the plate. On the other hand, Rapid' E. coli 2 agar does only select for coliforms. Since these organisms represent the dominating flora of sprouts with counts of up to $10^{5} \mathrm{cfu} / \mathrm{g}(18)$, the small number of $E$. coli present will be overgrown on the agar medium. The single enrichment of sprouts in BPW followed by real-time PCR for the top 6 serotypes (O157, O26, O145, O103, O111, O104) is the recommended ISO protocol for the detection of STEC (19). However, our results strongly suggest that low levels of contamination with STEC on sprouts are missed with this procedure. Jinneman et al. (13) found that the method as described in the U.S. Bacteriological Analytical Manual did detect low levels of $E$. coli $\mathrm{O} 104$ from a sprout matrix with different realtime PCR systems. Their enrichment involved addition of acriflavine, cefsulodin and vancomycin and increased incubation temperatures. However, they also reported non-isolation of the target organism on certain selective agars due to overgrowth of background flora.

Table 2. Detection (after $18 \mathrm{~h}$ incubation) of Salmonella and STEC in sprouts starting from various inoculum levels by selective plate counting and PCR

Inoculum $\sim 10^{1} \sim 10^{2} \sim 10^{3}$

(cfu/10 g sprouts)

\begin{tabular}{|c|c|c|c|c|c|c|c|c|c|c|c|c|}
\hline & STEC & & Salmonella & & STEC & & Salmonella & & STEC & & Salmonella & \\
\hline & $\begin{array}{l}\text { Cultural } \\
\text { (cfu/ml) }\end{array}$ & PCR & $\begin{array}{l}\text { Cultural } \\
(\mathrm{cfu} / \mathrm{ml})\end{array}$ & PCR & $\begin{array}{l}\text { Cultural } \\
(\mathrm{cfu} / \mathrm{ml})\end{array}$ & PCR & $\begin{array}{l}\text { Cultural } \\
(\mathrm{cfu} / \mathrm{ml})\end{array}$ & PCR & $\begin{array}{l}\text { Cultural } \\
(\mathrm{cfu} / \mathrm{ml})\end{array}$ & PCR & $\begin{array}{l}\text { Cultural } \\
(\mathrm{cfu} / \mathrm{ml})\end{array}$ & PCR \\
\hline BPW & $<10^{2}$ & - & $2.4 \times 10^{4}$ & - & $<10^{2}$ & - & $2.6 \times 10^{5}$ & - & $1.0 \times 10^{6}$ & - & $1.0 \times 10^{5}$ & + \\
\hline BPW-S & $<10^{2}$ & - & $1.1 \times 10^{4}$ & - & $<10^{2}$ & - & $1.1 \times 10^{5}$ & - & $3.0 \times 10^{6}$ & + & $4.0 \times 10^{5}$ & - \\
\hline $6 \times \mathrm{BPW}$ & $<10^{2}$ & - & $1.3 \times 10^{5}$ & - & $<10^{2}$ & - & $7.0 \times 10^{5}$ & + & $7.0 \times 10^{6}$ & + & $9.2 \times 10^{6}$ & + \\
\hline
\end{tabular}




\section{Conclusion}

Different buffered peptone water based enrichment broths were tested to evaluate their performance in a one-broth strategy for the detection of Gram-negative food borne pathogens. Desiccation stressed cells showed variable behaviour. Resuscitation of Cronobacter spp. was improved in BPW-S but stressed STEC cells did not show an improved recovery in pure culture experiments. When a selection of food products was spiked with low numbers of the pathogens, STEC and Salmonella growth was similar in all media. Cronobacter spp. detection from PIF was improved with BPW-S. Therefore, we suggest the use of BPW-S in a one-broth enrichment strategy for the isolation of Cronobacter spp. from PIF and similar products with low aw values. Moreover, this broth can be used for the parallel enrichment of Cronobacter spp., STEC and Salmonella from different food matrices. However, the one-broth strategy was not suitable for produce with high numbers of Gram-negative accompanying microflora. Low numbers of the pathogen will be overgrown by the background flora making their detection impossible. Next should be a thorough validation of the medium according to ISO standards. 


\section{References}

1. Baylis, CL., MacPhee, S., Betts, R.P. 2000. Comparison of two commercial preparations of buffered peptone water for the recovery and growth of Salmonella bacteria from foods. Journal of Applied Microbiology 89: 501-510.

2. Edel, W. and Kampelmacher, EH. 1973. Comparative studies on the isolation of "sublethally injured" Salmonellae in nine European laboratories. Bulletin of the World Health Organization 48: 167-174.

3. Andrews, WH. 1986. Resuscitation of injured Salmonella spp. and coliforms from foods. Journal of Food Protection 49: 62-75.

4. Gray, VL., Müller, CT., Watkins, ID., Lloyd, D. 2006. Peptones from diverse sources: pivotal determinants of growth dynamics. Journal of Applied Microbiology 104: 554-565.

5. Sata, S., Fujisawa, T., Osawa, R., Iguchi, A., Yamai, A., Shimada, T. 2003. An improved enrichment broth for isolation of Escherichia coli 0157, with specific reference to starved cells, from radish sprouts. Applied and Environmental Microbiology 69: 1858-1860.

6. Weber, C., Stephan, R., Druggan, P., Joosten, H., Iversen, C. 2009. Improving the enrichment procedure for Enterobacteriaceae detection. Food Microbiology 26: 565-572.

7. MacConkey, AT. 1905. Lactose-fermenting bacteria in faeces. International Journal of Hygiene and Environmental Health 5: 333-379.

8. D`Mello, A., Yotis, WW. 1987. The action of sodium deoxycholate on Escherichia coli. Applied and Environmental Microbiology 53: 1994-1996.

9. Hara-Kudo, Y., Ikedo, M., Kodaka, H., Nakagawa, H., Goto, K., Masuda, T., Konuma, H., Kojima, T., Kumagai, S. 2000. Selective enrichment with a resuscitation step for isolation of freeze injured Escherichia coli O157:H7 from foods. Applied and Environmental Microbiology 66: 2866-2872.

10. Stephens, PJ., Joynson, JA. 1998. Direct inoculation into media containing bile salts and antibiotics is unsuitable for the detection of acid/salt stressed Escherichia coli O157:H7. Letters in Applied Microbiology 2: 147-151.

11. MacDonald, IC., Hackney, CR., Ray, B. 1983. Enhanced recovery of injured Escherichia coli by compounds that degrade hydrogen peroxide or block its formation. Applied and Environmental Microbiology 45: 360-365.

12. Stephens, PJ., Druggan, P., Nebe-von Caron, G. 2000. Stressed Salmonella are exposed to reactive oxygen species from two independent sources during recovery in conventional culture media. International Journal of Food Microbiology 60: 269-285.

13. Jinneman, K., Waite-Cusic, YG., Yoshitomi, KJ. 2012. Evaluation of shiga-toxin producing Escherichia coli (STEC) method for the detection and identification of STEC 0104 strains from sprouts. Food Microbiology 30: 321-328.

14. Vold, L., Holck, A., Wasteson, Y., Nissen, H. 2000. High levels of background flora inhibits growth of Escherichia coli O157:H7 in ground beef. International Journal of Food Microbiology 56: 219-225.

15. Duffy, G., Whiting, RC., Sheridan, JJ. 1999. The effect of a competitive microflora, pH and temperature on the growth kinetics of Escherichia coli O157:H7. Food Microbiology 16: 299-307.

16. Cornu, M., Billoir, E., Bergis, H., Beaufort, A., Zuliani, V. 2011. Modelling microbial competition in food: application the behaviour of Listeria monocytogenes and lactic acid flora in pork meat products. Food Microbiology 28: 639-647.

17. Badosa, E., Chico, N., Pla, M., Pares, D., Montesinos, E. 2009. Evaluation of ISO enrichment realtime PCR methods with internal amplification control and detection of Listeria monocytogenes and Salmonella enterica in fresh fruit and vegetables. Letters in Applied Microbiology 49:105-111

18. Becker, B., Holzapfel, WH. 1997. Mikrobiologisches Risiko von fertigverpackten Keimlingen und Maßnahmen zur Reduzierung ihrer mikrobiellen Belastung. Archiv für Lebensmittelhygiene 48: 73-96.

19. ISO International Standard 6579, Microbiology of food and animal feeding stuffs- Horizontal method for the detection of Salmonella spp. 4 th edition: 2002-07-15. 


\section{Chapter}

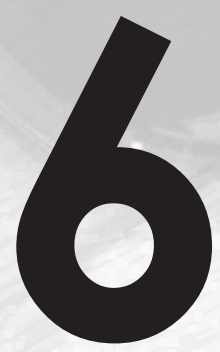

Effects of different media on the enrichment of low numbers of Shiga toxin-producing Escherichia coli in mungo bean sprouts and on the development of the sprout microbiome

Heike Margot, Taurai Tasara, Marcel H. Zwietering, Han Joosten, Roger Stephan 


\section{Abstract}

Sprouted seeds have been implicated in a number of serious outbreaks caused by Salmonella and Shiga toxin-producing E. coli. Sprouts pose a very complex challenge to bacterial pathogen enrichment and detection since they naturally contain high levels of background microflora including members of the Enterobacteriaceae. As such, the currently used method cannot ensure reliable detection of STEC in sprouts.

In this study, we compared different media for the enrichment of Enterobacteriaceae in their ability to promote the growth of stressed STEC at $37^{\circ} \mathrm{C}$ and $42^{\circ} \mathrm{C}$. Mung bean sprouts were spiked with low levels of STEC and their growth was recorded over time. In addition, the microbiome of mung bean sprouts was analysed before and after enrichment. Our results indicate that the growth of dry-stressed STEC is comparable in all of the tested enrichment media except for mTSB + Novobiocin and not influenced by the incubation temperature. Low levels of STEC spiked into the sprouts resuspended in media only grew to levels of around $4 \mathrm{log} \mathrm{cfu} / \mathrm{ml}$ during enrichment, which could reduce the probability of detection. Proteobacteria was the dominant phylum detected within the microbiome of non-enriched mung bean sprouts. During enrichment in EE-broth, Proteobacteria remained the most abundant phylum. In contrast, during enrichment in BPW the relative abundance of Proteobacteria decreased whereas Firmicutes increased when compared to the non-enriched mung bean sprout microbiome. The microbiome composition was not significantly influenced by the incubation temperature during enrichment in both BPW and EE-broth. This is the first study to examine the microbiome on sprouted mung bean seeds during BPW and $\mathrm{EE}$ enrichment and relates the bacterial community composition changes to the enrichment of pathogens. 


\section{Introduction}

In the past twenty years more than 50 outbreaks linked to the consumption of sprouts were reported, with Salmonella and Shigatoxin-producing E. coli (STEC) being the most frequent responsible agents (1). In 2011, a large outbreak linked to Shiga toxin-producing Escherichia coli $\mathrm{O} 104$ occurred in Germany. Trace back investigations supported the hypothesis that fenugreek seeds contaminated with this E. coli serotype were responsible (2). The seeds were imported from Egypt and grown in an organic farm in Germany. Even though big efforts were pursued, the strain was never isolated from neither the seeds nor the sprouts. However, that fact that farm workers were infected with EHEC and the causative strain was detected in an open bag with sprouts were indications for the farm being the source of the contamination.

Epidemiological data suggest that all sprout-associated outbreaks were caused by contaminated seeds $(3,4)$. Once present on or in the seeds, pathogens find perfect growth conditions during germination. Temperatures of $20^{\circ} \mathrm{C}$ to $25^{\circ} \mathrm{C}$ with high humidity and nutrition allow increase of bacterial counts of several log units. Dry seeds contain between $10^{3}$ and $10^{5}$ non-pathogenic bacteria per gram (5). These can multiply rapidly during sprout production and grow to numbers of $10^{8}$ to $10^{9}$ $\mathrm{cfu} / \mathrm{g}$ until sale. The high bacterial load may limit the growth of pathogenic bacteria through competition; however, high numbers of background flora can also hinder the detection of pathogens on the product (6). This is the reason why sprouts pose a challenge to microbiological detection methods. The ISO TS 13136:2012 method for the detection of STEC in seeds and sprouted seeds requires an enrichment of $25 \mathrm{~g}$ in $225 \mathrm{ml}$ BPW and a subsequent PCR for $s t x_{1}, s t x_{2}$ and eae. Several studies have been published on the improvement of detection methods for STEC in sprouts. Methods included immuno-magnetic separation (7), addition of selective substances (8) or post enrichment acid treatment (9). These studies mainly focussed on E. coli 0157. However, this serotype was shown not to be representative for other serotypes in regards to stress resistance and growth behaviour and is not the most prevalent STEC serotype in fresh produce in Europe (10). Another drawback of previously described methods is the lack of considering the physiological state of the cells. Bacteria on sprouts are very likely to have experienced various stresses and therefore present an additional challenge to analytical methods (8).

Data on the growth of non-O157 STEC serogroups in media for the enrichment of Enterobactericeae are scarce and there is a need to observe the fate of the target strains in the actual matrix during the enrichment. Even though the problem of detecting low numbers of pathogens in sprout samples has been well acknowledged, so far only little is known about the bacterial community composition of the sprout 
background flora and their influence on the enrichment of pathogens. Traditionally, the phyllospheric flora has been quantified and examined using culture-based approaches. However, bacteria that are not able to grow on standard microbiological media or are growing slowly might be missed. With the introduction of highthroughput sequencing it has become possible to study the microbial diversity of complex ecosystems including non-culturable microorganisms. Loui et al. (11) have examined the microflora of alfalfa sprouts with the help of 16S rRNA profiling.

In this study, different methods for the enrichment of low numbers of desiccation stressed non-O157 STEC were compared in mungo bean sprouts. Moreover, the influence of two enrichment broths and incubation temperatures on quantitative aspects of the background flora and composition of the microbiome was evaluated.

\section{Materials and Methods}

\section{Bacterial Strains}

Five STEC strains of different serogroups (Table 1) were used in this study. Strain 1970-08 (serogroup O80 STEC) was used in the spiking experiments of sprout samples since it harbours a natural Tetracycline resistance, which allowed the specific isolation and counting of this target strain.

Working cultures were made from frozen $\left(-80^{\circ} \mathrm{C}\right)$ BHI stocks (Oxoid, CM1135, Basingstoke, United Kingdom) with $20 \%$ glycerol and maintained on blood agar plates (Difco Columbia blood agar base, $5 \%$ sheep blood, Oxoid) at $4 \pm 1^{\circ} \mathrm{C}$.

Table 1. Strains used in the study

\begin{tabular}{llll}
\hline strain & serogroup & $s t x$ gene profile & source \\
\hline $1970-08$ & O80 & $s t x_{1}, s t x_{2}$ & clinical strain \\
$943-07$ & O111 & $s t x_{1}, s t x_{2}$ & clinical strain \\
N10 635 & O26 & $s t x 1$ & food isolate \\
$128-08$ & O148 & $s t x_{2}$ & clinical strain \\
$1146-05$ & O153 & $s t x_{1}$ & clinical strain \\
\hline
\end{tabular}

\section{Enrichment media}

Buffered peptone water (BPW, Oxoid CM1049), Enterobacteriaceae enrichment broth (EE broth, Oxoid CM0317), Brilliant Green Bile Broth 2\% (BGB, BD, Allschwil, Switzerland), modified Tryptone Soya Broth + Novobiocin (mTSB + N, Oxoid CM0989, Novobiocin selective supplement SR0181) were used for the enrichment experiments. Manufacturers' directions were followed for all media preparation. 


\section{Application of desiccation stress}

Desiccation stressed cells were prepared as described previously (12). $30 \mathrm{ml}$ BHI (Oxoid) were inoculated with a single colony from a blood agar plate and incubated at $37^{\circ} \mathrm{C}$ for $18 \pm 2 \mathrm{~h}$. After centrifugation for $12 \mathrm{~min}$ at $3200 \mathrm{~g}$ the supernatant was discarded. Small amounts of sterile $\mathrm{CaCO}_{3}$ (Sigma-Aldrich, Buchs, Switzerland) were added to the pellet and mixed vigorously with a spatula until homogenously distributed. More $\mathrm{CaCO}_{3}$ was added to a final amount of approximately $15 \mathrm{~g}$ of powder. The powder was stored in a desiccator with silica gel for two days. The homogeneity of the powder was verified one day before the actual experiment by weighing five time $0.1 \mathrm{~g}$ of powder, diluting in $0.9 \%$ saline and plating on tryptone soy agar (TSA, $\mathrm{BD}$, Allschwil, Switzerland). To obtain the desired bacterial concentration, $0.1 \mathrm{~g}$ spiked $\mathrm{CaCO}_{3}$ was suspended in $0.9 \%$ saline, diluted as necessary and added to the enrichment broth. The spiking level was checked by enumeration on Rapid E. coli 2 agar (Biorad, Marnes la Coquette, France).

\section{Growth of STEC in different selective enrichment media}

For the analysis of STEC growth without stress application, fresh BHI overnight cultures of the five strains were diluted in physiological saline solution $(0.9 \% \mathrm{NaCl})$ to $10^{-6}$ (mean inoculum $2 \log \mathrm{cfu} / \mathrm{ml}$ ). Two times $9 \mathrm{ml}$ of the respective enrichment broth (EE-broth, BGB-broth, mTSB + Novobiocin, BPW) were inoculated with $1 \mathrm{ml}$ of the inoculum. One tube of each medium was incubated at $37^{\circ} \mathrm{C}$ and one at $42^{\circ} \mathrm{C}$ for $24 \mathrm{~h}$ without agitation. After 4, 6, 8 and $24 \mathrm{~h}, 0.1 \mathrm{ml}$ was removed from the tube, diluted in saline solution and plated on TSA for enumeration. Agar plates were incubated for $24 \pm 2 \mathrm{~h}$ at $37^{\circ} \mathrm{C}$.

Enrichment broths were also inoculated with desiccation stressed STEC. $\mathrm{CaCO}_{3}$ with bacteria was diluted in $0.9 \%$ saline and $1 \mathrm{ml}$ (mean inoculum $2 \log \mathrm{cfu} / \mathrm{ml}$ ) was added to the different enrichment media. Enrichment broths were incubated at $37^{\circ} \mathrm{C}$ and $42^{\circ} \mathrm{C}$ for $24 \mathrm{~h}$. After 4, 6, 8 and $24 \mathrm{~h}, 0.1 \mathrm{ml}$ was removed from the tube, diluted in $0.9 \%$ saline and plated on TSA for enumeration. Agar plates were incubated for $24 \pm 2 \mathrm{~h}$ at $37^{\circ} \mathrm{C}$.

\section{Growth of STEC spiked into sprouts}

Growth of stressed cells of strain 1970-08 in sprouts was determined in EE-broth and BPW at both $37^{\circ} \mathrm{C}$ and $42^{\circ} \mathrm{C}$. The strain was desiccation stressed as described in section 2.3. A $10 \mathrm{~g}$ sample of fresh mungo bean sprouts was aseptically weighed into six replicates of $90 \mathrm{ml}$ of each EE-both and BPW and mixed in a Stomacher for $60 \mathrm{sec}$ at medium intensity. One additional sample served as an uninoculated 
control. $\mathrm{CaCO}_{3}$ containing E. coli $1970-08$ was diluted in $0.9 \%$ saline to obtain three different levels. Mean inoculum for low spiking level: $10 \mathrm{cfu}$ (minimum 1 cfu, maximum $30 \mathrm{cfu}$ ), medium spiking level $140 \mathrm{cfu}$ (minimum $10 \mathrm{cfu}$, maximum $390 \mathrm{cfu}$ ), high spiking level $1200 \mathrm{cfu}$ (minimum $230 \mathrm{cfu}$, maximum $3000 \mathrm{cfu}$ ). The sprouts were spiked with $1 \mathrm{ml}$ of each of the three inocula and then incubated at $37^{\circ} \mathrm{C}$ and $42^{\circ} \mathrm{C}$ for $24 \mathrm{~h}$. After 4, 8, 16, 20 and $24 \mathrm{~h}, 0.1 \mathrm{ml}$ was removed from the enrichment, diluted in $0.9 \%$ saline and plated on Rapid' E. coli 2 Agar (Biorad, Marnes la Coquette, France) containing $30 \mathrm{mg} / 1$ Tetracycline. All experiments were performed in triplicate.

\section{Enumeration of sprout background flora}

The sprout background flora was enumerated during incubation in BPW, EE-broth, BGB- broth and mTSB + Novobiocin. A $10 \mathrm{~g}$ sample of fresh mungo bean sprouts was diluted $1 / 10$ with one of the media mentioned above, mixed in a Stomacher for 60 sec at medium intensity and incubated both at $37^{\circ} \mathrm{C}$ and $42^{\circ} \mathrm{C}$ for $24 \mathrm{~h}$. After 4,8 , 16,20 and $24 \mathrm{~h}$ of incubation, $0.1 \mathrm{ml}$ samples were removed, diluted in $0.9 \%$ saline and plated on TSA plates. The agar plates were incubated at $37^{\circ} \mathrm{C}$ for $24 \mathrm{~h}$ and total viable counts were determined in triplicate. Some of the most abundant colonies on the plates were identified using Gram-staining and a biochemical test gallery (ID32E, Biomerieux, Geneva, Switzerland).

\section{Evaluation of a possible additional selective supplement}

Potassium-Tellurite (Sigma-Aldrich) was added to BPW, BPW $+0.5 \mathrm{~g} / \mathrm{l}$ Glucose, EE-broth, BGB-broth, TSB and "MacConkey-broth (20 g/l Bacteriological Peptone (Becton, Dickinson and Company), $10 \mathrm{~g} / 1$ Lactose (Merck), $5 \mathrm{~g} / 1$ Bile salts (Oxoid), $5 \mathrm{~g} / 1$ Sodium chloride, (Sigma-Aldrich)) in a concentration of $2.5 \mu \mathrm{g} / \mathrm{ml}$. The concentration of tellurite was chosen based on the concentration applied in the commercially available agar medium CT-SMAC (13). A $10 \mathrm{~g}$ sample of mungo bean sprouts was diluted $1 / 10$ with the above described media and incubated at $37^{\circ} \mathrm{C}$ for $24 \mathrm{~h}$. The final cell count was determined on TSA plates. The minimal inhibitory concentration (MIC) of tellurite for five STEC strains was determined in BPW, BPW $+0.5 \mathrm{~g} / 1$ Glucose and in TSB with a broth dilution method according to a protocol of EUCAST (14). The experiments were performed in duplicate.

\section{Analysis of the microbiome of mungo bean sprouts}

Fresh mungo bean sprouts originating from the same batch were purchased from a Swiss supermarket and used for microbial profiling of the phyllosphere bacteria. 10 
g portions of sprouts diluted $1 / 10$ in $0.9 \%$ saline were homogenized in a Stomacher to serve as the non-enriched $(\mathrm{t}=0)$ sample. In addition, $10 \mathrm{~g}$ portions from the same batch diluted 1/10 in either EE-broth or BPW were similarly homogenized in a Stomacher and incubated at $37^{\circ} \mathrm{C}$ and $42^{\circ} \mathrm{C}$. Samples were collected after $16 \mathrm{~h}$ of incubation. These experiments were performed independently on three occasions.

\section{DNA isolation:}

Two ml aliquots from the non-enriched and enriched homogenized sprout suspensions were briefly centrifuged (10 $\mathrm{min}$ at $3200 \mathrm{~g}$ ) to remove sprouts particles and debris. Bacteria community DNA from the non-enriched and enriched sprout suspensions was isolated from the enrichment using the NucleoSpin ${ }^{\circledR}$ Soil kit (Macherey Nagel, Düren, Germany) according to the manufacturers instructions.

\section{Microbial Profiling with Illumina HiSeq2500:}

Sequencing was performed at GATC (Konstanz, Germany) based on their 300bp paired-end protocol (https://www.gatc-biotech.com/de/produkte/inviewapplikationen/inview microbiome.html). Briefly, 471-bp fragment of the variable regions V1-V3 of the 16S rRNA gene in the samples were amplified using the primer pair 27F (AGAGTTTGATCCTGGCTCAG) and 534R (ATTACCGCGGCTGCTGG) and subjected to Illumina sequencing. The resulting 16S rRNA amplicons were quality filtered and merged based on overlapping bases using FLASh with maximum density of 0.25 (15). The aligned merged filtered sequences were clustered into operational taxonomic units (OTUs) defined by $97 \%$ similarity. The sequence libraries were further characterized to determine the degrees of diversity and similarity of the microbial communities present in the different samples. The Shannon diversity indexes for the samples were calculated using the R package Vegan (http://cc.oulu. $\mathrm{fi} /$ jarioksa/softhelp/vegan/htl/diversity.html). Venn diagrams were constructed using Venny (http://bioinfogp.cnb.csic.es/tools/venny/index.html). A Wilcoxon signed-rank test was performed with IBM SPSS Statistics to test if the bacterial richness was significantly influenced by enrichment medium and incubation temperature. 


\section{Results and Discussion}

\section{Growth experiments}

Growth of STEC strains in the different enrichment media

The growth curves of the five STEC strains in the four different enrichment media at $37^{\circ} \mathrm{C}$ and $42^{\circ} \mathrm{C}$ are shown in Figure 1. In EE-broth, four strains reached cell counts of $7.5 \log \mathrm{cfu} / \mathrm{ml}$ after $24 \mathrm{~h}$, while strain 943-07 reached $8.9 \log \mathrm{cfu} / \mathrm{ml}$. Growth at $42^{\circ} \mathrm{C}$ was similar, with strains growing to levels reaching from 6.5 to $8.0 \mathrm{log} \mathrm{cfu} / \mathrm{ml}$. In BGB-broth cell numbers of all strains remained under $6 \log \mathrm{cfu} / \mathrm{ml}$ until $8 \mathrm{~h}$. After 24 $\mathrm{h}$ all strains reached a density of between 7.6 and $8.4 \mathrm{log} \mathrm{cfu} / \mathrm{ml}$. At $42^{\circ} \mathrm{C}$ strain 1146 05 only grew to $5.3 \mathrm{log} \mathrm{cfu} / \mathrm{ml}$. In both EE-broth and BGB-broth, variation between strains and replicates was small. In mTSB + Novobiocin, variances in growth of up to 4 $\log \mathrm{cfu} / \mathrm{ml}$ were noticed. At both $37^{\circ} \mathrm{C}$ and $42^{\circ} \mathrm{C}$ strain N10-635 only reached 4.7 and $4.0 \log \mathrm{cfu} / \mathrm{ml}$, respectively. Strain $943-07$ reached $4.0 \log \mathrm{cfu} / \mathrm{ml}$ at $37^{\circ} \mathrm{C}$ but grew to $7.2 \log \mathrm{cfu} / \mathrm{ml}$ at $42^{\circ} \mathrm{C}$. On the other hand, strain $1970-08$ grew to colony counts of approximately $7.5 \log \mathrm{cfu} / \mathrm{ml}$ and 8.0 at $37^{\circ} \mathrm{C}$ and $42^{\circ} \mathrm{C}$, respectively. Whereas at $37^{\circ} \mathrm{C}$ growth of all strains was comparable until $8 \mathrm{~h}$ of incubation in mTSB + Novobiocin; the variation between strains was at about $2 \log \mathrm{cfu} / \mathrm{ml}$ already after $4 \mathrm{~h}$ when incubated at $42^{\circ} \mathrm{C}$. In BPW, all five strains showed mean final values of $8.2 \log \mathrm{cfu} / \mathrm{ml}$ with very little standard deviation at $37^{\circ} \mathrm{C}$. However at earlier stages of incubation, standard deviation between experiments was considerably larger. At $42^{\circ} \mathrm{C}$ final cell counts in BPW after $24 \mathrm{~h}$ incubation is almost identical for all strains. Growth of STEC without stress application in the different enrichment media was comparable with generally less variation between strains and experiments except for growth in mTSB + Novobiocin (data not shown).

For the enrichment of STEC in food products, several media are recommended, dependent on the food matrix and serotypes. Four of these media were examined in regards to their ability to promote the growth of pure cultures of STEC from different non-O157 serogroups. In all media, cells of most tested strains grew to satisfying densities of approximately $8 \mathrm{log} \mathrm{cfu} / \mathrm{ml}$ after $24 \mathrm{~h}$ in stressed and unstressed state. In BPW, which is the recommended enrichment medium for stressed STEC in sprouted seeds (ISO TS 13136:2012) good growth of all tested strains was expected. The recommended enrichment time is $18 \mathrm{~h}$ to $24 \mathrm{~h}$. The medium does not contain any selective agents and is designed for the enrichment of different pathogens in horizontal methods, thus in various food products. EE-broth and BGB-broth have a similar composition and were developed for the enrichment of Enterobacteriaceae from foods. The concentration of selective ingredients such as bile salts did not influence growth of stressed cells in a negative way. When incubated in mTSB + Novobiocin, 
variation between STEC strains was up to $4 \log \mathrm{cfu} / \mathrm{ml}$ and two strains showed notably decreased final colony counts. This observation was more pronounced at $42^{\circ} \mathrm{C}$ than at $37^{\circ} \mathrm{C}$. It is known that stressed cells can be more susceptible to selective compounds (16). However, since only two strains did not grow well in mTSB + Novobiocin and this observation was made also in unstressed cells, this was rather caused by a general Novobiocin susceptibility of these strains. Vimont et al. (17) showed that MICs for Novobiocin of non-O157 STEC varied greatly and were significantly lower than for $E$. coli O157. They advised not to use enrichment broths supplemented with Novobiocin to avoid possible false negative results. Our results confirmed their observation.

A
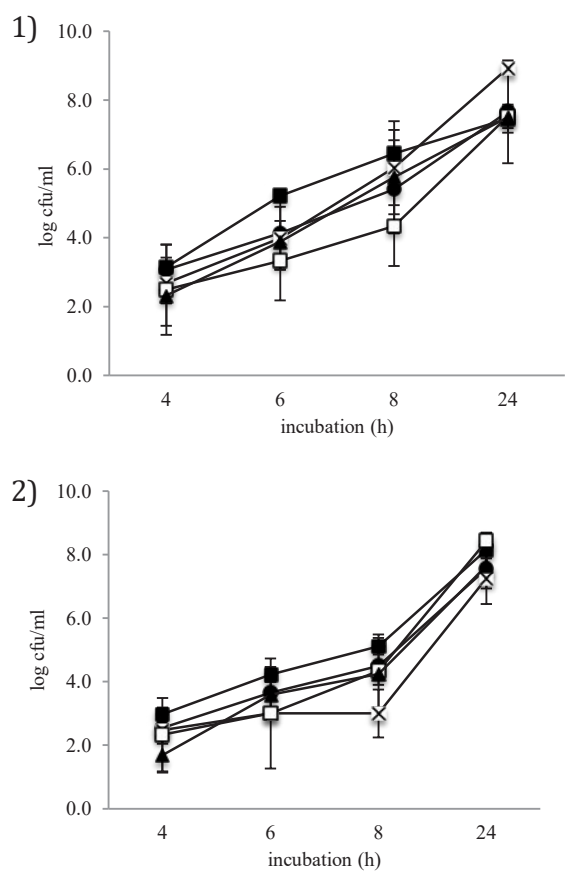

3) 10.0

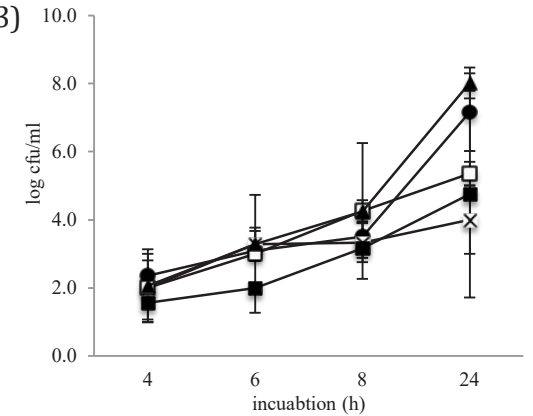

B
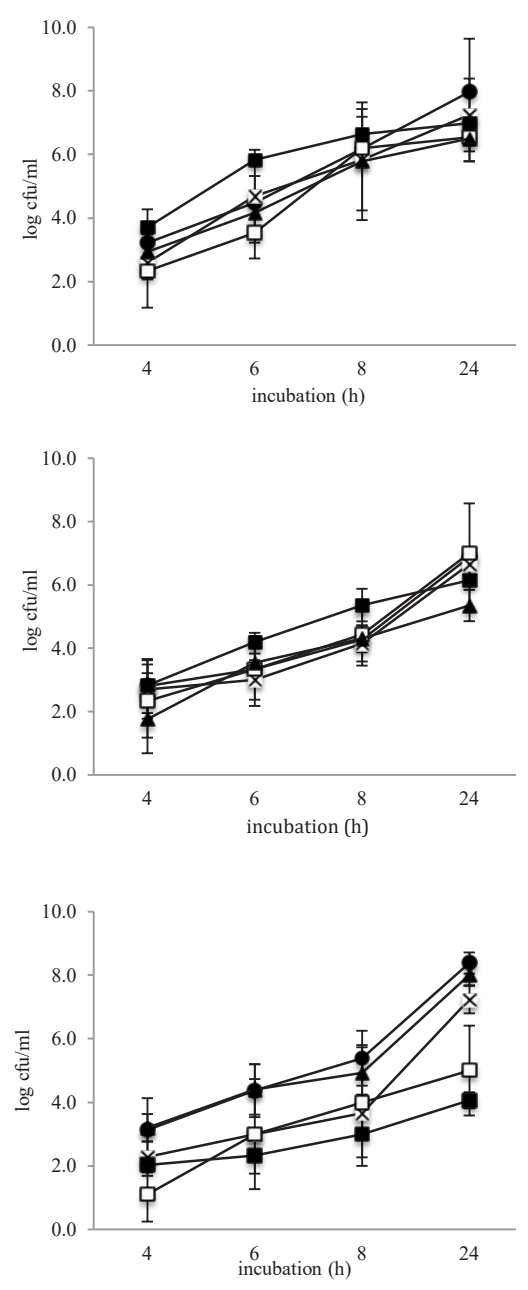

Figure 1. Growth of desiccation stressed STEC strains 1970-08 (•), 128-08(口), 1146-05( $\mathbf{\Delta}$ ), 943-07 ( $\times$ ), N10 625 (๘), EE-broth (1), BGB-broth (2), mTSB + Novobiocin (3) and BPW (4) at $37^{\circ} \mathrm{C}$ (column A) and at $42^{\circ} \mathrm{C}$ (column B). Points are means of triplicate experiments with standard deviations. 


\section{Growth of the sprout background flora in different enrichment media}

The total aerobic viable count of fresh mungo bean sprouts was determined in EEbroth, BGB-broth, mTSB + Novobiocin and BPW at both $37^{\circ} \mathrm{C}$ and $42^{\circ} \mathrm{C} . \log \mathrm{cfu} / \mathrm{ml}$ are shown in Figure 2. Final cell counts of sprouts were not influenced by either media or by the incubation temperature. However, at both $37^{\circ} \mathrm{C}$ and $42^{\circ} \mathrm{C}$ cells grew fastest in BPW. Initial cell counts were as high as $6.9 \log \mathrm{cfu} / \mathrm{ml}$ and reached 10.0 $\log \mathrm{cfu} / \mathrm{ml}$ at $37^{\circ} \mathrm{C}$ and $9.8 \log \mathrm{cfu} / \mathrm{ml}$ at $42^{\circ} \mathrm{C}$. Klebsiella spp., Citrobacter spp. and Pantoea spp. were among the flora recovered from the samples. As members of the coliform group, they are apparently affected by the selective compounds present in the in the enrichment media.
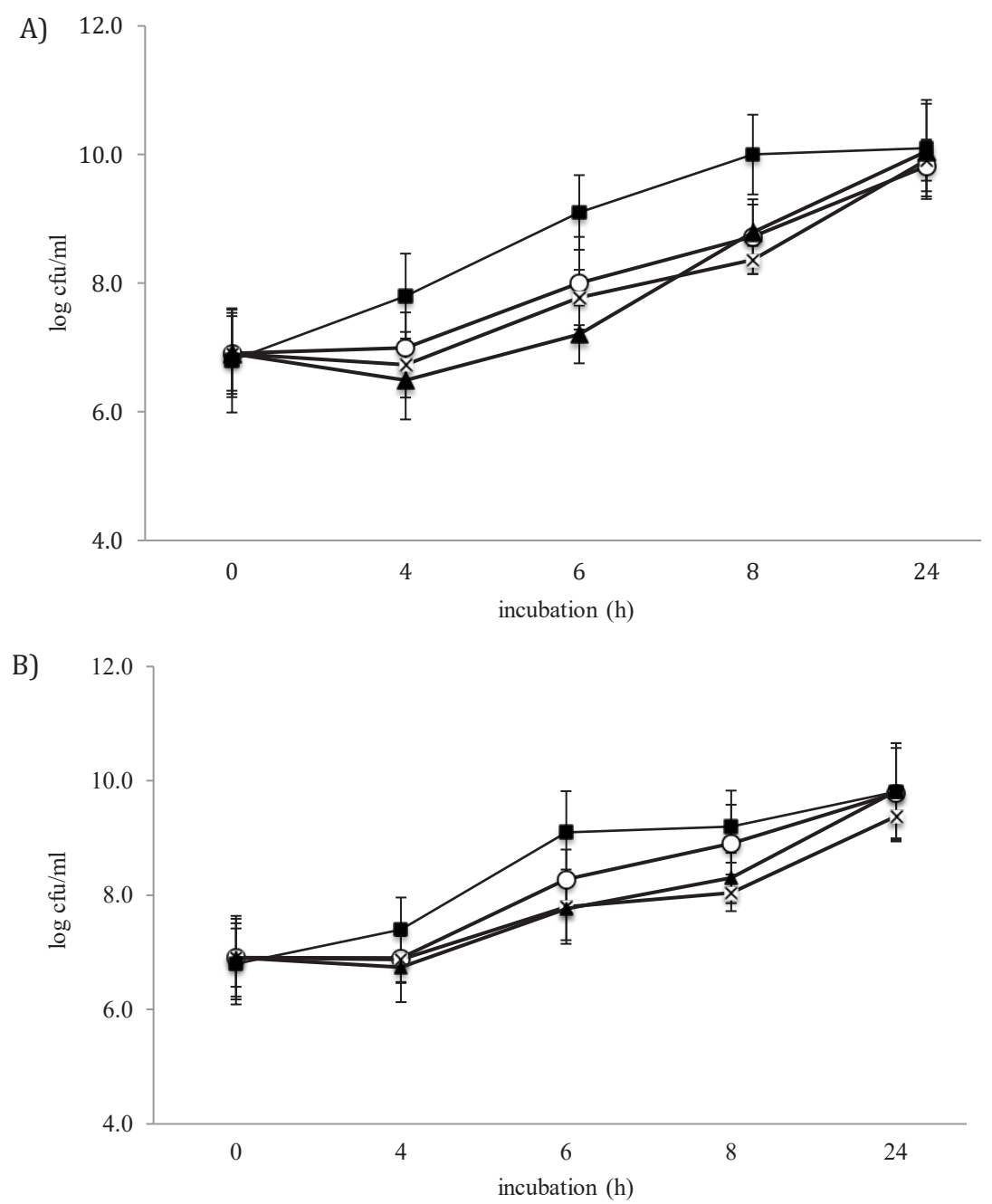

Figure 2. Growth of sprout background flora in EE broth (०), BGB ( $\times$ ), mTSB + Novobiocin $(\boldsymbol{\Delta})$, BPW (a) at $37^{\circ} \mathrm{C}(\mathrm{A})$ and $42^{\circ} \mathrm{C}(\mathrm{B})$. 


\section{Growth of STEC spiked into sprouts at different levels}

Fresh mungo bean sprouts mixed with enrichment broth were spiked with dry stressed tetracycline resistant $E$. coli 1970-08 at three different levels and cell counts of the target strain were determined. During the initial $4 \mathrm{~h}$ of incubation the cell counts of the target strain remained under the detection limit for all samples (see Figure 3). At $37^{\circ} \mathrm{C}$ EE-broth showed mostly higher cell counts than BPW. At $16 \mathrm{~h}$ of incubation cell counts of the low and medium spiking level reached values of about $5 \log \mathrm{cfu} / \mathrm{ml}$ in EE-broth whereas in BPW the cell counts reached $3.5 \log \mathrm{cfu} / \mathrm{ml}$ for the low spiked sample. From $16 \mathrm{~h}$ to $24 \mathrm{~h}$ cell counts remained relatively stable. At the end of incubation, cell counts of all samples are between 4.0 and $5.4 \log \mathrm{cfu} /$ $\mathrm{ml}$. At $42^{\circ} \mathrm{C}$, the target cells showed higher cell counts after $4 \mathrm{~h}$, which suggests a shorter lag time compared to incubation at $37^{\circ} \mathrm{C}$. However, at $16 \mathrm{~h}$ cell counts are at similar levels in both incubation temperatures. After $24 \mathrm{~h}$ there is less difference
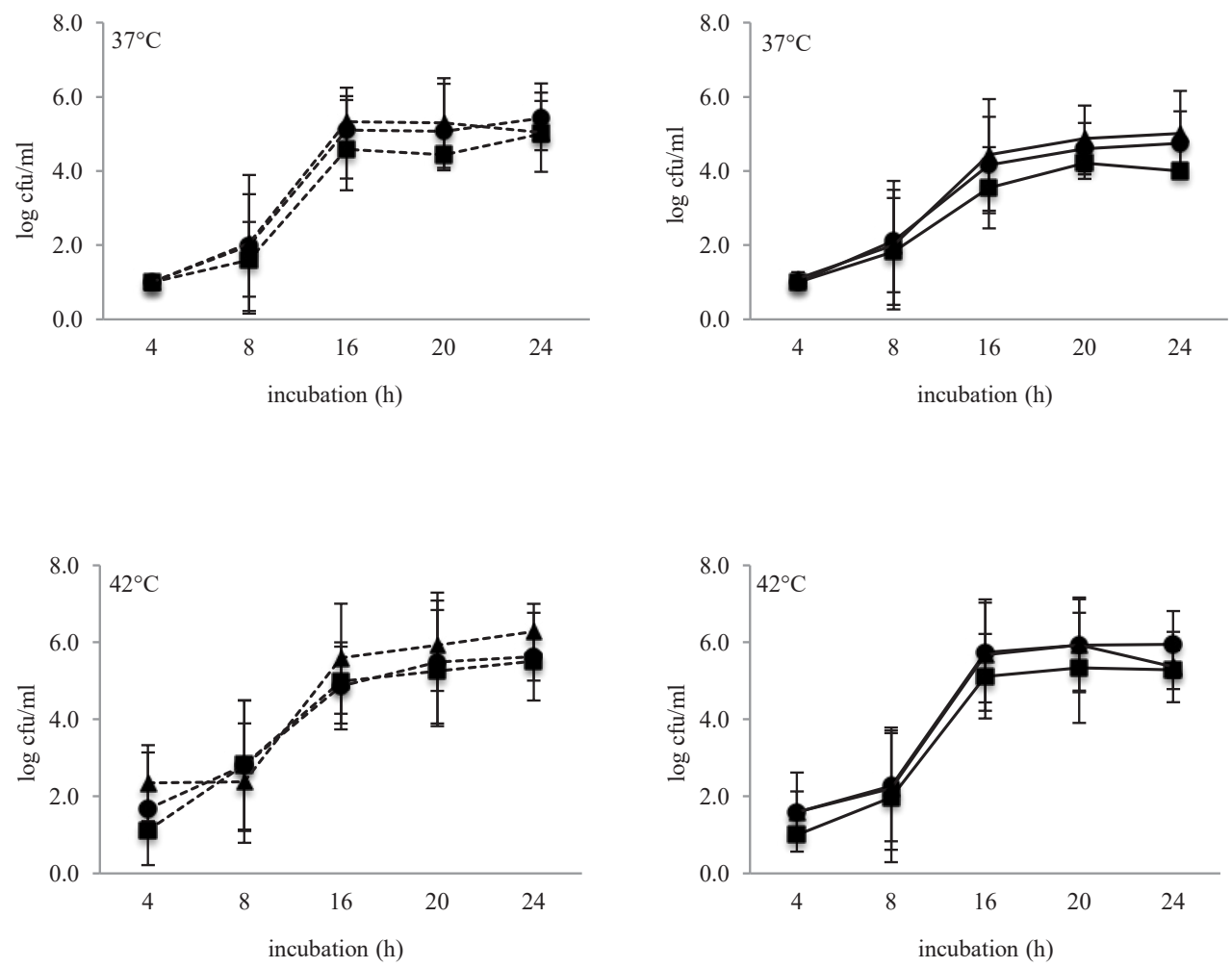

Figure 3. Growth of STEC 1970-08 spiked into sprout samples at three different contamination levels. Low spiking level (mean $10 \mathrm{cfu}$ ) (®), medium spiking level (mean $140 \mathrm{cfu})(\bullet)$, high spiking level (mean $1200 \mathrm{cfu})(\mathbf{\Lambda})$ in EE broth (dotted lines) and BPW (solid lines). Growth was determined at $37^{\circ} \mathrm{C}$ and $42^{\circ} \mathrm{C}$. 
between media and spiking levels at $42^{\circ} \mathrm{C}$. In all samples cell counts of 5.3 to $6.3 \log$ $\mathrm{cfu} / \mathrm{ml}$ were reached. Data from literature suggest that in the case of contamination, levels of STEC are usually very low (1) and the number of STEC cells required to cause an infection is reported to be $<100 \mathrm{cfu}$ (18). Therefore, trials evaluating the performance of STEC detection methods in this matrix should be performed with very low spiking levels. Our results showed that samples contaminated with low levels of pathogenic bacteria have lower cell counts after enrichment and therefore have a higher risk of a false negative result. The main problem in STEC detection from sprouts is the proportion of pathogens and the background flora. With low contamination levels, this imbalance is even more pronounced. Other researchers found that incubation at $42^{\circ} \mathrm{C}$ improved isolation of $E$. coli $\mathrm{O} 157$ in many cases (7, $19,20)$. This study demonstrated that at $42^{\circ} \mathrm{C}$ also non-O157, even in a stressed state, showed less variation between spiking levels and enrichment media. STEC incubated in EE-broth grew to slightly higher densities when compared to BPW. Since the counts of the background flora as well as the growth of the pure culture was very similar in the two media, this fact cannot be fully explained. Data on the dynamics of the flora during incubation might deliver more insight.

\section{Trials with supplementation of Tellurite}

Potassium-Tellurite was assessed as a possible supplement to increase the selectivity of enrichment media and thereby improve the isolation of STEC from sprouts. Since the evaluated STEC strains did not grow in BPW + tellurite during the first experiments, the minimal inhibitory concentration of tellurite on five STEC strains was determined. In BPW, concentrations of tellurite as low as $0.75 \mu \mathrm{g} / \mathrm{ml}$ were enough to inhibit growth of all of the five strains. In TSB a MIC of $2.5 \mu \mathrm{g} / \mathrm{ml}$ was determined for strains 1970-08, 94307 and 128-03. MICs of $5 \mu \mathrm{g} / \mathrm{ml}$ and $1.25 \mu \mathrm{g} / \mathrm{ml}$ were established for strains N10 935 and 114605, respectively. In BPW supplemented with $0.5 \mathrm{~g} / 1$ Glucose the MIC for tellurite was $2.5 \mu \mathrm{g} / \mathrm{ml}$ for strain 12803 and 1.25 $\mu \mathrm{g} / \mathrm{ml}$ for all other strains. Tellurite has been applied for many decades in the detection of pathogens such as Corynebacterium diphtheriae, Staphylococcus aureus and Vibrio cholera (13) before it was employed in the detection of E. coli 0157. In cefixime-tellurite sorbitol MacConkey agar (CT-SMAC), tellurite is used for the differentiation of from other non-pathogenic E. coli. However, tellurite sensitivity of STEC 0157 and non-O157 is known (21) and the tellurite sensitivity of the 0104 strain causing the severe German outbreak in 2011 was reported (22). Growth of the sprout background flora in media supplemented with $2.5 \mu \mathrm{g} / \mathrm{ml}$ tellurite was not influenced (data not shown). Since the retardation of the growth of the background flora is the main objective of a possible selective supplement and the sensitivity of 
potential contaminants cannot be excluded, the experiments with tellurite were not pursued. Poor detection of $E$. coli $\mathrm{O} 157$ from sprouts extracts with TSB supplemented with cefixime, potassium tellurite and vancomycin were already described by Hara-Kudo et al. (20). However, from their results it is not clear whether failure of detection was caused by tellurite or any of the other supplements.

\section{Microbiome analysis of mungo bean sprouts}

Sequencing results and bacterial community diversity on mungo bean sprouts

Out of the 15 mungo bean sprout samples sequenced, $388516 \mathrm{~S}$ rRNA sequence reads were obtained and assigned to 2382 OTUs based on $>97 \%$ sequence similarity. The number of different species in non-enriched and BPW and EE broth enriched sprout microbiomes expressed as species richness based on the number of species OTUs is shown in Figure 4A. Species richness is the sole count of species, whereas the species diversity consists of both the richness and the evenness. Species evenness quantifies the equality of the species abundances. The species richness of the microbiome on sprouts was reduced following BPW and EE broth enrichment protocols at both $37^{\circ} \mathrm{C}$ and $42^{\circ} \mathrm{C}$. In BPW enriched samples the mean number of microbial species OTUs decreased from 75 in non-enriched samples to 61 and 56 in samples enriched at $37^{\circ} \mathrm{C}$ and $42^{\circ} \mathrm{C}$, respectively. While in EE-broth enriched sprouts the microbiome species richness decreased to 28 and 36 OTUs at $37^{\circ} \mathrm{C}$ and $42^{\circ} \mathrm{C}$, respectively. The tendency of a decrease in species richness is clear even though due to large standard deviations the differences were not statistically significant. The fact that species richness is lower in EE-broth when compared to BPW shows that enrichment in EEbroth does select for certain species in the sample. The incubation temperature did not have an effect on the species richness in BPW. In EE-broth, species richness at $37^{\circ} \mathrm{C}$ is lower compared to $42^{\circ} \mathrm{C}$, which could point to an even stronger selection at this incubation temperature. Species diversity of the sprout microbial community was further assessed based on the Shannon diversity index, which is a combined measure of community richness and evenness. Results shown in Figure 4B show that there is a tendency of species richness and evenness to decrease in BPW and EE enriched sprout microbiomes although due to high levels of variability these differences were not statistically significant. 

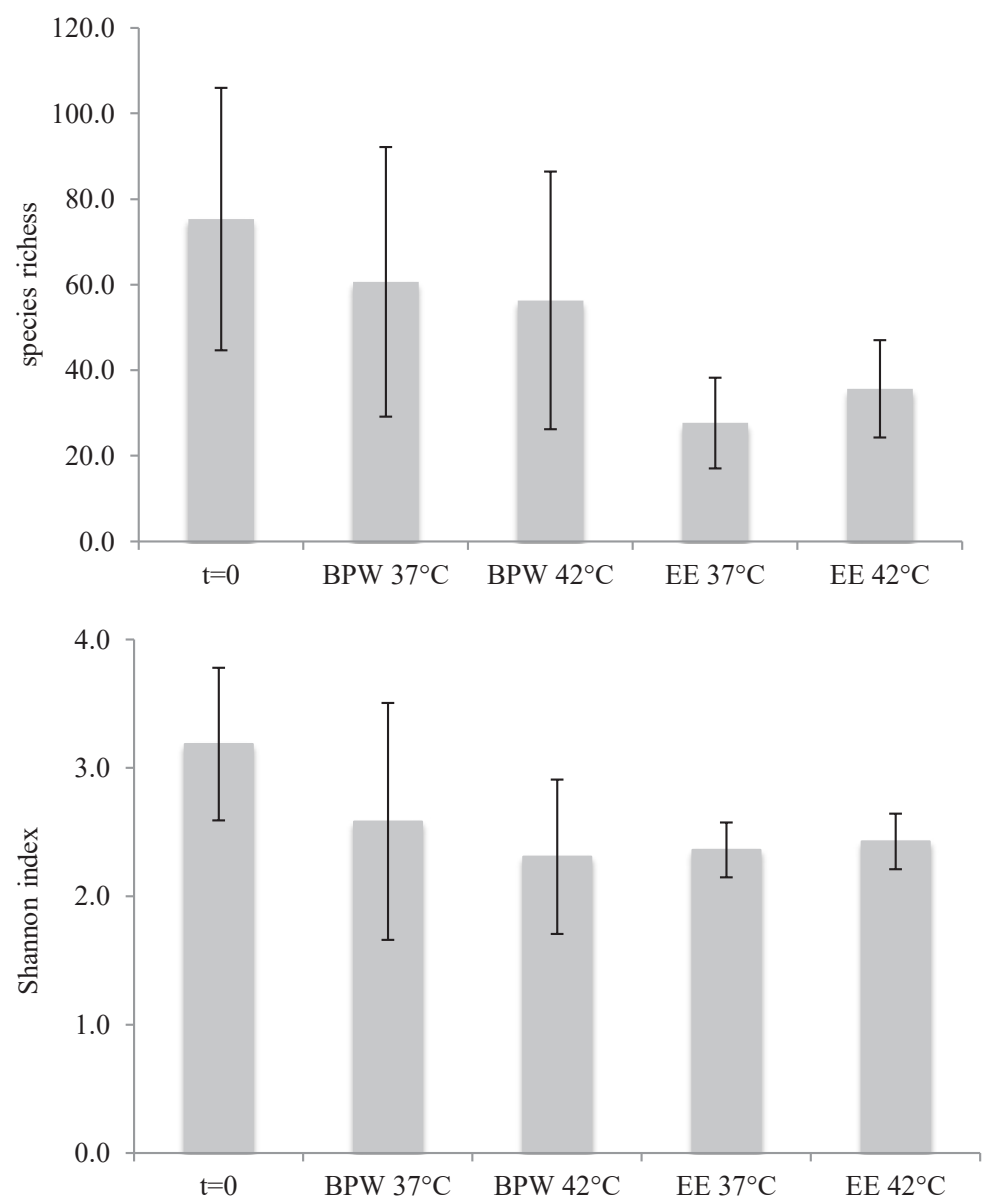

Figure 4. Species richness based on the number of species OTUs observed (A) and the Shannon diversity index (B) on sprout samples prior $(t=0)$ and after enrichment $(t=16)$ in both enrichment media and for both incubation temperatures with standard deviation.

Sprouts bacterial community composition and impact of enrichment media and temperature at phylum level

Results of phylum level distribution and abundance within the non-enriched and BPW and EE-broth enriched sprout microbiomes at $37^{\circ} \mathrm{C}$ and $42^{\circ} \mathrm{C}$ are shown in Figure 5 and Table S1. Of the 4 phyla present on sprouts prior to enrichment, 3 phyla (Proteobacteria, Bacteroidetes, Firmicutes) remained after enrichment in BPW, whereas only 2 phyla (Proteobacteria, Bacteriodetes) remained after EEbroth enrichment. Prior to enrichment the distribution of phyla was the following: Proteobacteria (90.4\%), Bacteroidetes (8.8\%), Firmicutes (0.6\%). Post enrichment in BPW at $37^{\circ} \mathrm{C}$ the distribution of the phyla was Proteobacteria (55.9\%), Firmicutes 
(42.6\%) and Bacteroidetes (1.5\%). In sprouts enriched in $\mathrm{BPW}$ at $42^{\circ} \mathrm{C}$ for $16 \mathrm{~h}$, Proteobacteria (71.9\%) were still the dominant phyla, the abundance of Firmicutes (26.2\%) increased and Bacteroidetes (1.9\%) decreased compared to the nonenriched sprout microbiome. After EE-broth enrichment the dominant phyla were Proteobacteria (99.5\%), Bacteroidetes (0.5\%) and Firmicutes (0.07\%). At $42^{\circ} \mathrm{C}$ in EEbroth the distribution was the following: Proteobacteria (99.5\%), Bacteroidetes (0.4\%), Firmicutes $(0.05 \%)$. Proteobacteria constitutes the predominating phylum of bacterial inhabitants of various plant species (23) and was shown to be the most abundant phylum on alfalfa sprouts (11). During the enrichment in EE-broth Proteobacteria remained the dominant phylum and its relative abundance even increased from 90.4\% to 99.5\%, whereas the Bacteroidetes and Firmicutes phyla decreased during the time of incubation and almost disappeared. The formulation of EE-broth is designed for the selective enrichment of Enterobacteriaceae, which belong to the Proteobacteria phylum. As expected Gram-positive bacteria were suppressed by in this media. The composition of the medium does apparently not only lead to slower growth of Grampositive bacteria but also of Gram-negative representatives of the Bacteroidetes. In BPW, the relative abundance of Firmicutes increased during incubation when at the same time the ratio of Bacteroidetes decreased and almost disappeared. This shows that in an unselective enrichment broth like BPW, Gram-positive genera belonging to the Firmicutes phylum can multiply. The fact that the proportion of Bacteroidetes is decreasing in both media might be an indication that these are not very good competitors or do not grow as fast in the investigated ecosystem. The incubation temperature did not have an influence on the phylum distribution in EE-broth. However, enrichment in BPW at $37^{\circ} \mathrm{C}$ favoured the multiplication of Firmicutes.

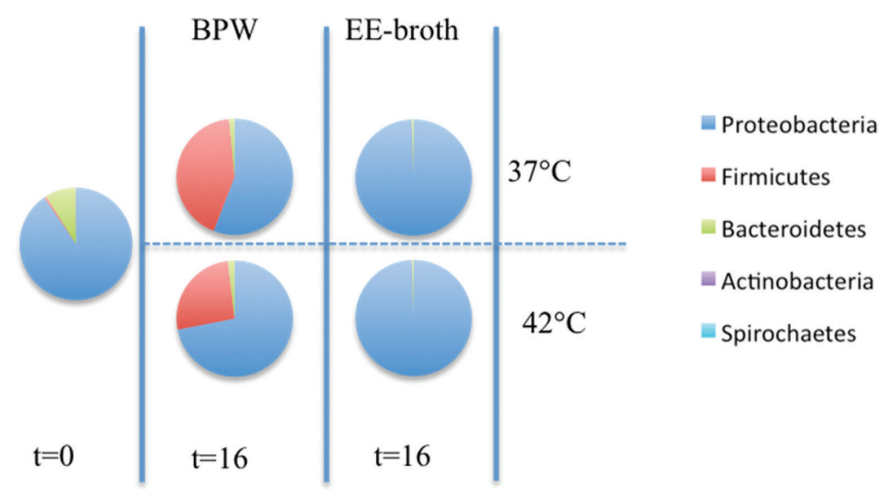

Figure 5. Phylum level OTU distributions observed in sprout microbiomes before $(\mathrm{t}=0)$ and after $16 \mathrm{~h}$ $(\mathrm{t}=16)$ of enrichment in BPW and EE-broth at $37^{\circ} \mathrm{C}$ and $42^{\circ} \mathrm{C}$. 
Sprouts bacterial community composition and impact of enrichment media and temperature at genus level

A list of the genera that were detected across all samples is provided in Table S2. Overall 146 genera were detected in the non-enriched sprout microbiome. Meanwhile there were 51 and 41 genera detected after the BPW enrichment protocol at $37^{\circ} \mathrm{C}$ and $42^{\circ} \mathrm{C}$, respectively. Twenty-four and 38 genera were detected following sprout enrichment in EE broth at $37^{\circ} \mathrm{C}$ and $42^{\circ} \mathrm{C}$, respectively. Overall the number of genera found on the mungo bean sprout microbiome here is comparable to the values described for alfalfa sprouts microbiome by Loui et al. (11) but differs considerably from data published by Wiken Dees et al. (24), who found 472 genera on leafy greens (rocket salad and lettuce) from Norway. The deviation is very probably based on the different production of leafy greens and sprouted seeds. The leafy green samples were collected from the field and might thus show a higher microbial diversity than sprouts that are usually grown soil free. Since the majority of the bacteria found on sprouted seeds are supposed to originate from the dry seeds, a possible reason for the limited number of genera could be the low $\mathrm{a}_{\mathrm{w}}$ on these seeds. However, during sprouting the microflora composition does presumably experience a large shift. To assess the impact of enrichment media the core genera of the sprout microbial community detected after enrichment in EE-broth and BPW at $37^{\circ} \mathrm{C}$ and $42^{\circ} \mathrm{C}$ were compared. The distribution and relative abundance of bacterial genera in non-enriched and BPW and EE-broth enriched sprout microbiomes is shown in Figure 6A. The three most abundant genera in the non-enriched sprout microbiome were Janthinobacterium (22.0\%), Pseudomonas (14.4\%) and Enterobacter (11.1\%). Post enrichment in BPW at $37^{\circ} \mathrm{C}$, Bacillus (18.9\%), Citrobacter $(17.0 \%)$ and Enterobacter (8.4\%) were the most dominant genera. In samples enriched at $42^{\circ} \mathrm{C}$, Bacillus (22.8\%), Klebsiella (20.7\%) and Pseudomonas (8.3\%) dominated. In EE-broth enriched sprouts Klebsiella (28.5\%), Cronobacter (27.6\%) Enterobacter (22.9\%) and were the most abundant genera at both $37^{\circ} \mathrm{C}$ and $42^{\circ} \mathrm{C}$. When the different time points are compared, the shift of bacterial genera in both enrichment media is obvious. Janthinobacterium, which represents the most abundant genus on non-enriched sprouts decrease in proportion to quantity on both BPW and EE broth, probably due to the aerobic conditions applied during enrichment. Event though Bacillus is not one of the 20 most abundant genera on non-enriched sprouts this genus appears to have a growth advantage in BPW. The question why at $37^{\circ} \mathrm{C}$ Citrobacter constituted $17 \%$ of the community whereas at $42^{\circ} \mathrm{C}$ Klebsiella represented the second most abundant genus even though both organisms share the optimal growth temperature of $37^{\circ} \mathrm{C}$ was not answered. Enrichment temperature seemed to have a smaller impact on genus distribution in EE-broth, probably due to the general tolerance for higher incubation temperatures of Enterobacteriaceae. 
Venn diagrams in figure 6B illustrate the distribution of unique and shared genera non-enriched and BPW and EE broth enriched sprout microbiomes. The greatest number of shared genera was seen in $\mathrm{BPW}$ at $37^{\circ} \mathrm{C}$, meaning that the composition of the sprout microbiome changed the least during this enrichment. In EE-broth, on the other hand, the bacterial community was strongly influenced by the medium, which is mostly visible in the reduction of genera. When the number of shared genera is considered, the enrichment in EE-broth at $37^{\circ} \mathrm{C}$ seems to differ from the other conditions.

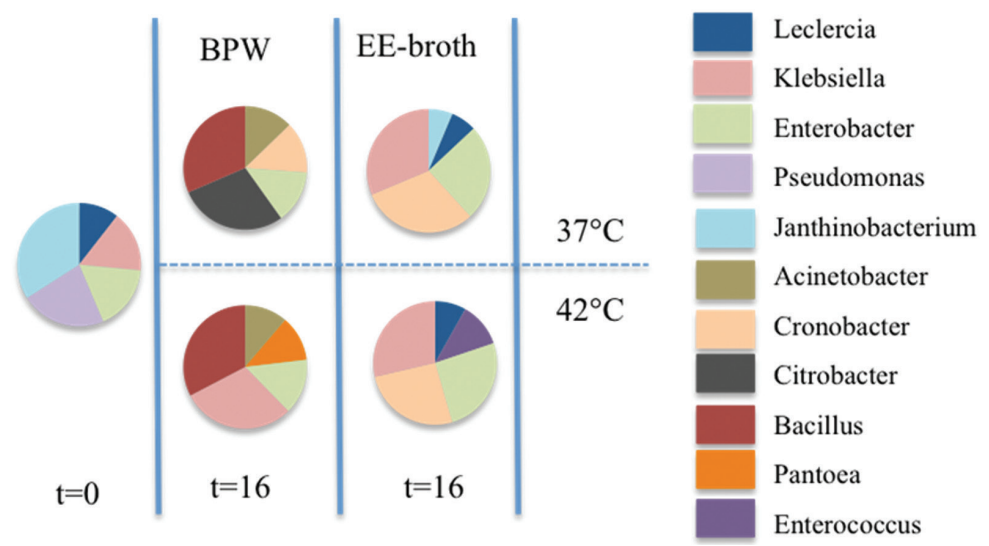

Figure 6a. OTU distribution of predominant genera ( $\geq 5 \%$ relative abundance) in sprout microbiomes prior $(\mathrm{t}=0)$ and after $16 \mathrm{~h}(\mathrm{t}=16 \mathrm{~h})$ of in both enrichment media $(\mathrm{BPW}$ and $\mathrm{EE})$ and incubation $\left(37^{\circ} \mathrm{C}\right.$ and $42^{\circ} \mathrm{C}$ ) temperatures.

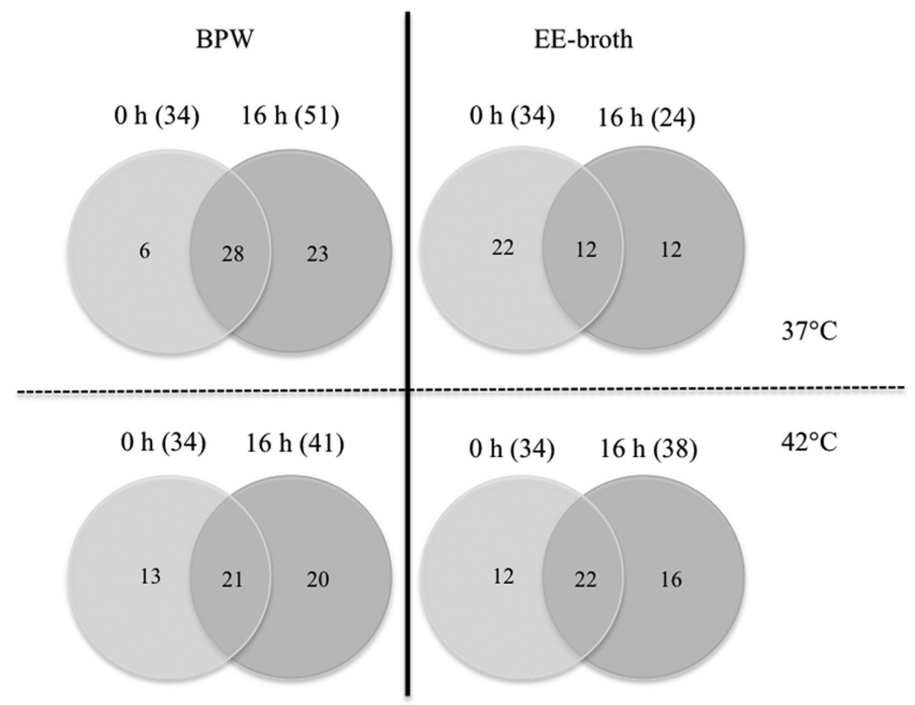

Figure 6b. Venn diagrams showing the distribution of unique and shared genera between mungo bean sprout microbial communities before $(0 \mathrm{~h})$ and after enrichment $(16 \mathrm{~h})$ in $\mathrm{BPW}$ at $37^{\circ} \mathrm{C}, \mathrm{BPW}$ at $42^{\circ} \mathrm{C}$, EE-broth at $37^{\circ} \mathrm{C}$ and EE-broth at $42^{\circ} \mathrm{C}$. 
One factor that probably has an influence on both community richness and diversity is the storage of the sprout samples at refrigeration temperatures in between experiments. On the other hand, since sprouted seeds are distributed and sold at $4^{\circ} \mathrm{C}$, the microflora might be adapted to these temperatures.

\section{Implications for the detection of STEC}

In this study we examined the development of the bacterial composition of mungo bean sprouts during BPW and EE broth enrichment. From cultural based studies the dominance of Enterobacteriaceae was already suggested (25). This was confirmed by the microbiome analysis. We also found that the phyllosphere of sprouted seeds can be compared to those of leafy greens in view of community composition even though the cultivation and production differ considerably. For the detection of STEC in sprouts, the great divergence in quantity of the target organism and the background flora as well as the similarity of both are the main problems. Our study showed that the enrichment in EE-broth does on the one hand increase growth of stressed STEC, but on the other hand also strongly favours the growth of the closely related competitive flora. Since there is only a marginal change in the microbiome in the course of the enrichment, the focus should be on genera that are already present in high numbers at the beginning of the enrichment. If the growth of these could be suppressed, E. coli possibly present might have larger chance to reach a detectable number. The genus Janthinobacter was one of the most abundant found in the mungo bean sprouts before enrichment. Janthinobacter is a strict aerobe (26), which distinguishes this genus from Escherichia coli, a facultative anaerobe. An enrichment in an anaerobe environment could present a possibility to selectively promote the growth of $E$. coli by limiting the growth of the main competitor. Williams et al. (23) showed that the microflora of romaine lettuce differed between samples that were inoculated with E. coli O157:H7 and those that were not. Therefore, it cannot be excluded that the sprouts microbiota might change in case of a contamination.

\section{Conclusions}

The current detection method for the detection of STEC from sprouts was shown not to reliably detect low levels of STEC (12). Previous attempts to improve the enrichment and detection were mainly aiming at E. coli $\mathrm{O} 157$ and are therefore not applicable for the most prevalent other serotypes. Cultural examination and microbiome analysis showed that the background flora of sprouts is dominated by coliforms, which complicates the detection of pathogens. In this study, we showed 
that media used for the enrichment of STEC in sprouts did all support the growth of pure cultures in a comparable way. Only mTSB + Novobiocin caused visible strain variation. Negative effects on the growth of sensitive STEC by Novobiocin was reported before and showed that extensive use of selective agents might not be appropriate. Increase of the incubation temperature to $42^{\circ} \mathrm{C}$ did not have an influence on the growth of STEC. The quantity and composition of the background flora was not influenced by media or by incubation temperature. Low levels of STEC spiked into sprouts grew to slightly higher levels when incubated at $42^{\circ} \mathrm{C}$ in EE-broth. A selective compound was assessed in this study. Potassium tellurite did however not reduce the growth of the background flora and was therefore not considered as potential media supplement for our purpose. So far, the greatest challenge for methods for the detection and isolation of pathogenic $E$. coli from sprouts was not solved. The great difference in colony counts of background flora and pathogenic bacteria still remains a challenge. Analysis of the bacterial communities associated with mungo bean sprouts gave indications that due to the aerobic nature of $63.9 \%$ of the 20 most abundant genera including the two most dominant ones, an anaerobic enrichment might improve the selectivity. 


\section{Supplementary material}

Table S1. Phylum level OTU distributions observed in sprout microbiomes before $(\mathrm{t}=0)$ and after $16 \mathrm{~h}$ $(\mathrm{t}=16)$ of enrichment in BPW and EE-broth at $37^{\circ} \mathrm{C}$ and $42^{\circ} \mathrm{C}$

\begin{tabular}{llllll}
\hline & \multicolumn{3}{c}{ BPW } & \multicolumn{3}{c}{ EE-broth } \\
\cline { 2 - 5 } & $\mathrm{t}=0$ & $37^{\circ} \mathrm{C}$ & $42^{\circ} \mathrm{C}$ & $37^{\circ} \mathrm{C}$ & $42^{\circ} \mathrm{C}$ \\
\hline Proteobacteria & 90.4 & 55.9 & 71.9 & 99.5 & 99.5 \\
Bacteroidetes & 8.8 & 1.5 & 1.9 & 0.5 & 0.4 \\
Firmicutes & 0.6 & 42.6 & 26.2 & 0.07 & 0.05 \\
Actinobacteria & 0.1 & 0.0 & 0.0 & 0.0 & 0.0 \\
Spirochaetes & 0.0 & 0.0 & 0.0 & 0.0 & 0.0 \\
\hline
\end{tabular}




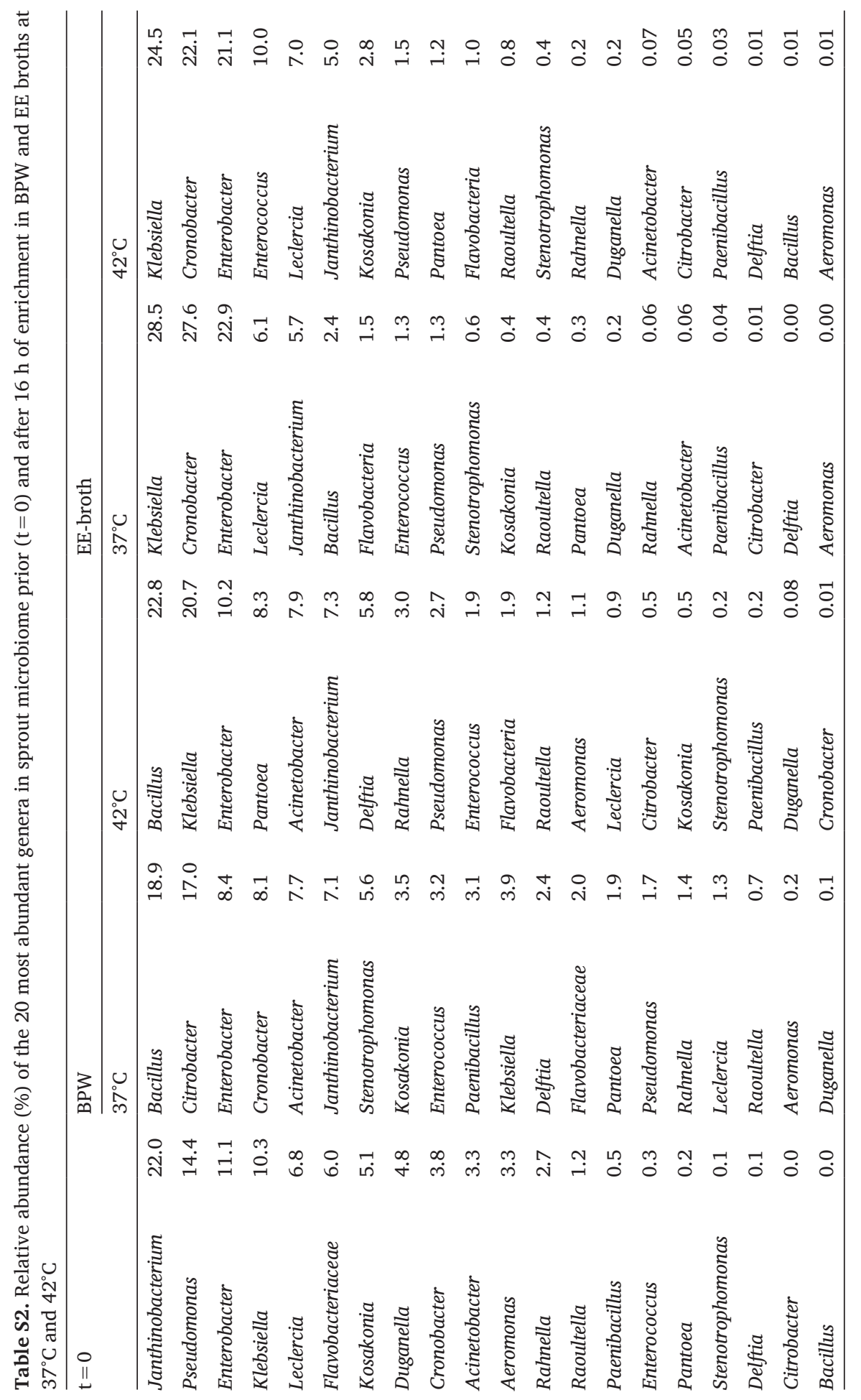




\section{References}

1. EFSA. 2012. Scientific opinion on the risk posed by Shiga toxin-producing Escherichia coli (STEC) and other pathogenic bacteria in seeds and sprouted seeds. EFSA Journal 9: 1-101.

2. Buchholz, U. 2011. German outbreak of Escherichia coli O104:H4 associated with sprouts. The New England Journal of Medicine 365: 1763-1770.

3. Mahon, BE., Ponka, A., Hall, W., Komatsu, K., Beuchat, L., Shiflett, S., Siitonen, A., Cage, G., Lambert, M., Hayes, P., Bean, N., Griffin, P., Slutsker, L. 1997. An international outbreak of Salmonella infections caused by alfalafa sprouts grown from contaminated seed. Journal of infectious disease 175: 876-882.

4. Beales, N. 2004. Review No. 41. Review of the microbiological risk associated with sprouted seeds. Campden and Chorleywood Food Research Association Group. 72pp

5. NACMCF, 1999. Microbiological safety evaluations and recommendations on sprouted seeds. National Advisory Committee on Microbiological Criteria for Foods. International Journal of Food Microbiology 52: 123-153.

6. Weagant, SD., Bryant, JL., Jinneman, KG. 1995. An improved rapid technique for isolation of Escherichia coli O157:H7 from foods. Journal of Food Protection 58: 7-12.

7. Weagant, SD., Jinneman, KA., Yoshitomi, KJ., Zapata, R., Fedio, WM. 2011. Optimization and evaluation of a modified enrichment procedure combined with immunomagnetic separation for detection of $E$. coli O157:H7 from artificially contaminated alfalfa sprouts. International Journal of Food Microbiology 149: 209-217.

8. Sata, S., Fujisawa, T., Osawa, R., Iguchi, A., Yamai, A., Shimada, T. 2003. An improved enrichment broth for isolation of Escherichia coli O157, with specific reference to starved cells, from radish sprouts. Applied and Environmental Microbiology 3: 188-1860.

9. Fedio, WM., Jinneman, KJ., Yoshitomi, KJ., Zapata, R., Weagant, SD. 2012. Efficacy of a post enrichment acid treatment for isolation of Escherichia coli 0157 from alfalfa sprouts. Food Microbiology 30: 83-90.

10. EFSA. 2007. Scientific opinion of the panel on biological hazards on a request from Efsa on monitoring of verotoxigenic Escherichia coli (STEC) and identification of human pathogenic types. EFSA Journal 579: 1-61.

11. Loui, C., Grigoryan, G., Huang, H., Riley, LW., Lu, S. 2008. Bacterial communities associated with retail alfalfa sprouts. Journal of Food Protection 71: 200-204.

12. Margot, H., Zwietering, MH., Joosten, H., Stephan, R. 2015. Evaluation of different buffered peptone water (BPW) based enrichment broths for detection of Gram-negative foodborne pathogens from various food matrices. International Journal of Food Microbiology 214: 109-115.

13. Zadik, PM., Chapman, PA, Siddons, CA. 1993. Use of tellurite for the selection of verocytotoxigenic Escherichia coli O157. Journal of Medical Microbiology 39: 155-158.

14. European Committee for Antimicrobial Susceptibility Testing (EUCAST) of the European Society of Clinical Microbiology and Infectious Diseases (ESCMID). 2003. Determination of minimum inhibitory concentrations (MICs) of antibacterial agents by broth dilution. EUCAST discussion document E.Dis 5.1

15. Magoc, T., Salzberg, SL. 2011. FLASH: Fast length adjustment of short reads to improve genome assemblies. Bioinformatics 27: 2957-2963.

16. Sata, S., Asai, Y., Yamai, S. 1999. Growth of starved Escherichia coli 0157 in selective and nonselective media. Microbiology and Immunology 43: 217- 227.

17. Vimont, A., Delignette-Muller, ML., Vernozy-Rozand, C. 2007. Supplementation of enrichment broths by novobiocin for detecting Shia toxin-producing Escherichia coli from food: a controversial use. Letters in Applied Microbiology 44: 326-331.

18. Paton, JC., Paton, AW. 1998. Pathogenesis and diagnosis of Shiga toxin--producing Escherichia coli infections. Clinical Microbiology Reviews 11: 450-79. 
19. Weagant, SD., Bound, AJ. 2001. Evaluation of techniques for enrichment and isolation of Escherichia coli O157:H7 from artificially contaminated sprouts. International Journal of Food Microbiology 71: 87-92.

20. Hara-Kudo, Y., Onoue, Y., Konuma, H., Nakagawa, H., Kumagai, S. 1999. Comparison of enrichment procedures for isolation of Escherichia coli 0157:H7 from ground beef and radish sprouts. International Journal of Food Microbiology 50: 211-214.

21. Kehl, SC. 2002. Role of the laboratory in the diagnosis of enterohemorrhagic Escherichia coli infections. Journal of Clinical Microbiology 40: 2711-2715.

22. Jinneman, KC., Waite-Cusic, JG., Yoshitomi, KJ. 2012. Evaluation of shiga toxin-producing Escherichia coli (STEC) method for detection and identification if STEC O104 strains from sprouts. Food Microbiology 30: 321-328.

23. Williams, R., Moyne, AL., Harris, LJ. Marco, ML. 2013. Season, irrigation, leaf age, and Escherichia coli inoculation influence the bacterial diversity in the lettuce phyllosphere. PLOS One 8: 1-14.

24. Wiken Dees, M., Lysoe, E., Nordskog, B., Brurberg, MB. 2015. Bacterial communities associated with surfaces of leafy greens: shift in composition and decrease in richness over time. Applied and Environmental Microbiology 81: 1530- 1539.

25. Abadias, M., Usall, J., Anguera, M., Solsona, C., Vinas, I. 2008. Microbiological quality of fresh, minimally-processed fruit and vegetables and sprouts from retail establishments. International Journal of Food Microbiology 123: 121-129. 


\section{Chapter}

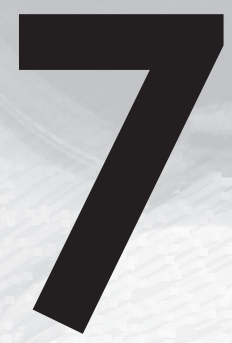

Determination of single cell lag times of

Cronobacter spp. strains exposed to different stress

\section{conditions: impact on detection}

Heike Margot, Marcel H. Zwietering, Han Joosten, Roger Stephan 


\section{Abstract}

The variability of stress resistance and lag time of single cells can have a big impact on the growth and therefore the detection probability of bacteria. In this study, six strains of Cronobacter spp. were subjected to heat, acid and desiccation stress and single cell lag times were determined using optical density measurements. The effect of the inactivation and an extended lag time on the cfu level reached after enrichment was calculated in different scenarios. Longest lag times were found after acid treatment. However, the inactivation effects of the different stresses applied and the change in lag times for each strain did not correlate.

By supposing different scenarios of cells in a sample experiencing reduction and increased lag time we showed that the detection of Cronobacter might fail because the detection limit of the subsequent method might not be reached. In general, such scenarios can help to visualize the effects of reduction and increased lag for a number of strains and thereby compare their behaviour. 


\section{Introduction}

Different studies showed that bacterial cells react to different stresses with an extended lag phase due to repair time $(1,2)$. Dupont and Augustin (3) investigated the influence of diverse stress conditions common in the food industry on the single cell growth probability and lag time distribution of Listeria monocytogenes. They found an increase in mean and variability of lag times in injured cells. During lag phase bacteria adapt to the new environmental conditions. This process includes the repair of macromolecular damage accumulated during stationary phase (or other stresses) and the synthesis of cellular components that are necessary for growth (4).

The mean value of single-cell lag times is not automatically equal to the population lag time and the lag time of the population does not necessarily give information on the variability of the single-cell lag time in a population (5). Therefore, knowledge about single cell lag time is critical in view of the detection probability in products with very low contamination levels. Experiments with single cells have given the opportunity to investigate the environmental effects of the distribution of lag times of single cells (6). One way to inoculate every well with approximately one cell is by serial dilution. With time-to-detection information obtained from OD measurements, lag time can be calculated if the cell concentration at the detection level and specific growth rate is accurately known $(3,7)$.

There are studies describing the influence of stress factors on single cells of Listeria monocytogenes, Lactobacillus and E. coli $(8,1,9)$. However, studies analysing the influence of stress on different species and strains of Cronobacter are scarce and often obtained from predictive modelling $(10,11)$. In this study we describe the influence of stress factors relevant to powdered infant formula (PIF) production and reconstitution on reduction and lag time of Cronobacter spp. single cells from different species, and show the impact on their probability of detection in different scenarios.

\section{Materials and Methods}

\section{Strains}

Six strains of different Cronobacter species were chosen for the experiments (Table 1). Working cultures were made from frozen stocks (BHI (Oxoid CM1, Basingstoke, United Kingdom) with $20 \%$ glycerol) and maintained on blood agar plates (Difco Columbia blood agar base, $5 \%$ sheep blood, Oxoid) at $4 \pm 1^{\circ} \mathrm{C}$. 
Table 1. Strains used in the study

\begin{tabular}{lll}
\hline strain & species & source \\
\hline E151 & C. sakazakii & demineralised whey powder \\
E288 & C. sakazakii & environment \\
E776 & C. sakazakii & milk powder \\
E465 & C. dubliensis & environment \\
E681 & C. turicensis & food \\
E688 & C. turicensis & food \\
\hline
\end{tabular}

\section{Stress application}

\section{Heat stress:}

$1 \mathrm{ml}$ of an overnight culture grown in brain heart infusion broth (BHI, Oxoid), was added to $9 \mathrm{ml}$ buffered peptone water preheated to $55^{\circ} \mathrm{C}$ in a water bath and incubated for $10 \mathrm{~min}$. Afterwards, the culture was diluted to singe cell level in cold BPW to stop the heat exposure and added to the wells of a 96 well plate. The stressed culture was also diluted in $0.9 \%$ saline and plated on TSA to determine cell counts.

\section{Acid stress:}

$1.5 \mathrm{ml}$ of an overnight culture grown in BHI was centrifuged at $13.000 \mathrm{~g}$ for $10 \mathrm{~min}$. The supernatant was discarded and the pellet was resuspended in $1.5 \mathrm{ml} \mathrm{LB}$ broth (Oxoid) adapted to $\mathrm{pH} 4.0$ with lactic acid. The suspension was incubated at room temperature for $2 \mathrm{~h}$ and diluted to single cell level in $\mathrm{BPW}(\mathrm{pH}=7)$ and added to the wells of a 96 well plate. The stressed culture was also diluted in $0.9 \%$ saline and plated on TSA to determine cell counts.

\section{Desiccation stress:}

Desiccation stress was applied as described previously (12). Briefly, $30 \mathrm{ml}$ of a BHI overnight culture were centrifuged at $3200 \mathrm{~g}$ for $12 \mathrm{~min}$. The supernatant was discarded and the pellet mixed with small amounts of sterile $\mathrm{CaCO}_{3}$ until a final amount of $15 \mathrm{~g}$ was achieved. The powder was stored in a desiccator with silica gel for two days before the experiment. The stressed culture was diluted in $0.9 \%$ saline and plated on TSA to determine cell counts before and after two days of storage in the desiccator. The powder was also diluted in BPW to reach the single cell level in the 96 well plate. 


\section{Population growth rate}

The population growth rates were determined as follows. Serial dilutions were performed in BPW in order to obtain $10^{2}-10^{3} \mathrm{cfu} / \mathrm{ml}$. The samples were incubated with agitation for $24 \mathrm{~h}$ at $37^{\circ} \mathrm{C} .100 \mu \mathrm{l}$ samples were removed periodically for $24 \mathrm{~h}$ and spread plated on TSA plates. The plates were incubated at $37^{\circ} \mathrm{C}$ for $24 \mathrm{~h}$. The growth rate was calculated using ComBase DMfit software (United States Department of Agriculture). Since bacterial counts were in $\log 10 \mathrm{cfu} / \mathrm{g}$, the maximum growth rate as determined by DMfit was in $\log 10 / \mathrm{h}$. Therefore the values were converted to maximum specific growth rate $(1 / \mathrm{h})$ by multiplying by $\ln (10)$. The experiment was performed in three independent experiments.

\section{Optical density calibration curve}

In order to determine $N_{d}$, the cell concentration corresponding to an OD of 0.050, a diluted overnight culture of each strain was incubated in the BioTek (Bio Tek, Luzern, Switzerland) instrument and the $\mathrm{OD}$ was recorded at $37^{\circ} \mathrm{C}$ and $\mathrm{OD}_{600 \mathrm{~mm}}$ was recorded every $10 \mathrm{~min} .100 \mu \mathrm{l}$ samples were taken just after each OD measurement and plated on TSA. The cell concentration corresponding to an OD of 0.050 was $N_{\text {E151 }}=8.0 \log \mathrm{cfu} / \mathrm{ml}, N_{\text {E288 }}=7.4 \log \mathrm{cfu} / \mathrm{ml}, N_{\text {E465 }}=7.9 \log \mathrm{cfu} / \mathrm{ml}, N_{\text {E618 }}=7.5$ $\log \mathrm{cfu} / \mathrm{ml}, N_{\mathrm{E} 688}=7.5 \log \mathrm{cfu} / \mathrm{ml}, N_{\mathrm{E} 776}=7.7 \log \mathrm{cfu} / \mathrm{ml}$.

\section{Determination of single cell lag times}

Cultures of stressed cells were diluted in BPW in order to reach a maximum concentration of $2.1 \mathrm{cfu} / \mathrm{ml}$ in the final dilution. Cells without application of stress were revived from frozen stocks, cultured in BPW for $24 \mathrm{~h}$ at $37^{\circ} \mathrm{C}$ and diluted in BPW to the same level. The wells of a 96-well plate were inoculated with $200 \mu \mathrm{l}$ of this suspension to obtain a target value of $0.42 \mathrm{cfu} /$ well. Assuming a Poisson distribution of the cells in the wells, a maximum concentration of 0.42 cell/well should correspond to $34 \%$ of the wells showing growth (13). By estimation, less than $20 \%$ of the wells showing growth should contain more than 1 cell. 96-well plates were incubated in the BioTek reader for $24 \mathrm{~h}$ at $37^{\circ} \mathrm{C}$ with shaking. OD at $600 \mathrm{~nm}$ was measured every $10 \mathrm{~min}$. Two plates were tested on three days per experimental set-up to obtain approx. 80 values per strain and stress factor. The time to detection in each well (time to reach an OD of 0.050) was calculated for each experiment with Microsoft Excel. Individual cell lag times were estimated from time to detection data according to protocols by Dupont and Augustin (3) and Guillier et al. (14). Assuming an exponential bacterial growth at a constant specific growth rate $(\mu)$ until the detection time, $T_{d}$ is related to the lag time of the culture 
with $\mathrm{N}_{0}$ cells (in this case $1 \mathrm{cfu} / 200 \mu \mathrm{l}$ ) (lag) by the following formula proposed by Baranyi and Pin (15):

$$
\operatorname{lag}=\mathrm{T}_{\mathrm{d}-}\left(\ln \left(N_{d}\right)-\ln \left(N_{0}\right)\right) / \mu
$$

The distribution of the individual lag times should be reflected by the distribution of the detection times when $\mathrm{N}_{0}=1$ (16).

Simulating the impact of sublethal stress on the lag time and growth of single cells The growth of a single Cronobacter cell in an enrichment of $100 \mathrm{ml}$ was simulated taking into account the population growth rate and the minimum, maximum and mean individual lag time determined in this study. The growth limit was set at $10^{9}$ $\mathrm{cfu} / \mathrm{ml}$. The effect of inactivation by desiccation stress and different lag times on the final cell counts and the probability of detection of six Cronobacter strains was calculated.

\section{Results and Discussion}

\section{Population growth rates}

The following specific growth rates were determined at $37^{\circ} \mathrm{C}$ in BPW:

E151: $1.94 \pm 0.09 \mathrm{~h}^{-1}$; E288: $1.88 \pm 0.29 \mathrm{~h}^{-1}$; E465: $2.21 \pm 0.07 \mathrm{~h}^{-1}$, E681: $1.89 \pm$ $0.23 \mathrm{~h}^{-1}$; E688: $1.89 \pm 0.09 \mathrm{~h}^{-1}$; E776: $1.83 \pm 0.44 \mathrm{~h}^{-1}$. In literature, growth rates of Cronobacter spp. determined at $37^{\circ} \mathrm{C}$ range from $1.80 \mathrm{~h}^{-1}$ to $2.72 \mathrm{~h}^{-1}$ in BHI (10) and from $1.32 \mathrm{~h}^{-1}$ to $2.89 \mathrm{~h}^{-1}$ in PIF (17). The great variation can be caused by various factors as different growth media, incubation temperatures, and species/ strain used (18). In this study, growth rates were determined in BPW, which is a medium less rich than BHI and reconstituted infant formula. Still, growth rate data are within ranges as given in literature. BPW was chosen because it is prescribed in the ISO method for the non-selective enrichment of Cronobacter spp. Differences in growth rates between studies can also be explained by the method that was applied to determine the growth rate. Miled et al. (19) used OD measurements for this purpose and obtained values of 1.72 to $2.34 \mathrm{~h}^{-1}$, whereas the values mentioned above were determined by plate counts. The correct estimation of the growth rate has a significant effect on the determination of lag time (20). 


\section{Distributions of single cell lag time}

Distributions of single cell lag times for each strain after exposure to desiccation, acid and heat stress are shown in Figure 1. For the different strains, distribution of lag times varied greatly. Whereas for strains E151, E465, E681 and E688, lag
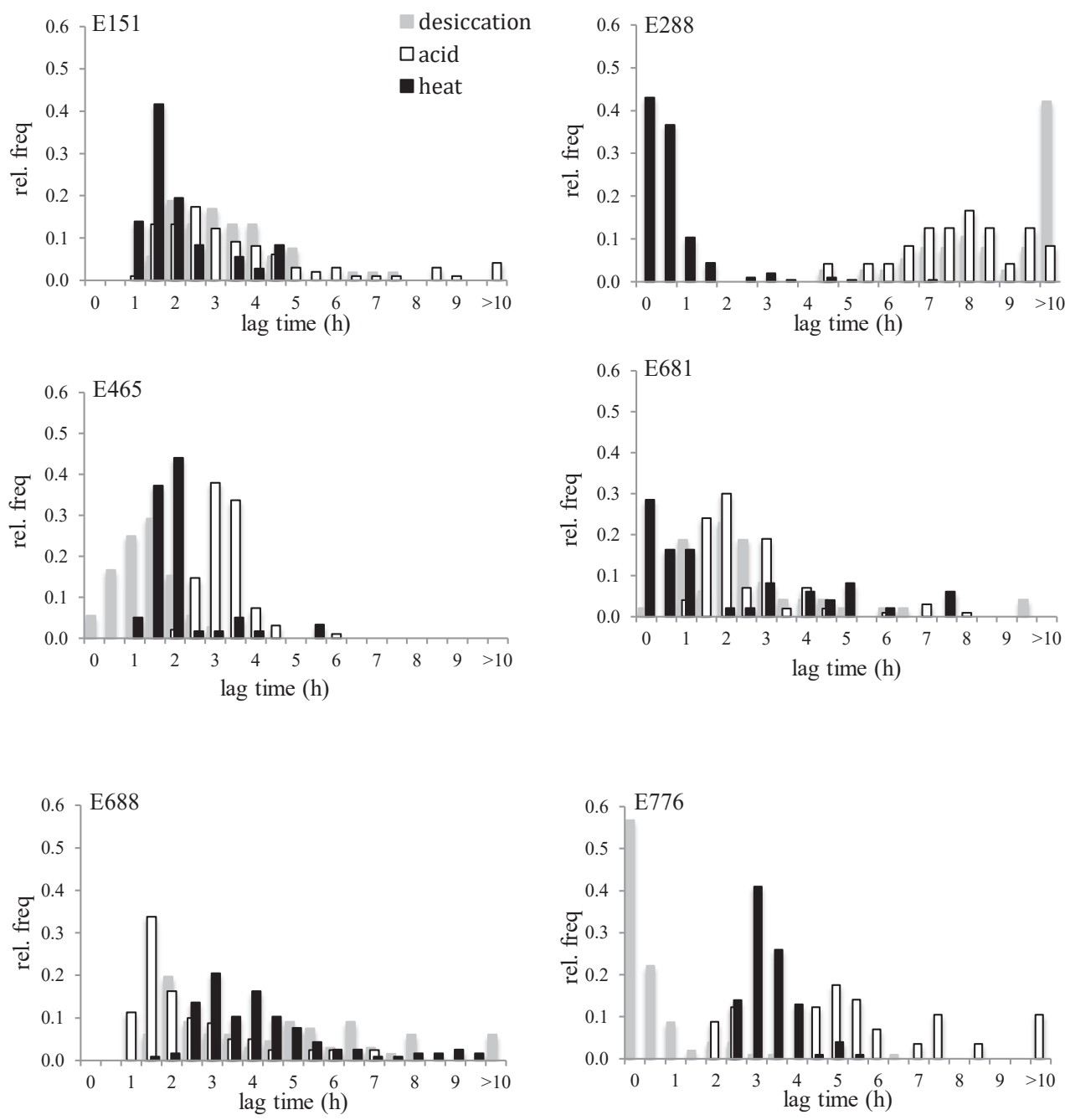

Figure 1. Distributions of single cell lag times for different stresses determined from detection times as calculated from OD measurements.

times are close, values obtained with E288 and E776 are clearly separated. Lag times after heat stress seemed to be less scattered for strains E151, E288 and E465. Other authors described the effect of stress factors like $\mathrm{pH}$ and temperature on single cell lag time and its distribution $(13,16,1)$. The common finding was that 
increasing intensity of stress treatment lengthened lag time and increased lag time variability. The determination of bacterial lag times from OD measurements is not always considered to be ideal. Variation in bacterial cell size and inaccurate biomass detection can result in misleading data (21). In addition, turbidity measurements have very high detection limits, which limit the range in which data are actually obtained. However, single cell lag time cannot be deduced from population lag and large quantities of replicate measurements are needed. Due to these reasons, viable counting cannot be used. Another method circumventing the above-mentioned limitations was described by Elfwing et al. (22). With the use of a flow chamber in which the cells are attached to a solid surface the divisions of single cells and the distribution of lag times can be monitored.

\section{Correlation of lag times and inactivation}

Both single cell lag time and log reduction by stress are shown in Figure 2. Mean lag times per strain after acid stress were between 2.7 and $9.5 \mathrm{~h}$. Strain E681 showed the lowest and E288 the highest value. The standard deviation was between 0.6 and $3.0 \mathrm{~h}$. Mean reduction values were between 1.9 and $4.0 \mathrm{log}$ (highest for E465; lowest for E688) with standard deviations ranging from 0.8 to $2.2 \mathrm{log}$. When treated with elevated temperature, mean lag times were between 0.8 and $4.3 \mathrm{~h}$ (shortest for E288; longest for E688) with standard deviations of 0.6 to $2.3 \mathrm{~h}$. Mean reduction was between 3.0 and $4.1 \log \mathrm{cfu} / \mathrm{ml}$ (highest for E681; lowest for E465) with standard deviations of 0.1 to 0.5 . Desiccation stressed cells showed mean lag times reaching from 0.6 to $4.5 \mathrm{~h}$ (shortest for E776; longest for E151). Standard deviations were between 0.7 and 2.7. Mean reduction values were between 2.3 and $4.2 \log$ (shortest E151; longest E776) with standard deviations of 0.2 to 2.3 log. Mean lag time for all strains was $5.0 \mathrm{~h}$ after acid stress, $2.5 \mathrm{~h}$ after heat stress and $2.7 \mathrm{~h}$ after desiccation stress. Mean log reduction was $2.9 \log$ after acid stress, $3.5 \mathrm{log}$ after heat stress and $3.3 \log$ after desiccation stress. Conclusively, acid stress did cause the longest lag times when at the same time reduction of cell counts were similar for all stress factors. The data suggest that lag times of cells are not correlated to inactivation. In addition, we showed that some strains can be more resistant to a certain stress factor and on the other hand have pronounced sensitivity for a different stress. Guillier et al. (14) measured lag times of Listeria monocytogenes after treatment with 9 stresses that all caused a reduction in cell numbers of $1.5 \mathrm{log} \mathrm{cfu} / \mathrm{ml}$. Even though inactivation was identical, length of lag varied significantly $(2.1 \mathrm{~h}-16.1 \mathrm{~h})$. Inactivation of Cronobacter spp. by drying was determined by Dancer et al. (23). They found that cells dried in TSB experienced a reduction between 0.8 and $1.5 \log$ after 3 days, values were lower when cells were desiccated in infant formula (0.5-1.3 log). 

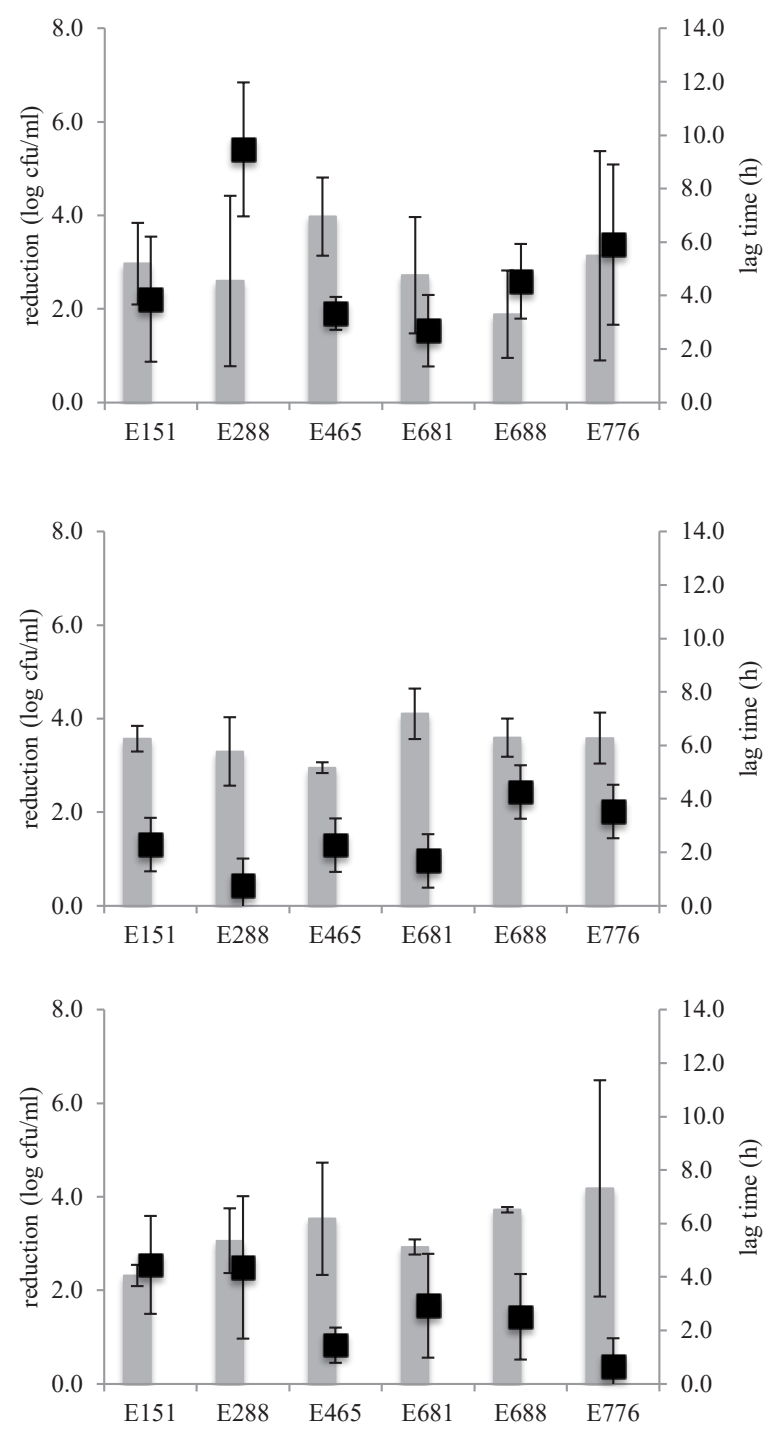

Figure 2. Log reduction and single cell lag times caused by different stresses for the 6 Cronobacter strains tested, a) acid stress, b) heat stress, c) desiccation stress. Bars are mean log reductions with standard deviation. Reduction means were determined in four independent experiments. Black squares are means of single cell lag times with standard deviation. Lag times are means of approx. 80 single values.

Caubilla-Barron et al. (24) studied the desiccation resistance of Cronobacter spp. in freeze- and air-dried infant formula and found a 2.0 log decrease. Gurtler and Beuchat (25) investigated the heat resistance of four Cronobacter spp. strains and found inactivation of 0.4 to $1.9 \mathrm{log} \mathrm{cfu} / \mathrm{ml}$ after $5 \mathrm{~min}$ at $55^{\circ} \mathrm{C}$. These values are close to the ones obtained in this work when the values are extrapolated to $10 \mathrm{~min}$ 
heat treatment (0.8-3.8 for Gurtler and Beuchat and 3.0-4.1 for our results). Xu et al. (11) found population lag times of Cronobacter turicensis of $6.2 \mathrm{~h}$ of heat treated cells incubated at $22^{\circ} \mathrm{C}$. Individual lag times of Cronobacter at $37^{\circ} \mathrm{C}$ had a mean of 4.5 $\mathrm{h}$ for 12 fitted shape parameters and population lag times between 2.25 and $3.71 \mathrm{~h}$. Kandhai et al. (17) estimated population lag times of $1.7 \pm 0.4 \mathrm{~h}$ of Cronobacter spp. in reconstituted infant formula at $37^{\circ} \mathrm{C}$. Cronobacter spp. has the ability to survive under dry conditions when compared to other Enterobacteriaceae. The desiccation tolerance of Cronobacter spp. increases its competitive advantage in production facilities and is an explanation for the contamination of infant formula (26). It was shown that the thermal tolerance varies between strains, which is confirmed by our data (27). The disparity between the different Cronobacter species and strains and the resulting variance in stress resistance and lag time presents a great challenge. Therefore, the collection of data, covering a wide selection of strains, should be the main focus of research activity.

\section{Simulating the impact of sublethal stress on the lag time and growth of single cells and their detection}

In order to visualize the effect of an increased lag time due to stress encountered during food production, different scenarios with desiccated cells were simulated (Figure 3). Desiccation stress was chosen, as it is the most relevant stress on Cronobacter along the powdered infant formula production line. The inactivation has an impact on the probability of the presence of a viable cell in the sample. Simulations take into account the maximum specific growth rate of each strain and mean individual lag time. The simulation is based on the assumed presence of 1 cell in a sample of $10 \mathrm{~g}$ diluted in $100 \mathrm{ml}$ enrichment medium.

This simulation shows for some Cronobacter strains that after an incubation of 18 $\mathrm{h}$, cell counts will remain at a very low level if the maximum lag time is assumed. Cell counts of strain E288 will remain below $4 \log \mathrm{cfu} / \mathrm{ml}$ when the maximum lag time is anticipated. When the "worst case" scenario was simulated, a single cell of Cronobacter E151 with a maximum lag of 9.7 h would have grown to $4.99 \log \mathrm{cfu}$ / $\mathrm{ml}$ after a $18 \mathrm{~h}$ incubation. In the standard detection method for the detection of Cronobacter spp. from infant formula, $10 \mathrm{~g}$ of powder are enriched in BPW for $18 \pm 2$ $\mathrm{h}$ at $37^{\circ} \mathrm{C}$. Afterwards, $0.1 \mathrm{ml}$ is transferred into the selective broth CSB (Cronobacter screening broth). According to Iversen et al. (28), $10^{4} \mathrm{cfu} / \mathrm{ml}$ in the enrichment are required for the slowest growing strain to change the colour of CSB, which is based on the fermentation of sucrose. The time to reach this level starting from a concentration of $0.01 \mathrm{cfu} / \mathrm{ml}$ (6 log $\mathrm{cfu} / \mathrm{ml}$ increase) is shown in Table 2. According to these values, the enrichment time of $18 \pm 2 \mathrm{~h}$ is sufficient to reach the required 
concentration if the mean lag time is assumed, but for strain E288 not if the largest lag time is occurring. Therefore, an extended recovery period will not have a great effect on detection in most cases, but in specific situations it might result in a false negative.
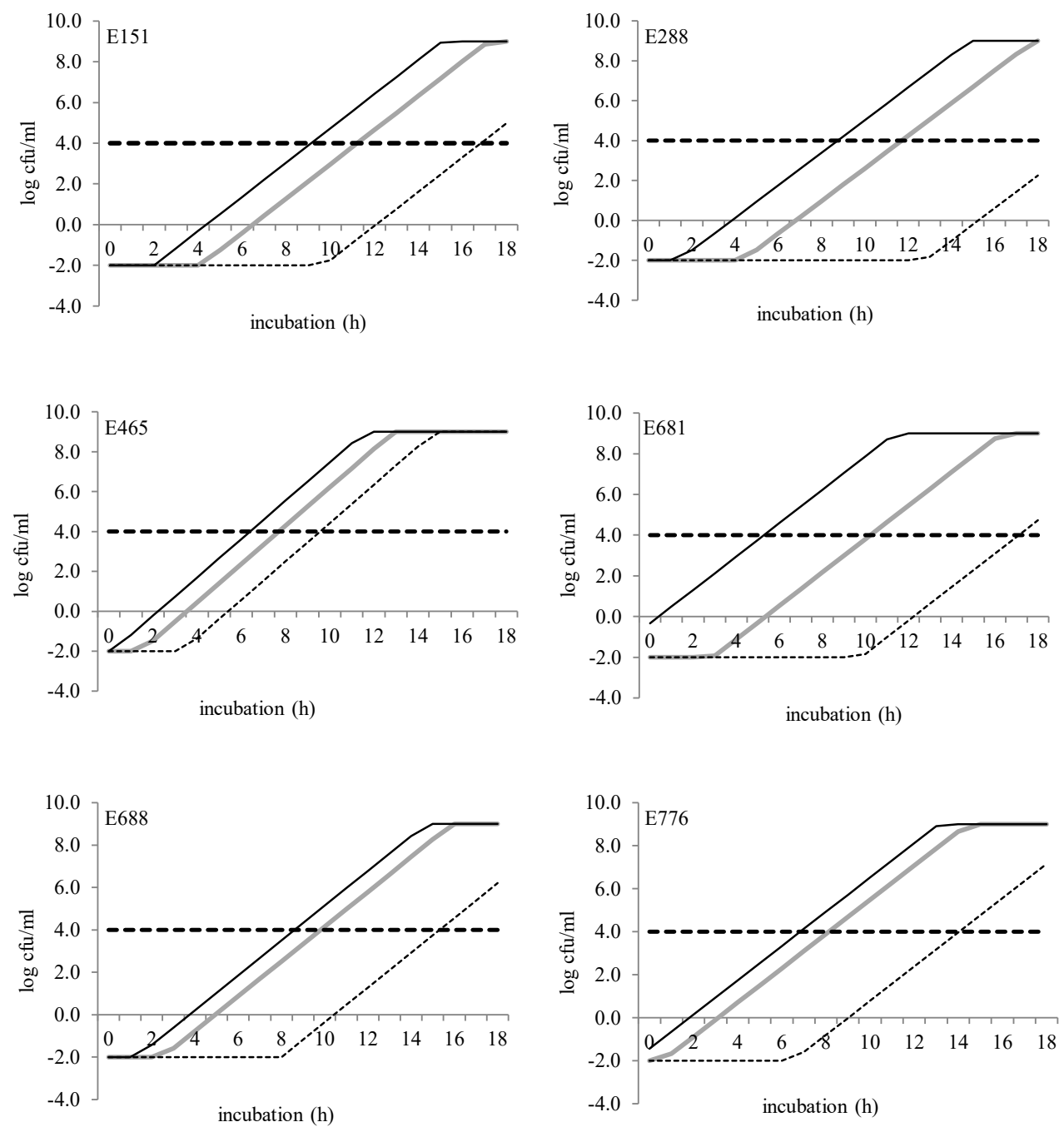

Figure 3. Simulated growth of $1 \mathrm{cfu}$ Cronobacter spp. in a $100 \mathrm{ml}$ enrichment at $37^{\circ} \mathrm{C}$ after minimum (black line), maximum (dotted line) and mean lag time (grey line) as determined after desiccation stress application.

The probability of detecting a positive sample was calculated assuming different contamination rates and sampling plans (Figure 4). The fraction of positive samples of 0.11 for a $10 \mathrm{~g}$ sample size was used for the calculation as determined by 
Jongenburger et al. (29), who sampled a contaminated batch of powdered infant formula. The influence of taking more samples on the probability of detection was simulated in dependency of the contamination rate. The scenarios show that with an increased number of samples the probability to detect a positive sample with a contamination rate of 0.11 is increased from 0.69 to 0.997 . On the other hand it is shown that at very low contamination levels, 250 samples would be necessary to achieve a comparable probability of detection $(\mathrm{P}=0.92)$. Miled et al. (10) estimated the probability of detecting Cronobacter with CSB with either 1 or 3 cells in a $10 \mathrm{~g}$ sample. In case a $10 \mathrm{~g}$ sample was contaminated with only 1 cell, the probability of detection would be $0.212 \pm 0.019$ according to them.

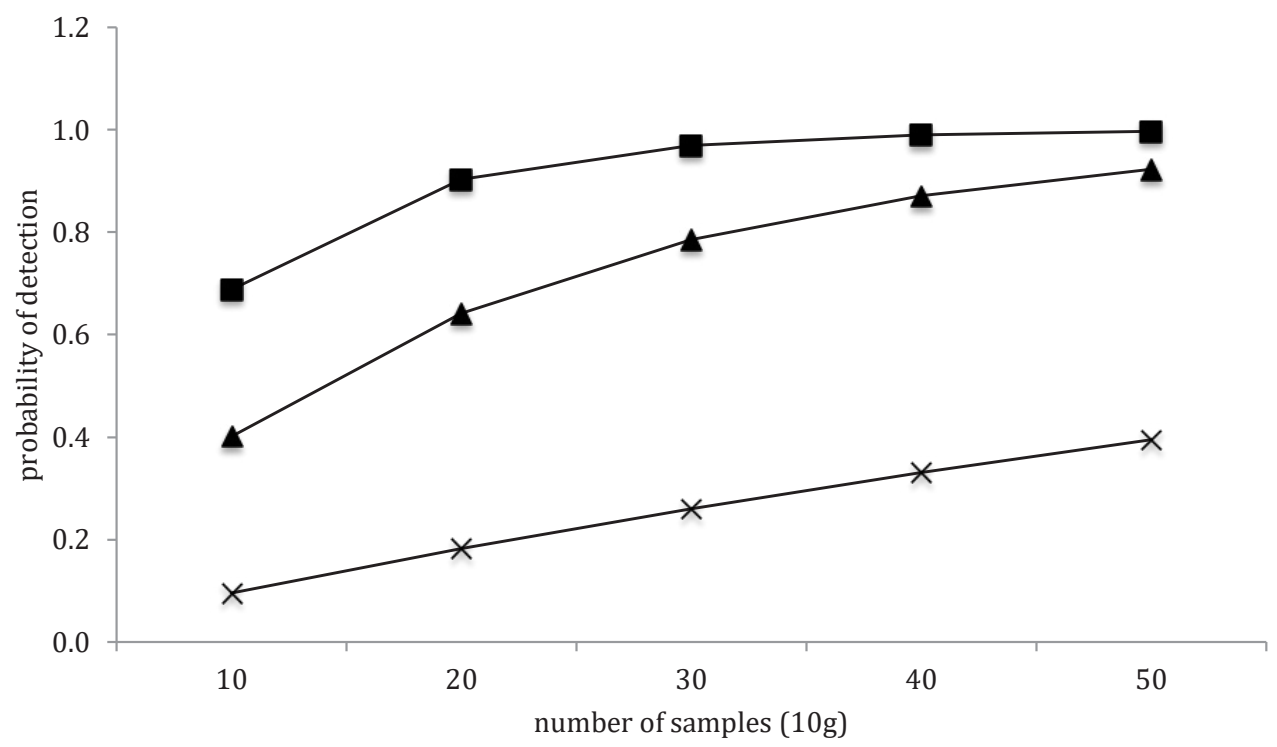

Figure 4. Probability of detection in dependence of the number of samples (10g) and the fraction of positive samples $(\square 0.11, \boldsymbol{\Delta} 0.05, \times 0.01)$.

This means that of 100 samples of $10 \mathrm{~g}$, each contaminated with 1 cell of Cronobacter, only 20 would be detected. The simulation of different scenarios can visualize the effect of an extended lag time if the contamination level is very low. The literature shows that levels of Cronobacter spp. found in powdered infant formula were between $-3.84 \pm 0.696 \mathrm{log} \mathrm{cfu} / \mathrm{g}$ (29). Therefore, our simulation shows a realistic situation for the detection of Cronobacter spp. from powdered formula. Growth rates determined in pure BPW might be lower than in the actual sample, where more nutrients are vitamins originating from the diluted infant formula are available to the bacteria. However, growth rates determined in BPW did not differ considerably from literature data obtained in diluted PIF. Even though bacterial counts in PIF are usually very low, it is not a sterile product. The background flora growing during the 
enrichment can reduce the outgrowth of Cronobacter due to depletion of nutrients or accumulation of toxic compounds in the medium. This was shown by Miled et al. (10), who simulated the growth of Cronobacter in a $10 \mathrm{~g}$ and $100 \mathrm{~g}$ sample in the presence of the background flora.

Table 2. Time for $6 \log$ increase, mean and maximum lag time and time needed for a 6 log increase after the maximum lag time for six Cronobacter spp. strains

\begin{tabular}{ccccc}
\hline Strain & $\begin{array}{c}\text { Time for } 6 \text { log } \\
\text { increase (h) }\end{array}$ & Mean lag time (h) & Max lag time (h) & $\begin{array}{c}\text { Time for } 6 \text { log increase } \\
\text { + Max lag time (h) }\end{array}$ \\
\hline E151 & 7.1 & 4.1 & 9.7 & 16.8 \\
E288 & 7.3 & 4.4 & 12.8 & 20.1 \\
E465 & 6.2 & 1.5 & 3.3 & 9.5 \\
E681 & 7.3 & 2.9 & 9.8 & 17.1 \\
E688 & 7.3 & 2.5 & 8.0 & 15.3 \\
E776 & 7.5 & 0.6 & 6.5 & 14.0 \\
\hline
\end{tabular}

\section{Conclusion}

The variability of lag time of individual cells following exposure to stress can have an impact on the growth and detection of bacteria. This is even more important in conditions of very low contamination levels of a product (7) since stressed single cells might be missed during detection due to an increased lag time.

The presented data demonstrate that the Cronobacter strains chosen for this study displayed great variation in lag time and stress resistance. The duration of lag time was highest after acid stress and did not correlate to stress resistance. By considering different scenarios of one cell in a sample experiencing reduction due to desiccation and increased lag time we showed that the detection of Cronobacter might fail because the detection limit of the subsequent method might not be reached. However, this was only the case for one strain. If the incubation time would be set at $21 \mathrm{~h}$, also for this strain even at the highest found individual lag time a sufficient level would be found. It was shown that the number of samples taken did have a very large effect on detection probability, especially at low contamination rates. Therefore increasing the number of samples is also a suitable strategy to improve detection.

In general, such scenarios can help to visualize the effects of reduced and increased lag for a number of strains and thereby compare their behaviour.

In future studies, data considering also growth experiments with the product should be collected to respect also the influence of the product and of the background flora. 


\section{Acknowledgements}

We thank Paul Torgerson (Vetsuisse Faculty, University of Zurich) for valuable assistance with the statistical analysis of the probability of detection.

\section{References}

1. Smelt, JPPM., Otten, GD., Bos, AP. 2002. Modelling the effect of sublethaly injury on the distribution of the lag times of individual cells of Lactobacillus plantarum. International Journal of Food Microbiology 73: 207-212.

2. Stephens, PJ., Joynson, JA., Davies, KW., Holbrook, R., Lappin-Scott, HM., Humphrey, TJ. 1997. The use of an automated growth analyser to measure recovery times of single heat-injured Salmonella cells. Journal of Applied Microbiology 83: 449-455.

3. Dupont, C., Augustin, JC. 2009. Influence of stress on single cell lag time and growth probability for Listeria monocytogenes in Half Fraser broth. Applied and Environmental Microbiology 75: 30693076.

4. Dukan, S., Nystrom, T. 1998. Bacterial senescence: stasis results in increased and differential oxidation of cytoplasmic proteins leading to developmental induction of the heat shock regulon. Genes and Development 12: 3431-3441.

5. D`Arrigo, M., Garcia de Fernando, GD., Velasco de Diego, R., Ordonez, JA., George, SM., Pin, C. 2006. Indirect measurement of the lag time distribution of single cells of Listeria innocua in food. Applied and Environmental Microbiology 72: 253-258.

6. Pin, C., Baranyi, J. 2008. Single-cell and population lag times as a function of cell age. Applied and Environmental Microbiology 74: 2534-2536.

7. Guillier, L., Augustin, JC. 2006. Modelling the individual cell lag time distributions of Listeria monocytogenes as a function of the physiological state and the growth conditions. International Journal of Food Microbiology 111: 241-251.

8. Gnanou Besse, N., Dubois Brisonnet, F., Lafarge, V., Leclerc, V. 2000. Effect of various environmental parameters on the recovery of sublethally salt-damaged and acid-damaged Listeria monocytogenes. Journal of Applied Microbiology 89: 944-950.

9. Li, Y., Odumeru, JA., Griffiths, M., McKellar, RC. 2006. Effect of environmental stresses on the mean and distribution of individual cell lag times of Escherichia coli O157:H7. International Journal of Food Microbiology 110: 278-285.

10. Miled Bennour, R., Guillier, L., Neves, S., Augustin, JC., Colin, P., Gnanou Besse, N. 2011. Individual cell lag time distributions of Cronobacter (Enterobacter sakazakii) and impact of pooling samples on its detection in powdered infant formula. Food Microbiology 28: 648-655.

11. Xu, YZ., Metris, A., Stasinopoulos, DM., Forsythe, SJ., Sutherland, JP. 2015. Effect of heat shock and recovery temperature on variability of single cell lag time of Cronobacter turicensis. Food Microbiology 45: 195-204.

12. Margot, H., Zwietering, MH., Joosten, H., O`Mahony, E., Stephan, R. 2015. Evaluation of different buffered peptone water (BPW) based enrichment broths for detection of Gram-negative foodborne pathogens from various food matrices. International Journal of Food Microbiology 214: 109-115.

13. Francois, K., Devlieghere, F., Standaert, AR., Geeraerd, AH., van Impe, JF., Debevere, J. 2003. Modelling the individual cell lag phase: Isolating single cell: protocol development. Letters of Applied Microbiology 37:26-30.

14. Guillier, L., Pardon, P. Augustin, JC. 2005. Influence of stress on individual lag time distributions of Listeria monocytogenes. Applied and Environmental Microbiology 71: 2940-2948. 
15. Baranyi, J., Pin, C. 1999. Estimating bacterial growth parameters by means of detection times. Applied and Environmental Microbiology 65: 732-736.

16. Metris, A., George, SM., Peck, MW., Baranyi, J. 2003. Distribution of turbidity detection times produced by single cell-generated bacterial populations. Journal of Microbiological Methods 55: 821-827.

17. Kandhai, MC., Reij, MW., Grognou, C., van Schothorst, M., Gorris, LGM., Zwietering, MH. 2006. Effects of preculturing conditions on lag time and specific growth rate of Enterobacter sakzakii in reconstituted powdered infant formula. Applied and Environmental Microbiology 72: 2721-2729.

18. Swinnen, LAM., Bernearts, K., Dens, EJJ., Geeraerd, AH., Van Impe, JF. 2004. Predictive modelling of the microbial lag phase: a review. International Journal of Food Microbiology 94: 137-159.

19. Miled Bennour, R., Ells, TC., Pagotto, FJ., Farber, JM., Kerouanton, A., Meheut, T., Colin, P., Joosten, H., Leclercq, A., Gnanou Besse, N. 2010. Genotypic and phenotypic characterisation of a collection of Cronobacter (Enterobacter sakazakii) isolates. International Journal of Food Microbiology 139: 116-125.

20. Aguirre, JS., Monis, A., Garcia de Fernando, GD. 2014. Improvement in the lag phase estimation of individual cells that have survived mild heat treatment. International Journal of Food Science \& Technology 49: 884-894.

21. Rolfe, MD., Rice, CJ., Lucchini, S., Pin, C., Thompson, A., Cameron, ADS., Alston, M., Stringer, MF., Betts, RP., Baranyi, J., Peck, MW., Hinton, JCD. 2012. Lag phase is a distinct growth phase that prepares bacteria for exponential growth and involves transient metal accumulation. Journal of Bacteriology 194: 686-701.

22. Elfwing, A., LeMarc, Y., Baranyi, J., Ballagi, A. 2004. Observing growth and division of large numbers of individual bacteria by image analysis. Applied and Environmental Microbiology 70: 675-678.

23. Dancer, GI., Mah, JH., Rhee, MS., Hwang, IG., Kang, D. 2009. Resistance of Enterobacter sakazakii (Cronobacter spp.) to environmental stress. Journal of Applied Microbiology 107: 1606-1614.

24. Caubilla-Barron, J., Iversen, C., Forsythe, SJ. 2004. The desiccation survival of Enterobacter sakazakii and related Enterobacteriaceae. Abstr. $104^{\text {th }}$ General meeting of American Society for Microbiology, Washington D.C.

25. Gurtler JB., Beuchat, LR. 2005. Performance of media for recovering stressed cells of Enterobacter sakazakii determined using spiral plating and ecometric techniques. Applied and Environmental Microbiology 71: 7661-7669.

26. Breeuwer, P., Lardeau, A., Peterz, M., Joosten, H. 2003. Desiccation and heat tolerance of Enterobacter sakazakii. Journal of Applied Microbiology 95: 967-973.

27. Nazarowec-White, M., Farber, J.M. 1997. Thermal resistance of Enterobacter sakazakii in reconstituted dried-infant formula. Letters in Applied Microbiology 24: 9-13.

28. Iversen, C., Druggan, P., Schumacher, S., Lehner, A., Feer, C., Gschwend, K., Joosten, H., Stephan, R. Development of a novel screening method for the isolation of "Cronobacter" spp. (Enterobacter sakazakii). Applied and Environmental Microbiology 74: 2550-2553.

29. Jongenburger, I., Reij, MW., Boer, EPJ., Gorris, LGM., Zwietering, MH. 2011. Actual distribution of Cronobacter spp. in industrial batches of powdered infant formula and consequences for performance of sampling strategies. International Journal of Food Microbiology 151: 62-69. 


\section{Chapter}

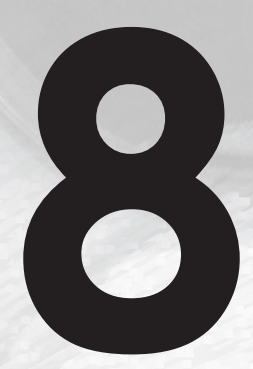

Summarizing discussion, conclusions and future perspectives 


\section{Introduction}

Reliable analytical methods to detect pathogens are an important tool in the verification of food safety. Even though many researchers have focused on this topic and advanced the technology of detection methods, numerous challenges are still encountered. Some of these are addressed in this thesis with special attention to bacterial enrichment procedures and molecular detection systems. Control measures aim at eliminating all pathogens from food. However, the complete absence of pathogens can never be guaranteed only can their number be limited. In addition, regulations aim at best possible consumer protection and require that testing methods have a limit of detection of $1 \mathrm{cfu}$ in $25 \mathrm{~g}$ of food in multiple samples up to 60 in some instances. On the other hand, detection thresholds of current detection methods such as PCR are around $10^{4} \mathrm{cfu} / \mathrm{ml}$. As a consequence, to achieve this limit of detection the target needs to multiply first. This is why nearly all detection methods are preceded by an enrichment step. Before bacteria can multiply, they often need to recover from possible damages caused by food processing. Therefore, media used for the resuscitation of damaged bacteria are designed to protect them from negative, stressful influence. The time needed for the recovery can be very variable depending on the extent of stress experienced and their initial number. The duration of the enrichment time should be long enough to prevent false negative results. However, very long enrichment periods can be inefficient and do not necessarily ensure detection either. Establishing the optimal length of the enrichment procedure should be based on experimental evidence. In the food matrix, bacteria are not present in isolation but in a complex setting. The natural flora of the food product may interfere with the growth of the target bacteria during enrichment. This can happen for example via the consumption of nutrients or the decrease of $\mathrm{pH}$ through production of acids. Selective steps in the enrichment are needed to suppress growth of competitors as much as possible but on the other hand, selective compounds should not exert negative influence on the target bacteria. In some cases, the presence of competitors that are closely related to the target bacteria complicates the application of a selective enrichment.

\section{Limitations of rapid methods}

In the first three chapters of this thesis the evaluation of alternative, commercially available methods for the detection of Salmonella and STEC is described. The focus was on real-time PCR methods, but rapid cultural methods were included as well. In general, the advantage of applying rapid methods for the detection of foodborne pathogens is the reduced time needed to obtain a negative result. Therefore, 
these methods are in particular useful for the screening of food products, which are expected to be free from pathogens. In addition, in contrast to most classical cultural methods, the amount of culture media and manipulation is considerably reduced. Above mentioned facts and the time pressure in today's food production are reasons for the increased demand and use of rapid methods. However, as rapid methods are used more frequently also their limitations become more apparent. In contrast to cultural methods, rapid methods based on the amplification of DNA cannot consistently deliver conclusions on whether the detected pathogen is alive and virulent. The persistence of DNA after the death of the organism is well known and due to the low detection limit of real-time PCR methods (when compared to cultural detection), amplified DNA from dead cells may lead to false-positive results indicating bacterial contamination (1). There are a number of approaches to avoid the detection of DNA from dead cells. Using mRNA as a template for amplification instead of DNA or staining of cells with ethidium monoazide bromide have been proposed but have so far not been widely adopted in commercial rapid methods. Generally it is now accepted that positive results obtained after an enrichment step imply the presence of living cells that still have the ability to multiply (2). In any case, even the presence of DNA originating from dead cells of pathogens might be an indication that somewhere along the production chain a contamination took place (3).

One of the main attributes of PCR methods is the rapid detection of pathogens in a sample. However, rapid is not a concrete declaration but must be regarded relative. The actual amplification and detection step of a real-time PCR might take only a couple of hours but this technical advancement has not circumvented the necessity of an initial cultural enrichment step. Reasons for the need for enrichment steps are related to the complexity of the food matrix and the detection limit of the assays, which is linked to small reaction volumes (4). In addition, food products often contain many ingredients that can inhibit nucleic acid amplification. With the application of an enrichment step, the negative influence of these components on the detection step is decreased by dilution. In addition, target bacteria are usually present only in low numbers accompanied with high numbers of background flora. The enrichment step can help to increase the relative proportion of target flora if it is selective. Enrichment is usullay preceeded by tenfold dilution of the sample but this dilution factor is not always enough to reduce PCR inhibitors sufficiently. Therefore samples from complicated matrices such as cocoa, tea and herbs and others need to be subjected to a sample clean-up or require a higher dilution factor of the sample, which not only dilutes inhibitory compounds but also decreases the concentration of the target (5). Low concentrations of the target DNA may lead to a false-negative result. DNA-clean-up kits often include a filter column that retains inhibitors from 
the nucleic acid solution with only little impact on the DNA concentration. To assess their effectiveness, different extraction methods for sample clean-up prior to PCR were compared (Chapter 2). It was shown that the proprietary extraction methods of the kit suppliers were regularly not sufficient to remove PCR inhibitors and that for samples containing cocoa or tea, an additional inhibitor removal step was necessary. However, this step resulted in a longer time to result, more handling of the samples and increased cost. There have been attempts to provide testing results for pathogens on the day the samples have been received and many commercial systems advertise their "same-day" detection systems. However, the failure to detect Salmonella from chicken samples after a pre-enrichment of 8 hours is documented in the literature $(6,7)$ and the limited success of one-day detection has also been described for E. coli $\mathrm{O} 157$ on leafy greens (8). In this study it was shown that for certain types of produce, with very low expected contamination levels a reduced enrichment period would have resulted in a negative result assuming a detection limit of $10^{3}$ to $10^{4} \mathrm{cfu} / \mathrm{ml}$ in the PCR. The application of methods for the concentration of the target in the sample by immuno-magnetic capture systems has been reported to increase detection sensitivity even after a short pre-enrichment step (9), still this will again result in increased hands on time.

The above-mentioned facts indicate that even though detection of pathogens with rapid methods is faster when compared to the cultural methods the bottleneck of the rapid methods is the sample preparation. The decision of whether to apply rapid methods therefore needs to be evaluated taking into account the sample matrix, the targeted pathogen as well as the workflow in the laboratory.

\section{Heterogeneity within bacterial populations and its influence on detection}

The creation of variant subpopulations helps bacteria to be better prepared to endure stressful events and to use new niches. The innate differences among identically treated bacterial strains of the same species, defined as strain variability, constitute a significant source of variability in microbiological studies. Strain variability in growth, inactivation and virulence is described for many foodborne organisms $(10,11,12)$. Due to this variability, results of research obtained with a certain bacterial strain is of limited value for predicting the behaviour of other strains belonging to the same species. Information about variability of phenotypic traits of foodborne bacterial strains under certain environmental conditions is thus valuable for the selection of strains for the validation of detection methods as well as in food safety studies. The ISO standard for the validation of microbiological methods (ISO 16140) (13) requires the testing of only one strain per food matrix for the 
determination of the limit of detection. This means, if an alternative method for the detection of Enterobacteriaceae in a certain product needs to be validated, choosing one representative strain originating from any genus within the family would be sufficient. The knowledge about strain variability raises doubt about this standard since the value for the limit of detection (LOD50) is also highly dependent on the composition of the food microflora. However, method validations, in particularly the determination of the detection limit are very time and labour-intensive studies. Therefore, it cannot be expected that these are executed with a very large number of strains. In many cases, preliminary experiments with a selection of strains are performed on small scale to screen for relevant traits that match the objectives of the study. Ideally, strains from different origins like food product, environment, human or animal are chosen.

For the evaluation of buffered peptone water variants described in Chapter 5, four different food matrices were spiked with either Salmonella, Cronobacter spp. or STEC. Two strains were selected for every genus and the growth of the target bacteria in the different enrichment media was recorded. In this particular case, the variability between strains was smaller than the variability between single experiments. However, the strain variability in desiccation resistance, tested with 10 strains, was considerably larger. Weber et al. (14) tested the ability of four methods to recover 11 desiccated Cronobacter spp. strains from artificially contaminated milk powder. They found $\log \mathrm{cfu} / \mathrm{ml}$ cell counts ranging from 5.1 to 8.9 in the supplemented enrichment media when our values only showed about $1 \log \mathrm{cfu} / \mathrm{ml}$ difference. This might indicate that an even larger selection of strains for the matrix experiments would have probably shown a less homogenous image in our study.

Chapter 2 and 3 describe the evaluation of various newly developed real-time PCR and rapid cultural methods. The studies did not aim to provide a complete method validation since this was already done by the kit manufacturers. However, during the official method validation only a limited number of food matrices were tested which do not necessarily coincide with the ones on which the method will finally be applied. Therefore the performance of the methods was verified in food matrices that are known to be challenging for analysis. The inclusivity and exclusivity of the tested methods were assessed by testing 49 Salmonella strains from different serotypes. The strains were selected to represent a variety of serotypes of which all strains originated from food products and were obtained from the institute's strain collection. In the validation of microbiological methods the number of strains that has to be tested for inclusivity is usually 20 (AFNOR) but is increased to 50 (ISO 16140) and sometimes even 100 in methods for the detection of Salmonella. For exclusivity, 30 non-Salmonella strains should be tested. Ideally, bacteria which could 
lead to false positive results within the PCR are selected. When the real-time PCR systems for the detection of Salmonella (Chapter 2) were evaluated, 4 Citrobacter spp. strains were included. These were conspicuous before, when false-positive results for Salmonella were obtained in vegetable samples. Of the four strains tested, two of them lead to false-positive results with two real-time PCR systems. The fact that the other two strains gave correct negative results and that none of the kit manufacturers ever reported false-positive results before shows that the selection of strains plays a key role on the validation of a method.

Next to the variability of strains belonging the same species, genus or family, cells of the same strain can present considerable variability in their physiological state, which can have an effect on many aspects of the detection of these bacteria. The heterogeneity of single cells is often disguised in microbiological experiments, which focus on results obtained with several millions of cells. Variability of cells will be most pronounced in growth and inactivation behaviour as well as in virulence. The most relevant source of variability for this discussion is the heterogeneity caused by the effects of stress on strain and single cell level.

Many food preservation processes aim at the extension of the lag phase of foodborne bacteria by the application of at least one environmental stress factor to slow down or prevent growth of bacteria. Environmental stress includes external factors that have a negative effect on the physiological state of bacteria, which can result in growth retardation or even to the death of individual cells or of the entire population (15). Bacteriostatic or bactericidal effects can be caused by stress factors like extreme heat or cold, $\mathrm{pH}$, osmotic pressure, depletion of nutrients and low $\mathrm{a}_{\mathrm{w}}$. During food production, a substantial proportion of bacteria experience some degree of damage, depending on the intensity of the applied stress and the resistance of the organism. Sublethal injury of bacteria entails the damage of intracellular structures, which can result in some loss of cell function that can be transient or permanent (16). Various aspects of bacterial physiology are affected by sublethal injury. Some will have an effect on their culturability and probability of detection. Biological media contain a great variety of compounds that preferentially or selectively allow the growth of a target organism in a food sample that most probably contains a mixed population of bacteria. Components employed in selective media include compounds with surface activity, such as sodium deoxycholate; toxic compounds such as selenite and tellurite, salts, antibiotics and acids (17). The sensitivity of injured bacterial cells to selective agents in both broth and agar media has already been described in 1971 (18). The site of cellular injury leading to increased sensitivity has been identified in some cases: sensitivity to bile salts and some antibiotics is caused by damage to the outer membrane of Gram-negative bacteria and decreased tolerance to salt and 
acid is related to the disruption of the cytoplasmic membrane function (19). For the detection of STEC from sprouts described in Chapter 6, three selective compounds were assessed in regards to the suppression of the background flora and the growth promotion of stressed STEC. Modified tryptone soy broth with added novobiocin is used for the enrichment of enterohemorhagic $E$. coli in meat and meat products. Novobiocin is added as a selective agent to inhibit the growth of the Gram-positive background flora. We showed that the presence of novobiocin during the enrichment of stressed STEC strains resulted in great variation in growth. One of the six strains tested showed almost no growth. Similar results were reported by Vimont et al. (20), who determined the MIC for 129 E. coli strains and found that $31 \%$ of the E. coli nonO157:H7 strains were inhibited by the recommended concentration in the enrichment broth. In addition, strains having a higher MIC still showed reduced growth compared to an enrichment without novobiocin. Our results support their recommendation not to use novobiocin for the enrichment of E. coli O157:H7 and non-O157:H7 E. coli from food.

The use of potassium-tellurite as a supplement was assessed in the same chapter because its application in cefixime-tellurite sorbitol MacConkey (CT-SMAC) agar for the cultivation of $E$. coli $\mathrm{O} 157$ is well-described (21). In this study, potassium-tellurite was added to different enrichment media and the growth of the sprout flora was measured. Since during first experiments the selected STEC strains failed to grow in BPW with tellurite, the MIC was determined. In BPW, a concentration of 0.75 $\mu \mathrm{g} / \mathrm{ml}$ was sufficient to inhibit growth of all STEC strains. In TSB the MIC ranged from 1.25 to $5.00 \mu \mathrm{g} / \mathrm{ml}$. These results show that the sensitivity of STEC is strain dependent and that the levels added to selective media can lead to inhibition. The sensitivity of stressed STEC to tellurite in media and resulting failure of isolation from the food matrix was also shown for E. coli $\mathrm{O} 157$ and non-O157 strains $(22,23)$. An additional compound was included in the study: Pyr-AEP (L-pyroglutamyl-L-1aminoethylphosphonic acid) is a phosphonopeptide whose antibacterial properties were already described in 1978 by Allen et al. (24). Its mode of action is based on the activity of a pyrrolidonyl-arylamidase activity in certain species of Enterobacteriaceae. In species that do express the enzyme, Pyr-AEP will be cleaved into a carrier moiety and a toxic moiety. The toxic moiety will inhibit the peptidoglycan synthesis and thereby constrain cell growth. Cells that do not express the enzyme will remain unaffected. The ability of Pyr-AEP to serve as a selective supplement and promote the growth of STEC in sprouts was tested in matrix experiments. In addition, the growth of pure STEC cultures at different concentrations of Pyr-AEP was determined. This highlighted that the dominant species of the background flora were much more resistant to the compound than the target bacteria, therefore the trials were not pursued. The fact that stressed STEC cells are more sensitive to selective compounds in the enrichment 
is also shown in Chapter 5. When stressed STEC, Salmonella and Cronobacter spp. were grown in BPW and BPW containing supplements aiming at the inhibition of Gram-positive bacteria (BPW-S), STEC strains showed significantly less recovery in the medium containing supplements. Sodium deoxycholate was identified as the most likely responsible agent for the reduced recovery of STEC since the negative effect on stressed STEC is described in the literature $(25,26)$. Acknowledging the sensitivity of certain pathogenic bacteria to selective agents in enrichment media is necessary to avoid false-negative results and risking the distribution of contaminated products.

\section{Extension of lag phase}

Another important effect caused by stress is the increased lag period of cells. Within any population of cells experiencing stress, there will be a heterogeneous response as some cells will die, some will be injured and others will not be affected at all. This heterogeneity is also reflected in the time that cells take to resuscitate and this is most apparent when inocula are low (25). With the extension of the lag time, the probability of detection in case of very low contamination levels decreases, as the time for the cell needed to grow to detectable levels can be longer than time that is available for growth. The latter is anyway limited by the length of the incubation, but usually even much shorter due to the presence of competitors that deplete the medium of nutrients long before the end of the incubation (see also next chapter). In Chapter 7 of this thesis, the effect of stress on the lag time duration and the distribution thereof was determined using single Cronobacter spp. cells. The longest lag time was $12.8 \mathrm{~h}$ after desiccation stress.

With scenarios simulating growth of desiccation stressed cells with the maximum lag time, the effect on the detection of single cells in a $10 \mathrm{~g}$ sample was visualized. Since Cronobacter is a possible contaminant in powdered infant formula, the detection method applied in this product was chosen for the simulation. It was shown that during the unselective enrichment in BPW, five of six strains tested would reach the limit of detection of the subsequent selective broth ( $\log 4)$ within the enrichment period of $18 \mathrm{~h}$ (provided that growth was not interrupted due to the presence of competitors).

Increasing the enrichment time could in some cases increase probability of detection since target cells can grow to higher numbers. On the other hand, it has been shown that a shorter enrichment period might improve detection by limiting the growth and influence of the background flora in food. An extended enrichment period would not have had substantial impact on the probability of detection in the simulation of one single cell with an extended lag phase growing in a diluted sample, described in Chapter 7. 
Next to extending the enrichment time, the probability of detecting a contaminated sample can be increased by improving the recovery during enrichment. With improved recovery, more cells in the sample can initiate growth, leading to a shorter lag phase and higher final cell counts. Attempts to increase resuscitation of stressed Cronobacter cells with a modified enrichment medium (BPW-S) are depicted in Chapter 5 of this thesis. After rehydration with the BPW-S, the resuscitation of desiccation stressed Cronobacter cells was improved by $20 \%$ in the mean for ten strains when compared to the standard medium (BPW). The final cell counts were slightly higher in BPW-S than in BPW. The exact inoculum present after desiccation was not determined but was assumed to be identical for each strain before rehydration. However, it is difficult to make a quantitative postulation about the effect of the improved recovery on the single cell level. When lag times for single cells were determined in BPW and BPW-S, results did not show shorter lag times in the modified medium. Therefore the assumption can be made that the effect of a higher final cell count in BPW-S is caused by a higher number of cells being recovered and not by a shorter lag time.

Not only can the improved recovery during primary enrichment increase the probability of detection, lowering the detection limit of the detection step can have the same result. The detection limit of the selective broth (CSB) used for the detection of Cronobacter is $10^{4} \mathrm{cfu} / \mathrm{ml}$ in the BPW pre-enrichment (27). If the sensitivity of this medium could be improved to a level where $10^{3} \mathrm{cfu} / \mathrm{ml}$ would be sufficient to cause a colour change of the medium, all six strains would have been detected even if the maximum lag time was assumed.

\section{Influence of the sample matrix on the success of detection-Jameson effect}

The limitations of detection methods are linked to the fact that pathogens are not present as pure cultures in a defined medium but in food, which is a complex matrix, and with other flora present. The problems that arise during the detection of foodborne pathogens can be caused by the composition of the food matrix, the heterogeneous distribution of the target bacteria in the product and the presence of bacteria belonging to the background microflora of the product (29). Most processed food products experience some kind of bacterial inactivation. Therefore, the negative influence of the background flora tends to be more pronounced in raw products. However, inactivating conditions can also lead to the activation of spores, which can grow out in the product resulting in a background flora of Gram-positive spore forming bacteria.

In Chapter 5 and $\mathbf{6}$ of this thesis, the problems linked to the detection of STEC and Salmonella from sprouted seeds are elaborated. For the evaluation of different 
buffered peptone water variations, the growth of STEC in sprouts, diluted in the media variations, was recorded. However, when very low STEC spiking levels were used, the detection with the standard selective detection medium (Rapid E. coli2 agar) was not possible. The agar plates were completely covered with other coliform bacteria originating from the background flora of the sprouts. The enumeration of the background flora after enrichment in the tested media showed that a maximum population density of up to $10 \mathrm{log} \mathrm{cfu} / \mathrm{g}$ was reached. STEC cell counts in sprouts remained at maximum level of $6 \log \mathrm{cfu} / \mathrm{ml}$. The large divergence in final cell counts did not only lead to overgrowth of STEC on agar media but also resulted in failure of PCR detection in some cases.

Competitive inhibition of foodborne pathogens has been described first for Salmonella (30). The growth suppression of multi species bacterial populations in batch cultures by a single dominant strain or group of bacteria is known as the "Jameson effect" (30). According to Jameson et al. two bacterial populations with equal growth rates inoculated into a medium or food matrix will grow in numerical parity similar to their initial proportion until stationary phase of the numerical dominant population is reached, which is proposed to be determined by the limitation of nutrients or the accumulation of toxic compounds (31). Additional causes of the overgrowth described in the literature are selective growth advantages of one of the two populations, which can be represented by a faster growth rate and a shorter lag time.

In the case of STEC growth in the sprout matrix, the growth advantage is unlikely because the enrichment medium used was not containing any selective substances (BPW). In addition, the growth of the target STEC strains was tested in this medium in pure culture. In this case, all strains reached maximum population densities of $9 \mathrm{log} \mathrm{cfu} / \mathrm{ml}$ and did not show an extended lag period. However, inoculum levels in pure culture experiments were higher than those spiked into sprouts. Literature showed that lag time can be extended for low inoculum sizes (32); this was also noticed in our experiments. The growth rate of the target strains was not determined, however, there are publications indicating that the difference in the growth rate is not responsible for the overgrowth in many cases $(33,32)$. Mellefont et al. (33) and Cornu et al. (31) could show that the initial inoculum concentration did not in all cases determine which species became dominant. Under some circumstances the species with the lower initial concentration achieved a higher final maximum population density when grown in co-culture. In this case, one population is growing faster than the other one. In contrast to their experiments, which did combine only two different species, a realistic situation in food would rather be a large group of background flora competing with one pathogenic strain. 
This difference in numbers was found in our study in sprouted seeds but also in minced meat for example. Vimont et al. (34) compared diverse enrichment media and described the parallel growth of the meat flora and E. coli O157. They noticed that enrichment protocol factors (such as incubation temperature) had little influence on the background flora. The same was noticed in our study. When sprouts were incubated in the different broths, the maximum population density of the background flora was very uniform and even the addition of selective supplements such as novobiocin and tellurite did not inhibit growth. In order to find out if overgrowth in the enrichment of sprouted seeds is linked to the growth advantage of the background flora or by the sheer difference in numbers, the enrichment suspension could have been diluted to reach values similar to the ones of the target strains.

The problem of overgrowth in the enrichment of food products can be tackled by the addition of media supplements or the adaptation of the enrichment protocol. Ideally, the background flora and the target pathogen differ from each other with respect to their nutrient requirements, susceptibility to inhibitors or ideal growth temperature. In the enrichment of Campylobacter on chicken for example, overgrowth of ESBL is identified as an emerging problem. With the use of Preston broth, which successfully inhibited growth of ESBL by the virtue of polymyxin B, the isolation of Campylobacter is improved (unpublished data by Heidy den Besten, Laboratory of Food Microbiology, Wageningen University). In case the background flora and the target pathogen are very closely related it is very difficult or even impossible to create an environment that offers a selective advantage to the target population.

For Listeria monocytogenes detection in food products, a double enrichment in half-Fraser and Fraser broth is utilized. The medium contains aesculin and ferric ammonium citrate for the differentiation of $L$. monocytogenes and several antibiotics for selectivity. Products contaminated with $L$. monocytogenes can also contain other Listeria species. Listeria innocua is a non-pathogenic species, physiologically close to L. monocytogenes and occurs in the same food products and ecological niches. There are publications describing the overgrowth of $L$. monocytogenes by $L$. innocua in the enrichment $(31,35)$. Even though this can lead to false negative results, there are no changes in the enrichment procedure (ISO 11290-1) for L. monocytogenes so far. In the detection of STEC from sprouts, similar challenges are faced. There are very few biochemical characteristics that can be used to differentiate pathogenic $E$. coli from their commensal relatives. In the sprout samples collected during the course of this thesis, no sample was naturally contaminated with $E$. coli but very high numbers of coliforms were noticed. The dominating representatives identified both with cultural methods and the microbiome analysis described in Chapter 6 were Klebsiella, Enterobacter and Citrobacter. The microbiome analysis also revealed that during enrichment in EE-broth, which is selective for Enterobacteriaceae, growth of 
the competitor organisms is selectively promoted. It was shown that EE-broth also resulted in good growth of STEC however, the problematic situation of low maximum population densities of the target strain in the matrix is still present. In BPW, which is the medium that is actually used for the detection of STEC from sprouts, the growth of Gram-positive bacteria such as Bacillus lead to a shift in the microbiome composition. Knowing that obligate aerobic organisms like Janthinobacterium dominate the microflora of raw sprouts the enrichment procedure could be made more selective by imposing an anaerobic atmosphere and addition of inhibitors against Bacilli. The Jameson effect does not only influence pathogen detection in matrices with very high levels of background flora like sprouted seeds. Miled et al. (36) modelled the effect of an extended lag time of Cronobacter in powdered infant formula and demonstrated the existence of bacterial interactions during the pre-enrichment. They noticed that Cronobacter growth ceased as soon as the background flora reached its maximum population density. When this observation was included in their simulations, the reliability of the growth prediction for Cronobacter was improved. This indicates that bacterial interactions need to be accounted for when growth and detection probability of pathogens are simulated. In the scenarios predicting the growth of Cronobacter spp. after an extended lag phase in Chapter 7, growth of background flora was not included and may therefore overestimate the maximum levels that can be reached by Cronobacter.

\section{Sampling Plan}

The probability of detecting a microorganism in a contaminated batch does not only depend on the reliability of the detection methods but also on the sampling plan. The sampling plan for Cronobacter spp. in powdered infant formula requires 30 samples of each $10 \mathrm{~g}$ to be tested. The probability to detect a positive sample with this sampling plan in a contaminated batch of powdered infant formula was calculated by Jongenburger et al. (28). The contamination level of 0.109 was determined for a $10 \mathrm{~g}$ sample of such exemplar-contaminated batch. When 30 samples are taken, the probability to detect at least positive sample is 0.9689 . For the same total weight of the sample $(300 \mathrm{~g})$, but only taking 10 times samples of $30 \mathrm{~g}$, the probability of detection is decreased to 0.8958 . Taking 300 samples of each $1 \mathrm{~g}$ would increase the probability to 0.9999 . This calculation shows that the probability to detect a positive sample in a heterogeneously contaminated batch is increased when more and samples of smaller size are taken. However, next to the detection probability, the feasibility of testing in an industrial environment has to be accounted for. As a conclusion of the example mentioned above, the best achievable result would be obtained if both the enrichment medium would lead to increased recovery of stressed cells and a sampling plan with more smaller samples would be followed. 


\section{Determination of single cell lag time}

The mean level of Cronobacter contamination in powdered infant formula estimated from published data and FAO/WHO studies is $-3.84 \mathrm{log} \mathrm{cfu} / \mathrm{g}$ (37). Routine samples are therefore likely to contain very low or close to zero numbers of target bacteria. This is why the lag time of single cells rather than population lag times are of importance for the detection of Cronobacter spp. in these products. If only the expected (average) value of lag phase would be used for drawing conclusions about the safety of a food batch, then the chance of underestimating risk due to cells that have short lag phases could increase (38). Extended lag phase of stressed cells is of relevance for the detection probability and therefore for the risk of false negative detection results. The only rationale to define lag at a single cell level is the time required for one cell to divide into two cells (39).

In Chapter 7 of this thesis, the lag time of single cells was calculated using time to detection values collected from optical density measurements. Single cells were obtained by dilution according to a protocol of Francois et al. (40). This method is based on assuming a Poisson distribution of cells in the wells. The presence of 0.42 cells per well should result in a maximum of $35 \%$ of all wells showing growth with $80 \%$ of those only containing one cell. The selection criterion for the data included in the lag time determinations was thus that no more of 33 wells of a 96-well plate should show growth. However, not all lag time values in this work originated from one cell. The probability that a well showing growth contains more than one cell is $20 \%(0.2)$. The limitation of the dilution method and the fact that actually not lag time of single cells, but lag time of cultures with different numbers of cells following a Poisson distribution is measured, was pointed out by other researchers $(39,41)$. Since the cell showing the shortest lag time will outgrow the other cells in the well, actual lag time might be underestimated. Nevertheless, Aguirre et al. (39) concluded that the assumption of only one cell initiating growth in a well when in fact there are more cells present in some wells does not lead to a big difference in estimated lag time when the ratio between lag phase and doubling time is at least 10 .

A more accurate inoculation with only one cell could have been achieved by flowcytometry with cell sorting.

After single cells have been isolated, the time to the first division can either be observed real-time under the microscope or calculated from time to detection determined with optical density measurements. The video imaging of live cells as described by Elfwing et al. (42) and Koutsoumanis and Lianou (43) is regarded the most accurate method, since the error of parameter estimation of mathematical models is significantly decreased and the time to the first division is directly 
observed (39). the requirement to collect a large amount of data in a relatively short time was the reason why lag times in this work were determined from optical density measurements, although the video imaging would have added value to the study. Optical density data were used to determine the time that is needed to reach a defined limit of detection (time to detection: TTD). With the TTD, the growth rate and the number of cfu at the time to detection, the lag time can be calculated. Although this method is easy and rapid and is described by several authors $(44,45)$, certain limitations should be pointed out. The main problem when using OD is the limited range of validity resulting from a high detection limit of the method $\left(10^{6}-10^{7}\right.$ $\mathrm{cfu} / \mathrm{ml}$ ) (46). This concentration will be reached at a late phase of bacterial growth and thus only a very short part of the growth curve is observed. Due to this, single cell lag time cannot be directly determined with OD data but has to be calculated from time to detection. In addition, an increase in OD is not always caused by the multiplication of cells but can be initiated by increased length of cells. This phenomenon is particularly known for stressed cells (47).

The detection limit used for the determination of TTD is the threshold of OD at which a significant increase of the signal is recorded. This value has thus an influence on TTD and lag time. In our study, the detection limit was set at 0.05 according to Miled et al. (22). Values in other studies differ considerably ranging from 0.11 (48) to 0.20 (49). Baka et al. (49) have tested the influence of different detection limits on the growth rate and lag time values and found an immense rise in the lag time with increased detection limits. In the literature, no explanation is given for the selection of the detection limit. Applying a detection limit of 0.20 would have resulted in $68 \%$ higher values of TTD for in some cases. This shows that the limit of detection seems to be crucial and should be carefully selected.

It is often assumed that the distribution of detection times is identical to a shifted lag time distribution. This is true only if the growth rate is constant during the exponential growth phase. In bacterial populations, this is usually the case. In the presence of single cells, however, growth rate can increase after the first generations after lag phase (41). The accurate determination of the growth rate is considered to most influential factor in the calculation of lag time since a slight error in the growth rate determination may cause considerable error in the lag time (39). The growth rates, which were used for the calculation of the lag time were determined in BPW. They were between $1.83 \mathrm{~h}^{-1}$ and $2.21 \mathrm{~h}^{-1}$. Values compared to the ones published by Miled et al. (36), who diluted contaminated infant formula in BHI for the determination of population growth rates $\left(1.8 \mathrm{~h}^{-1}-2.72 \mathrm{~h}^{-1}\right)$. When Miled et al. (50) measured growth rates by OD, values were between 1.72 and $2.34 \mathrm{~h}^{-1}$. Kandhai et al. (51) found growth rates of $2.42 \mathrm{~h}^{-1}$ in infant formula diluted with tap water 
and measured by plate counts. Growth rates by Iversen et al. (52) were between $1.43 \mathrm{~h}^{-1}$ and $2.97 \mathrm{~h}^{-1}$ in TSB as documented with the rapid automated impedance technique. The extensive variation of growth rates listed above shows again the effect of the selection of experimental conditions and the difficulty to compare values from different publications.

Biestra-Peters et al. (53) have compared two optical density based methods to the plate count method for the determination of the growth rate. Viable count measurements were described to be very time and labour-intensive and therefore only a limited amount of data points can be collected. At the same time, reproducibility of the plate count method was less when compared to optical density based methods.

In summary, one needs to be aware that the described approach for the determination of single cell lag time shows estimates of actual lag times but nevertheless conveys important hints concerning the variability of single stressed cells.

\section{Conclusions}

Within this thesis, multiple aspects of the detection of foodborne pathogens were investigated. In the first chapters (Chapter 2, 3 and 4), the evaluation of rapid methods for the detection of two of the most important Gram-negative foodborne pathogens, Salmonella and Shiga toxin-producing E. coli, were described. Rapid methods presented a considerable timesaving when compared to traditional cultural methods and they were mostly as sensitive and specific as the reference methods. Complex matrices such as tea and cocoa powder were problematic as they caused PCR inhibition or colour change on selective agars. The fact that there were falsepositive results with the Salmonella real-time PCR systems and false negative results with the STEC real-time PCR systems which were evaluated, shows that even though the methods are promoted on the market, additional verification is still recommendable. With the increasing availability and affordability of nucleic acid extraction procedures and advent of automated technologies, PCR based technologies are poised to find even more usage in the food industry. However, before considering the purchase and application a new rapid method or a proprietary system, laboratories need to make a clear evaluation of their needs and demands including an analysis of the food products that are going to be tested, the work flow and the available space in the laboratory as well as the costs per test.

The current ISO standards for the primary enrichment of stressed cells, particularly those in dry foods, showed some limitations. Large variability between media from different brands and batches was noticed in previous studies. Media variants with 
a buffered peptone water base were compared in their capability to resuscitate dry stressed cells and promote their growth in the food matrix with the aim to develop an improved enrichment medium for a horizontal one-broth enrichment for Cronobacter spp., Salmonella and STEC. It was shown that the supplemented enrichment broth performed better for the resuscitation and enrichment of Cronobacter. However, these results were only obtained with a limited number of strains. The selection of strains and the awareness of bacterial variability are very important when evaluating a medium or a method. In addition, it proved that the one-broth enrichment with a medium that is only moderately selective does not work in matrices with a high level of background flora.

Experiments described in this thesis showed that the detection limit of the current ISO method for the detection of STEC from sprouted is very high. It was found that the Jameson effect caused by the large number of coliforms on sprouts interfered with the detection and that none of the selective media or supplements, nor altered temperature gave any improvement. The analysis of the sprout microbiome gave some indications on a possible intervention, which includes the anaerobic incubation of the sprout samples. The detection of low numbers of pathogens from sprouted seed is still a major problem and so far no valid solution is in sight. In the end, an improved detection method has to be combined with better hygiene in the production of seeds and the development of a working decontamination to improve the safety of these products.

Another very important aspect of bacterial detection is increased lag time due to stress. The lag time of Cronobacter spp. single cells was quantified using optical density measurements. With these data, information about the detection probability of single cells with an extended lag from powdered infant formula was gained. Lag time and inactivation after stress were not linked but increase in lag time was connected to increase in lag time variability. In conclusion, the single cell lag time of stressed cell is important in view of detection of pathogens that contaminate products in low numbers. The heterogeneous distribution of the bacteria and the selection of a sampling plan contribute to the probability of detecting a pathogen in a food batch.

The results obtained in this study also show the importance of testing the behaviour of foodborne bacteria in enrichments including the food matrix. It became very clear that trying to apply results from pure-culture experiments in food matrices can even lead to wrong perceptions. 


\section{Challenges and future perspectives}

Within this study methods for the detection of Gram-negative foodborne pathogens were evaluated. In addition, modified enrichment media were compared and the enrichment ecology of STEC in sprouted seeds was investigated. The single cell lag time of Cronobacter spp. after stress was determined to find out the influence on detection probability.

The experiments with different buffered peptone water variants revealed large variation in resuscitation for the different Salmonella and Cronobacter spp. strains. Large variability between experiments with the same strain was noticed in the matrix experiments. This was most probably due to cell count variations of spiking inocula. Difficulties to prepare a contaminated powder to be used as inoculum, where pathogens are heterogeneously distributed, were also observed when sprouted seeds were spiked with STEC. The preparation of a dry inoculum containing a sufficient number of sublethally injured cells was a major challenge. Due to this complication, the spiking levels of STEC in sprouted seeds were in some instances not as low as desired. In future experiments, the preparation of desiccation stressed cells should be optimised and standardized.

In general, the stress treatment of cells did require some preliminary experiments to determine the appropriate intensity and duration of the stress application. Stress conditions used in this study were adapted from values found in the literature. Since stress resistance of Cronobacter spp. was subject to variation, the dilution to single cell level had to be repeated in some cases to reach the targeted level of a maximum of $35 \%$ of wells showing growth.

The assessment of possible selective agents for an enrichment broth improving the detection of STEC from sprouts proved to be challenging because the selective properties of the agents were dependent on the medium they were added to. This was unexpected and required several repetitions of the experiment.

Since the evaluation of the different BPW variants was only performed with a limited number of strains, additional experiments should extend the trials in order to be able to give a sound recommendation.

It was noticed that STEC cells were not resuscitated in BPW-S to the same levels as in BPW. The cause for this observation needs to be clarified to exclude any deleterious effects on STEC detection from a modified enrichment medium. The negative effect of media supplements was not only noticed with BPW-S but also with $\mathrm{mTSB}+$ novobiocin, tellurite and the novel substance Pyr-AEP. Therefore better characterization of the sensitivity of stressed STEC towards various types of inhibitors could be a big step to avoid false-negative results due to enrichment failure. 
There are still many aspects of enrichment ecology of foodborne pathogens that are not fully elucidated. The failure to isolate low levels of STEC from sprouts shows the impact of the background flora on the detection. The Jameson effect is one possible explanation but more research, identifying the exact mechanisms of overgrowth should be done. With the advent of microbiome analysis and the increased affordability of these methods, the opportunity should be taken to gain more insight in bacterial communities in food enrichment cultures. With this information, enrichment could become more than a "black box" and knowledge could be applied to improve currently used methods. Applying anaerobic conditions during the enrichment and thereby inhibiting dominant representatives of the sprout flora could be a first step. 


\section{References}

1. Cocolin, L., Donaghy, J., Renault, P., Ross, P., Van Ranst, M. 2013. Safety implications of the presence of nucleic acids of inactivated microorganisms in foods. ILSI Europe Report Series. http://www.ilsi. org/Europe/Publications/ILSI-12-010\%20Rep_safety\%20Nucleic.pdf

2. Rossen, L., Holstrom, K., Olsen JE., Rasmussen, EF. 1991. A rapid polymerase chain reaction (PCR)based assay for the identification of Listeria monocytogenes in food samples. International Journal of Food Microbiology 14: 135-145.

3. Cocolin, L., Rajkovic, A., Rantsiou, K., Uyttendaele, M. 2011. The challenge of merging food safety diagnostic needs with quantitative PCR platforms. Trends in Food Science \& Technology 22: S30-S38.

4. Dwivedi, HP., Jaykus, LA. 2011. Detection of pathogens in food: the current state-of-the-art and future directions. Critical Reviews in Microbiology 37: 40-63.

5. Kontanis, EJ., Reed, FA. 2006. Evaluation of real-time PCR amplification efficiencies to detect PCR inhibitors. Journal of Forensic Sciences 51: 795-804.

6. Josefsen, MH., Krause, M., Hansen, F., Hoorfar, J. 2007.Optimization of a 12-hour TaqMan PCRbased method for detection of Salmonella in meat. Applied and Environmental Microbiology 73: 3040-8.

7. Myint, MS., Johnson, YJ, Tablante, NL., Heckert, RA. 2006. The effect of pre-enrichment protocol on the sensitivity of PCR for detection of naturally contaminated Salmonella in raw poultry compared to conventional culture. Food Microbiology 23: 599-604.

8. D`Lima, CB., Suslow, TV. 2009 Comparative evaluation of practical functionality of rapid test format kits for detection of Escherichia coli 0157:H7 on lettuce and leafy greens. Journal of Food Protection 72: 2461-2470.

9. Fedio, WM., Jinneman, KC., Yoshitomi, KJ., Zapata, R., Wendakoon, CN., Browning, P., Weagant, SD. 2011. Detection of $E$. coli O157:H7 in raw ground beef by Pathatrix ${ }^{\mathrm{TM}}$ immunomagnetic-separation, real-time PCR and cultural methods. International Journal of Food Microbiology 148: 87-92.

10. Lianou, A., Koutsoumanis, KP. 2011. Effect of the growth environment on the strain variability of Salmonella enterica kinetic behaviour. Food Microbiology 28: 828-837.

11. Whiting, RC., Golden, MH. 2002. Variation among Escherichia coli O157:H7 strains relative to their growth, survival, thermal inactivation, and toxin production in broth. International Journal of Food Microbiology 75: 127: 133.

12. De Jesus, AJ., Whiting, RC. 2003. Thermal inactivation, growth and survival studies of Listeria monocytogenes strains belonging to three distinct genotypic lineages. Journal of Food Protection 66: 1611-1617.

13. Anonymous. 2002. Microbiology of food and feeding stuffs. Protocol for the validation of alternative methods (EN ISO 16140). European Committee for Standardization, AFNOR, Paris, France.

14. Weber, C., Stephan, R., Druggan, P., Joosten, H., Iversen, C. 2009. Improving the enrichment procedure for Enterobacteriaceae detection. Food Microbiology 26: 565-572.

15. McMahon, MAS., Xu, J., Moore, JE., Blair, IS., McDowell, DA. 2007. Environmental stress and antibiotic resistance in food-related pathogens. Applied and Environmental Microbiology 73: 211217.

16. Wesche, AM., Gurtler, JB., Marks, BP., Ryser, ET. 2009. Stress, sublethal injury, resuscitation, and virulence of bacterial foodborne pathogens. Journal of Food Protection 72: 1121-1138.

17. Stephens, P. 2004. Recovery of stressed bacteria. Culture 26: 5-8.

18. Scheusner, DL., Busta, FF., Speck, ML. 1971. Inhibition of injured Escherichia coli by several selective agents. Applied Microbiology 21: 46-49.

19. Stephens, PJ., Mackey, BM. 2012. Recovery of stressed microorganisms. Chapter 2 in handbook of culture media for food and water microbiology. RSC Publishing DOI:10.1039/978184755145000039. 
20. Vimont, A., Delignette-Muller, ML., Vernozy-Rozand, C. 2006. Supplementation of enrichment broths by novobiocin for detecting Shiga toxin-producing Escherichia coli from food: a controversial use. Letters in Applied Microbiology 326-331.

21. Zadik, PM., Chapman, PA, Siddons, CA. 1993. Use of tellurite for the selection of verocytotoxigenic Escherichia coli O157. Journal of Medical Microbiology 39: 155-158.

22. Jinneman, KC., Waite-Cusic, JG., Yoshitomi, KJ. 2012. Evaluation of shiga toxin-producing Escherichia coli (STEC) method for the detection and identification of STEC O104 strains from sprouts. Food Microbiology 30: 321-328.

23. Kehl, SC. 2002. Role of the laboratory in the diagnosis of enterohemorragic Escherichia coli infections. Journal of Clinical Microbiology 40: 2711-2715.

24. Allen, JG. 1979. Phosphono peptides as antibacterial agents, alaphosphin and related phosphono peptides. Antimicrobial agents and chemotherapy 15: 684-695.

25. Stephens, PJ., Joynson, JA. 1998. Direct inoculation into media containing bile salts and antibiotics is unsuitable for the detection of acid/salt stressed Escherichia coli O157. Letters in Applied Microbiology 147-151.

26. Hara-Kudo, Y., Ikedo, M., Kodaka, H., Nakagawa, H., Goto, K., Masuda, T., Konuma, H., Kojima, T., Kumagaim, S. 2000. Selective enrichment with a resuscitation step for isolation of freeze-injured Escherichia coli O157:H7 from foods. Applied and Environmental Microbiology 66: 2866-2872.

27. Iversen, C., Druggan, P., Schumacher, S., Lehner, A., Feer, C., Gschwend, K., Joosten, H., Stephan, R. 2008. Development of a novel screening method for the isolation of Cronobacter spp.. Applied and Environmental Microbiology 74: 2550-2553.

28. Jongenburger, I., Reij, M.W., Boer, E.P.J., Gorris, L.G.M., Zwietering, M.H. 2011. Actual distribution of Cronobacter spp. in industrial batches of powdered infant formula and consequences for performance of sampling strategies. International Journal of Food Microbiology 151: 62-69.

29. Lopez-Campos, G., Martinez-Suarez, JV., Aguado-Urda, M., Lopez-Alonso, V. 2012. Detection, identification, and analysis of foodborne pathogens. Chapter 2 Microarray detection and characterization of bacterial foodborne pathogens Springer Briefs in Food, Health, and Nutrition pp. 13-32.

30. Jameson, JE. 1962. A discussion of the dynamics of Salmonella enrichment. Journal of Hygiene 60: 193-207.

31. Cornu, M., Kalmokoff, M., Flandrois, JP. 2002. Modelling the competitive growth of Listeria monocytogenes and Listeria innocua in enrichment broths. Journal of Food Microbiology 73: 261-274.

32. Augustin, JC., Brouillaud-Delattre, A., Rosso, L., Carlier, V. 2000. Significance of inoculum in the lag time of Listeria monocytogenes. Applied and Environmental Microbiology 66: 1706-1710.

33. Mellefont, LA., McMeekin, TA., Ross, T. 2008. Effect of relative inoculum concentration on Listeria monocytogenes growth in co-culture. International Journal of Food Microbiology 121: 157-168.

34. Vimont, A., Vernozy-Rozand, C., Montet, MP., Lazizzera, C., Bavai, C., Delignette-Muller, ML. 2006. Modelling and predicting the simultaneous growth of Escherichia coli 0157:H7 and ground beef background microflora for various enrichment protocols. Applied and Environmental Microbiology 72: 261-268.

35. Gnanou-Besse, N., Barre, L., Buhariwalla, C., Vignaud, ML., Khamissi, E., Decourseulles, E., Nirsimloo, M., Chelly, M., Kalmokoff, M. 2010. The overgrowth of Listeria monocytogenes by other Listeria spp. in food undergoing enrichment cultivation has a nutritional basis. International Journal of Food Microbiology 136: 345-351.

36. Miled, RB., Guillier, L., Neves, S., Augustin, JC., Colin, P., Besse, NG. 2011. Individual cell lag time distributions of Cronobacter (Enterobacter sakazakii) and impact of pooling samples on its detection in powdered infant formula. Food Microbiology 28: 648-655.

37. FAO/WHO (Food and Agriculture Organization /World Health Organization). 2006. Enterobacter sakazakii and Salmonella in powdered infant formula. Meeting report: Microbiological Risk Assessment Series, 10. 
38. Malakar, PK., Barker, GC. 2009. Estimating risk from small inocula by using population growth parameters. Applied and Environmental Microbiology 75: 6399-6401.

39. Aguirre, JS., Monis, A., Garcia de Fernando, GD. 2014. Improvement in the lag phase estimation of individual cells that have survived mild heat treatment. International Journal of Food Science \&Technology 49: 884-894.

40. Francois, K., Devlieghere, F., Standaert, AR., Geeraerd, AH., Van Impe, JF., Debevere, J. 2003. Modelling the individual lag phase. Isolating single cells: protocol development. Letters in Applied Microbiology 37: 26-30.

41. D`Arrigo, MD., Garcia de Fernando, GD., Velasco de Diego, R., Ordonez, JA., George, SM., Pin, C. 2006. Indirect measurement of the lag time distribution of single cells of Listeria innocua in food. Applied and Environmental Microbiology 72: 2533-2538.

42. Elfwing, A., LeMarc, Y., Baranyi, J., Ballagi, A. 2004. Observing growth and division of large numbers of bacteria by image analysis. Applied and Environmental Microbiology 70: 675-678.

43. Koutsoumanis, KP., Lianou, A. 2013. Stochastisity in colonial growth dynamics of individual bacterial cells. Applied and Environmental Microbiology 79: 2294-2301.

44. Metris, A., George, SM., Peck, MW., Baranyi, J. 2003. Distribution of turbidity detection times produced by single cell-generated bacterial populations. Journal of Microbiological Methods 55: 821-827.

45. Guillier, L., Augustin, JC. 2006. Influence of stress on individual lag time distributions of Listeria monocytogenes. Applied and Environmental Microbiology 71: 2940-2948.

46. Swinnen, IAM., Beernaerts, K., Dens, EJJ., Geeraerd, AH., Van Impe, JF. 2004. Predictive Modelling of the microbiological lag phase: a review. International Journal of Food Microbiology 94: 137-159.

47. Bereksi, N., Gavini, F., Benezech, T., Faille, C. 2002. Growth, morphology and surface properties of Listeria monocytogenes Scott A and LO28 under saline and acid environments. Journal of Applied Microbiology 92: 556-565.

48. Buchanen, RL., Klawitter, LA. 1991. Effect of temperature history on the growth of Listeria monocytogenes at refrigeration temperatures. International Journal of Food Microbiology 12: 235246.

49. Baka, M., Noriega, E., Stamati, I., Logist, F., Van Impe, JFM. 2014. Critical assessment of the timeto-detection method for accurate estimation of microbial growth parameters. Journal of Food Safety 35: 179-185.

50. Miled-Bennour, R., Ells, TC., Pagotto, FJ., Farber, JM., Kerouanton, A., Meheut, T., Colin, P., Joosten, H., Leclerq, A., Gnanou Besse, N. 2010. Erratum to "Genotypic and phenotypic characterization of a collection of Cronobacter (Enterobacter sakazakii) isolates". International Journal of Food Microbiology 144: 209-211.

51. Kandhai, MC., Reij, MW., Grognou, C., Van Schothorst, M., Gorris, LGM., Zwietering, MH. 2006. Effect of pre-culturing conditions on lag time and specific growth rate of Enterobacter sakazakii in reconstituted powdered infant formula. Applied and Environmental Microbiology 72: 2721-2729.

52. Iversen, C., Lane, M., Forsythe, SJ. 2004. The growth profile, thermotolerance and biofilm formation of Enterobacter sakazakii grown in infant formula milk. Letters in Applied Microbiology 38: 378-382.

53. Biestra-Peters, EG., Reij, MW., Joosten, H., Gorris, LGM., Zwietering, MH. 2010. Comparison of two optical density based method and a plate count method for estimation of growth parameters of Bacillus cereus. Applied and Environmental Microbiology 76: 1399-1405. 


\section{Summary}

Acknowledgements

About the author

List of publications

Overview of completed training activities 


\section{Summary}

Gram-negative pathogens such as Salmonella and Shigatoxin-producing E. coli are the most prevalent causes of bacterial foodborne illness in Europe and worldwide. They can contaminate a wide range of food products from animal origin as well as fresh produce.

The testing for these pathogens in the frame of complete food safety risk management can be used to assess whether the required level of control is delivered. The reasons for microbiological testing can be the verification of the HACCP plan, regulatory requirements or epidemiological investigations. Since pathogens in foods may be present in low numbers, the methods for the detection and isolation of pathogens usually consists of a sequence of steps aiming at the resuscitation and enrichment of the target followed by the detection and possibly isolation.

Within this thesis, the different steps of detection were investigated with a main focus on methods for the detection of Salmonella, Shigatoxin-producing E. coli and Cronobacter spp.

Because the detection of Salmonella and STEC with the culture based reference methods is very time consuming and labour-intensive and at the same time the results of the analysis are requested quickly, more and more rapid methods are introduced to the market that are designed for the use in the food industry. The evaluation of rapid cultural methods and real-time PCR systems showed that the majority of the tested methods were as sensitive and specific as the reference methods. There was a considerable time saving but the testing of complex food matrices like cocoa powder required additional sample preparation. The fact that there were both false-positive and false-negative results with the real-time PCR systems for Salmonella and STEC, respectively, showed the limitations of these methods.

In all methods for the detection of pathogenic Gram-negative organisms in food (Salmonella, Cronobacter and STEC), the ability to recover low numbers of usually sublethally stressed cells to a detectable level is of major importance. The enrichment step is common to all current detection methodologies and is also the main time limiting factor in regard to turn-around-time. Preliminary work indicated that there are inconsistencies in the performance of pre-enrichment media and that the composition of culture media in ISO standards is sometimes poorly defined. Therefore, improvements to the current pre-enrichment formulation that should be applied across the relevant ISO standards were investigated.

The supplementation of BPW was chosen as a strategy for enhanced resuscitation of damaged cells and for their recovery from food products in a one-broth enrichment. BPW was supplemented with compounds aiding resuscitation and selective agents inhibiting Gram-positive bacteria that can be present in food. 
Experiments with desiccated cells showed that resuscitation of Cronobacter spp. was improved in BPW-S whereas STEC recovery was superior in BPW. When recovery from the food matrix was compared in the different media variants, cell counts of Cronobacter in infant formula with BPW-S were somewhat higher. The application of a one-broth enrichment was not successful in foods with very high levels of background flora.

Since during the comparison of different BPW variants the problem of detecting low levels of STEC in sprouted seeds became apparent, the enrichment strategy became subject of a more detailed study in this thesis. The growth of stressed STEC was observed in media used for the enrichment of Enterobacteriaceae. Except of increased strain variability observed in $\mathrm{mTSB}+$ novobiocin, growth was similar in all media. The cell counts of the background flora were not influenced by the media, neither by the incubation temperature and reached values of 9 to $10 \log \mathrm{cfu} / \mathrm{g}$. When sprouted seeds were spiked with low numbers of STEC, levels of the target pathogen only reached $3.5 \mathrm{log} / \mathrm{cfu}$ in BPW after $16 \mathrm{~h}$ of incubation. An analysis of the sprout microbiome over the course of the enrichment suggested that with an enrichment step in EE-broth, the Gram-negative representatives of the flora, which complicate the detection of STEC, will be selectively promoted. During the enrichment in BPW biodiversity was larger caused by multiplication of Gram-positive bacteria. The study gave indications on how the enrichment of STEC from sprouted seeds could be enhanced but also illustrated the difficult initial condition of this product.

Another important aspect of detection is bacterial variability caused by stress. Bacterial cells in food products will be stressed in most cases due to the production process and the properties of the food. Cronobacter spp. was desiccation stressed before the lag time of single cells was measured. There was great strain variation in lag time and stress resistance. The duration of lag time was longest after acid stress and was not related to the reduction of cell numbers caused by this stress. By supposing different scenarios of one cell in a $10 \mathrm{~g}$ sample with an extended lag time we showed that the detection of low numbers of Cronobacter might fail because the detection limit of the subsequent method might not be reached.

The insights and results obtained through the work on this thesis might help laboratories in the food industry to make "evidence based" decisions when choosing a rapid alternative method for the detection of Salmonella or STEC. The comparison of buffered peptone water variants indicated one more time the importance of the selection of strains for matrix studies and might point into a direction for the improvement of the common enrichment step for the most common Gram-negative pathogens. With the microbiome data of sprouted seeds, scenarios for the improvement of the detection of STEC can be designed resulting in the increased safety of this product. 


\section{Acknowledgements}

Thank you very much Roger for giving me the possibility to do my PhD at the ILS. Your guidance, encouragement and patience led me through many difficult periods during this project. I truly appreciate your help and advise even after having left the institute. Thank you Marcel for agreeing to be my Promotor. Your demanding questions and attention to detail challenged from time to time but also made me look at my work from another angle. Thank you Han for your valuable contributions and the time you invested into this project.

I want to acknowlegde Emer O`Mahony and David Tomas Fornes from the Nestlé Research Center and Carol Iversen for their scientific input.

Next to my supervisors there are many people that contributed to this project with their help and advise. Taurai, thank you very much for helping me with the microbiome analysis. Thank you Angelika, Herbert, Grethe, Regula and everyone else at the ILS for your help and for making the institute such a pleasant place to work. Thank you to all past colleagues and especially Andrea, Eleonora, Hennis, Kati, Mirjam and Sarah.

I am thankful to my friends in Zürich: Pamela, Lidija, Cri and Denise. Your support and encouragement during all these years means a lot to me. My friends back home in Germany: I truly appreciate your interest in my work during all these years and the moments of distraction that always gave me new energy.

Thank you Iliana for your help during these last stressful weeks of finishing this thesis.

Never would this have been possible without the support of my family. Thank you Mama for your love, trust and support through every step of my education and life. Jan, you made Zurich become my home. Thank you! 


\section{About the author}

Heike Franziska Thekla Margot was borne on 17 November 1985 in Reutlingen, Germany. From 2005 she followed a BSc in Nutritional Science at the Technical University of Munich in Freising. Upon completing her BSc 2008, she started the MSc program Food Safety at Wageningen University. Her MSc thesis was entitled "Detection of pathogenic E. coli from herbs using multiplex PCR" and was conducted at the Laboratory of Food Microbiology.

In 2011 she did an internship at the Nestlé Research Center in Vers-chez-les-Blanc, Switzerland, where she worked on the use of Maldi-Tof MS for the identification of Cronobacter spp. After graduating from her MSc studies, Heike returned to the NRC as a research assistant for the period of 6 months. During that time she was working on a comparative study of different enrichment media.

In November 2011, she started her PhD project at the Institute for Food Safety and Hygiene at the University of Zürich, Switzerland. The results of the thesis entitled "Improvement of detection methods for Gram-negative foodborne pathogens" are described in this thesis and have been published in international peer-reviewed journals.

Heike started working as Quality Specialist at the Migros-Genossenschafts-Bund in Zürich in January 2016. 


\section{List of publications}

Inclusivity, exclusivity and limit of detection of commercially available realtime PCR assays for the detection of Salmonella. Heike Margot, Roger Stephan, Salvatore Guarino, Balamurugan Jagadeesan, David Chilton, Emer O'Mahony, Carol Iversen. Published in International Journal of Food Microbiology (2013) 165: 221-226.

Comparison of rapid cultural methods for the detection of Salmonella species. Heike Margot, Roger Stephan, Emer O'Mahony, Carol Iversen. Published in International Journal of Food Microbiology (2013) 163: 47-50.

Evaluation of seven different commercially available real-time PCR assays for detection of shiga toxin 1 and 2 gene subtypes. Heike Margot, Nicole Cernela, Carol Iversen, Claudio Zweifel, Roger Stephan. Published in Journal of Food Protection (2013) 76: 871-873.

Evaluation of different buffered peptone water (BPW) based enrichment broths for detection of Gram-negative foodborne pathogens from various food matrices. Heike Margot, Marcel H. Zwietering, Han Joosten, Emer O`Mahony, Roger Stephan. Published in International Journal of Food Microbiology (2015) 214: 109-115.

Effects of different media on the enrichment of low numbers of Shiga toxin-producing Escherichia coli in mungo bean sprouts and on the development of the sprout microbiome. Heike Margot, Taurai Tasara, Marcel H. Zwietering, Han Joosten, Roger Stephan. Published in International Journal of Food Microbiology (2016) 232: 26-34.

Determination of single cell lag times of Cronobacter spp. strains exposed to different stress conditions: impact on detection. Heike Margot, Marcel H. Zwietering, Han Joosten, Roger Stephan. Accepted for publication in International Journal of Food Microbiology.

Performance of a commercially available latex agglutination test kit for the identification of Salmonella. Heike Margot, Grethe Sägesser, Claudio Zweifel, Roger Stephan. Published in Archiv für Lebensmittelhygiene (2013) 64: 75-77.

Occurrence of Salmonella, L. monocytogenes, Shigatoxin-producing E. coli and ESBL-producing Enterobacteriaceae in sprout samples collected from the Swiss market. Heike Margot, Rebecca Ebner, Sophie Peterhans, Roger Stephan. Published in Journal of Consumer Protection and Food Safety (2015). 


\section{Overview of completed training activities}

\section{Discipline specific activities}

\section{Courses}

Management of microbiological hazards in foods (2013)

\section{Meetings}

FEMS meeting, Leipzig (poster) (2013)

Fachsymposium Food Microbiology (poster) $(2013,2015)$

Arbeitstagung Lebensmittelhygiene, Garmisch (poster) $(2013,2015)$

FoodMicro Conference, Nantes (poster) (2013)

Symposium Schnellmethoden und Automatisierung (oral presentation) (2014)

IAFP European Symposium (poster) $(2014,2015)$

\section{General courses}

Introduction to modeling (2011)

Writing research paper for publication (2013)

French oral expression (2013)

Introduction to SPSS (2014)

Writing and formatting of scientific reports (2014)

Inferential statistics with SPSS and R (2015)

Seminar cell biology $(2014,2015)$

\section{Other activities}

Preparation of $\mathrm{PhD}$ research proposal (2011)

Summer school ILS (2011)

Journal club, ILS (2013, 2014, 2015)

Skills club, ILS (2013, 2014, 2015)

Participation in ISO CEN TC 275/WG6/TAG9 (2013, 2014)

VLAG PhD trip Laboratory of Food Microbiology, Ireland (2014) 
The research described in this thesis was financially supported by the Nestlé Research Centre, Vers-chez-les-Blanc, Switzerland.

Financial support from Wageningen University for printing this thesis is gratefully acknowledged.

Cover design \& layout: Iliana Boshoven-Gkini || AgileColor.com

Book layout: Iliana Boshoven-Gkini || AgileColor.com

Printed by: GVO drukkers \& vormgevers, Ede (NL) || gvo.nl 